\title{
Thiago Rodrigues Alves
}

\section{Análise filogenética de ralídeos Neotropicais (Aves: Rallidae) com base em caracteres osteológicos}

Phylogenetic analysis of the Neotropical rails (Aves: Rallidae) based on osteological characters

São Paulo, 2012 


\section{Thiago Rodrigues Alves}

\section{Análise filogenética de ralídeos Neotropicais (Aves: Rallidae) com base em caracteres osteológicos}

\section{Phylogenetic analysis of the Neotropical rails (Aves: Rallidae) based on osteological characters}

Dissertação apresentada ao Instituto de Biociências da Universidade de São Paulo, para obtenção do Título de Mestre em Ciências, na área de Zoologia.

Orientadora: Profa. Dra. Elizabeth Höfling

São Paulo, 2012 


Alves, Thiago Rodrigues
Análise filogenética de ralídeos
Neotropicais (Aves: Rallidae) com base em
caracteres osteológicos.
84p.
Dissertação (Mestrado) - Instituto de
Biociências da Universidade de São Paulo.
Departamento de Zoologia.
1. Rallidae 2. Osteologia 3. Sistemática
Filogenética I. Universidade de São Paulo.
Instituto de Biociências. Departamento de
Zoologia

Comissão Julgadora: 
Dedicatória

À minha família 


\section{Agradecimentos}

À Profa. Dra. Elizabeth Höfling pela orientação, amizade, paciência e apoio durante todo o período da minha pós-graduação. Muito obrigado.

À Coordenadoria de Aperfeiçoamento de Pessoal de Ensino Superior (CAPES) pela bolsa de mestrado concedida e à PROAP/PROEX pelos auxílios financeiros.

Aos coordenadores do Curso de Pós-graduação em Zoologia do IBUSP: Profs. Drs. Antônio Carlos Marques e Marcelo Rodrigues de Carvalho.

Aos curadores e responsáveis pelas coleções, pela consulta e empréstimo de materiais imprescindíveis para a realização desta dissertação: Dr. Herculano Marcos de Ferraz Alvarenga (Museu de História Natural de Taubaté), Dr. Luís Fábio Silveira (Museu de Zoologia da Universidade de São Paulo), Dr. Marcos Raposo e Dr. Guilherme Renzo Rocha Brito (Museu Nacional do Rio de Janeiro).

Ao Dr. Herculano Alvarenga pela amizade, confiança e todos os ensinamentos durante meu período em Taubaté. Espero que toda sua dedicação à Ornitologia e seus esforços na direção do MHNT sejam recompensados pelo cumprimento de seus objetivos.

Aos professores das disciplinas da pós-graduação que contribuíram em muito para minha formação como biólogo: Profs. Luís Ricardo Lopes de Simone, Elizabeth Höfling, Mario César Cardoso de Pinna e Marcos Antônio dos Santos Silva, em especial aos docentes da disciplina de Vertebrados (Profs. Drs. Eleonora Trajano, Elizabeth Höfling, Luís Fábio Silveira, Miguel Trefaut Urbano Rodrigues, Marcelo Rodrigues de Carvalho, Mônica de Toledo Piza-Ragazz, Renata Pardini, e Taran Grant) pelas aulas, explicações e inúmeras discussões zoológicas. 
Agraceço ao Dr. Peter Gibbs do Plant Sciences Laboratory School of Biology da University of St. Andrews, Escócia, pela revisão do Abstract.

Aos Amigos do laboratório de Ornitologia do IBUSP: Rafael Migotto, Viviane Kupriyanov, Guilherme Renzo Rocha Brito e Talitha da Cunha Pires pela dedicação inspiradora ao estudo da Ornitologia e ao companheirismo.

Agradecimentos especiais a Rafael Migotto pelo exemplo de amizade e determinação. Por toda sua confiança e paciência, sempre com sugestões e críticas construtivas sobre esta dissertação e ao Guilherme Renzo Rocha Brito por me ajudar na fase final deste trabalho. Muito obrigado.

Aos amigos do Museu de História Natural de Taubaté pelos momentos de aprendizado e descontração durante os dois anos do meu período em Taubaté: Fernanda Porcari Molena, Fernando Procorro, Diana da Silva, Graziela do Couto Ribeiro e Ricardo Mendonça dos Santos. Em especial a Fernanda Porcari pelas viagens a São Paulo, conversas e por disponibilizar sua residência quando a república em que morava estava em pé de guerra.

Aos colegas monitores da disciplina de Vertebrados: João Paulo Capretz, Marco Sena, Rodrigo Borghesan, Carolina Nisa e Paula Moraes, pelo companheirismo indiscutível. Mesmo cansados de tantas aulas e monitorias, sempre estávamos de bom humor e buscando mais conhecimento sobre os grupos zoológicos estudados.

À minha família pela confiança, respeito pela minha profissão e incentivo em todas as minhas metas, não somente na vida acadêmica: meus pais Cláudio Sérgio Alves e Teresa Cristina Rodrigues Alves, meu irmão Lucas Rodrigues Alves, minha avó materna Teresa Albertina Ferreira Rodrigues e meus avós paternos Teresa Pettenusi Alves e Lourenço Alves Neto.

Aos meus colegas de república pelo valor baixo da hospedagem, respeito, descontração e muitas risadas: Roberto Kupper, Paulo Roberto, Eduardo Júnior e o Rottweiler Lex. 
Aos meus amigos de longa data que sempre acreditaram no meu esforço: Guilherme Madeira, Célio Justus, Rodrigo Viana, Denis Freitas, Diego Freitas, Arnaldo Pereira e André Rodrigues. Pelos bons fins de semana quando eu retornava para Santos e conseguia recompor minhas energias.

Em especial a José Fontenelle, Eduardo Mourão e Raquel Alves por todo apoio durante minha graduação, pelos intensivos estudos antes do meu ingresso na pósgraduação, caronas, risadas e muitas outras vivências excelentes. Obrigado por tudo.

Para todos aqueles não mencionados que contribuíram de forma indireta para este trabalho. 


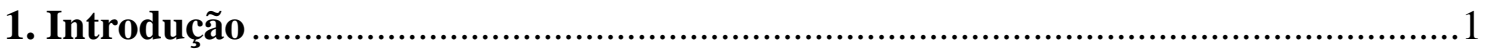

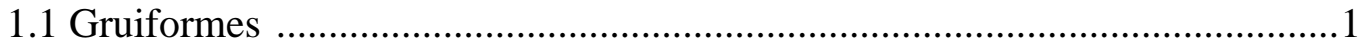

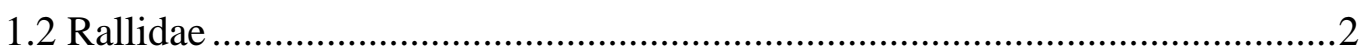

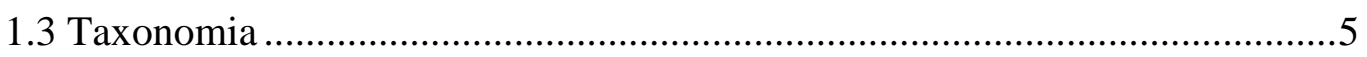

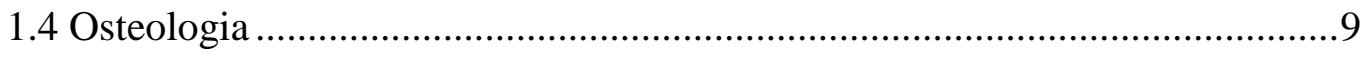

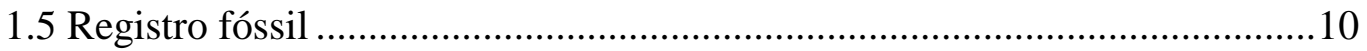

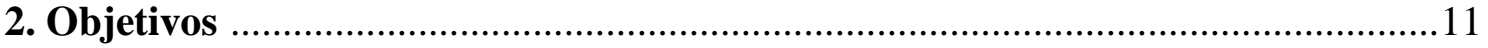

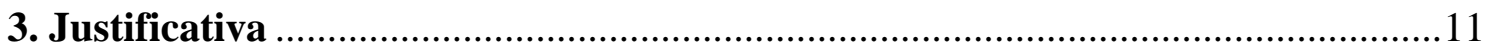

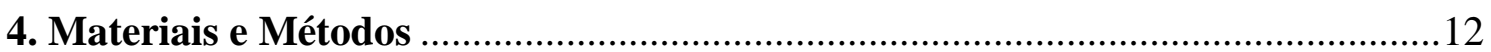

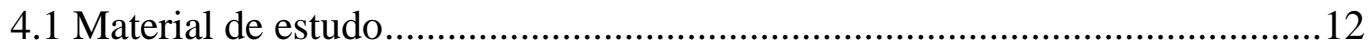

4.2 Análises filogenéticas ........................................................................ 13

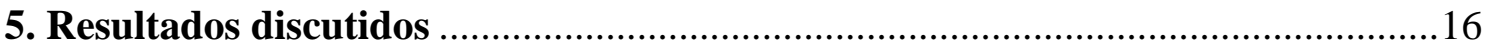

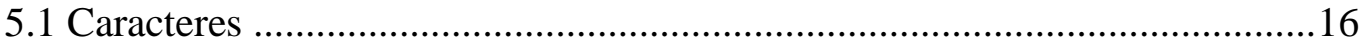

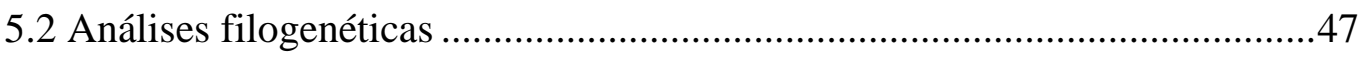

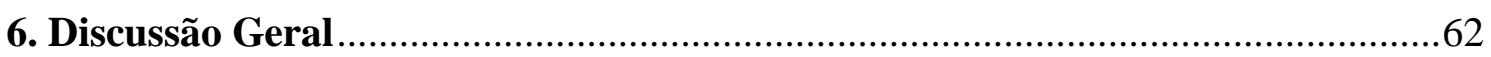

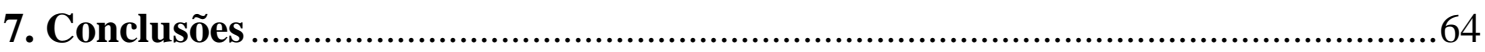

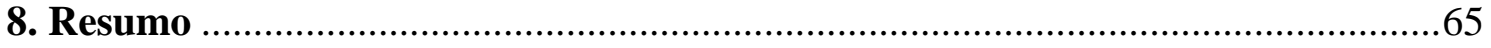

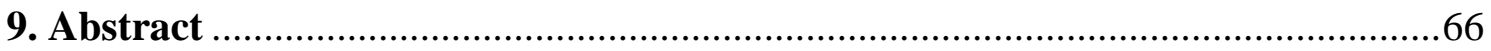

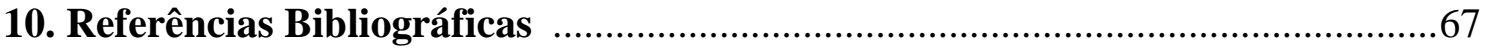

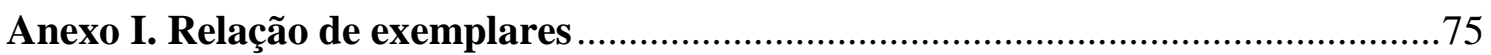

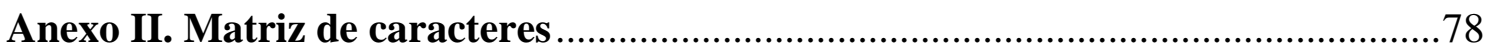

Anexo III. Valores de IC, IR e RC para cada caráter..........................................83 


\section{Introdução}

\subsection{Gruiformes}

Devido a aspectos morfológicos externos e hábitos terrestres, os representantes da ordem Gruiformes já foram relacionados aos Galliformes e Ciconiiformes (Seebohm, 1895; Fürbringer, 1888; Hellmayr \& Conover, 1942), no entanto, a maioria dos trabalhos suporta a hipótese de parentesco com Charadriiformes (Sharpe, 1894; Lowe, 1931; Sibley \& Ahlquist, 1990; Livezey, 1998; Ericson et al., 2006).

A ordem é um grupo diverso de aves terrestres tradicionalmente constituída por dez a doze famílias atuais: Mesitornithidae, Pedionomidae, Turnicidae, Gruidae, Aramidae, Psophiidae, Rallidae, Heliornithidae, Rhynochetidae, Eurypygidae, Cariamidae e Otididae (Beddard, 1898; Peters, 1934; Taylor, 1996; Livezey, 1998). Estudos baseados em caracteres morfológicos e moleculares apontam diferentes hipóteses de relacionamento, frequentemente propondo a inclusão de Pedionomidae e Turnicidae em outros táxons (Sharpe, 1984; Taylor, 1996; Livezey \& Zusi, 2007; Ericson et al., 2006).

A tradicional composição da ordem tem seu monofiletismo questionado por diversos autores. A filogenia proposta por Livezey \& Zusi (2006; 2007) baseada em 2954 caracteres osteológicos, miológicos, siringiais e tegumentares propõe que Gruiformes seja constituído das famílias: Otididae, Cariamidae, Eurypygidae, Rhynochetidae, Psophiidae, Aramidae e Gruidae. As famílias Turnicidae e Mesithornithidae foram incluídas em sua própria ordem, Turniciformes. O estudo também corrobora a relação de grupo-irmão entre Rallidae e Heliornithidae suportada por diversos autores (Fürbringer, 1888; Beddard, 1898; Lowe, 1931; Livezey, 1998; Cracraft et. al, 2004; Ericson et al., 2006; Livezey \& Zusi, 2007; Fain et al., 2007; Hackett et al., 2008), no entanto, este clado (Ralliformes) é grupo-irmão de Charadriiformes.

A maioria dos trabalhos baseados em dados moleculares (Sibley \& Ahlquist, 1990; Dyke \& van Tuinen, 2006; Ericson et al., 2006; Fain et al., 2007; Hackett et al., 
2008) afirmam que as relações evolutivas da tradicional ordem Gruiformes são problemáticas e o grupo certamente não é monofilético. Nas filogenias propostas por Ericson et al. (2006) e Hackett et al. (2008) são encontrados quatro clados distintos: (1) Gruiformes, composto por Aramidae, Gruidae, Psophiidae, Heliornithidae e Rallidae; (2) Otididae como grupo-irmão do clado (Gruiformes + Cuculiformes); (3) um clado composto por Eurypygidae e Rhynochetidae, no qual é grupo-irmão dos Caprimulgiformes e (4) Cariamidae como grupo-irmão de um grande clado constituído por Passeriformes, Psittaciformes e Falconidae. Além disso, Hackett et al. (2008) questionam o monofiletismo da família Rallidae, uma vez que o gênero Sarothrura é mais proximamente relacionado a Heliornithidae.

Dentre as propostas filogenéticas mais fortemente corroboradas está a relação de grupo-irmão entre as famílias Eurypygidae e Rhynochetidae (Cracraft, 1982; Livezey, 1998; Ericson et al., 2006; Livezey \& Zusi, 2007; Fain et al. 2007; Hackett et al. 2008), relação próxima já refletida em trabalhos de classificação do século XIX (Bartlett, 1862; Sharpe, 1894) e a relação de grupo-irmão entre as famílias Gruidae e Aramidae, tendo Psophiidae como grupo externo formando um clado (Livezey, 1998; Ericson et al., 2006; Livezey \& Zusi, 2007; Hackett et al., 2008), também mencionadas por taxonomistas em trabalhos anteriores (Sharpe, 1891; Beddard, 1898; Peters, 1934; Hellmayr \& Conover, 1942).

\subsection{Rallidae}

A família Rallidae é representada por aves de hábitos terrestres popularmente conhecidas como saracuras, sanãs, carquejas, galinhas-d'água, frangos-d'água e pintosd'água (Pinto, 1978; Sick, 1997). Dentre as famílias de vertebrados terrestres, os ralídeos apresentam uma das maiores distribuições geográficas, ocorrendo em todos os continentes com exceção da Antártica, e em diversas ilhas oceânicas remotas (Olson, 1973; Ripley \& Beehler, 1985). A maioria das espécies ocorre em hábitats relacionados a ambientes aquáticos como regiões estuarinas e litorâneas, porém, certos gêneros ocupam desde florestas densas a savanas (Taylor \& Perlo, 1998). 
Morfologicamente, é um grupo bastante homogêneo, com corpo curto e achatado lateralmente. Na maioria das espécies não existe dimorfismo sexual externo acentuado, sendo os machos ligeiramente maiores que as fêmeas. Apenas os gêneros africanos Sarothrura e os representantes de Rallina da Nova Guiné possuem plumagem sexualmente dimórfica (Taylor \& Perlo, 1998).

Devido à grande amplitude de hábitos alimentares, a forma do bico é bastante variada, sendo longa e levemente curvada para baixo nas espécies que forrageiam o alimento no solo úmido, até curta e robusta, nas espécies de hábitos vegetarianos. Galinhas-d'água e carquejas possuem um escudo frontal pronunciado e colorido na região proximal do bico, mais evidente durante o período reprodutivo (McFarlane, 1975; Taylor \& Perlo, 1998).

Os ralídeos apresentam pernas longas e finas, com dedos relativamente curtos nas espécies terrestres e longos nas espécies semiaquáticas e aquáticas. Os representantes com hábitos aquáticos mais especializados possuem lobos laterais nos dedos, vestigiais nas galinhas-d'água e bastante desenvolvidos em carquejas (Fjeldså, 1982; Taylor \& Perlo, 1998).

A maioria dos ralídeos possui plumagem críptica, de coloração marrom, cinza ou preta, porém, nos frangos-d'água, a coloração é predominantemente azul e verde iridescentes. As partes inferiores, em alguns gêneros, são listradas (ex: Porzana) ou uniformes (ex: Aramides). Em galinhas-d'água, carquejas e frangos-d'água, as coberteiras inferiores da cauda são brancas, de grande contraste com o restante da plumagem (Taylor \& Perlo, 1998; Stang \& McRae, 2009).

Características relacionadas à perda da capacidade de voo são observadas frequentemente em ralídeos insulares, que compõem cerca de $25 \%$ das espécies atuais e extintas (Slikas et al., 2002). Este fator envolve redução da musculatura e dos componentes ósseos das asas e cintura escapular, degeneração das penas e maior desenvolvimento da musculatura da perna (Fedducia, 1996; Livezey, 2003). Estes caracteres evoluíram certamente por convergência e por isso possuem pouca importância filogenética (Diamond, 1991; Trewick, 1997). Olson (1973), Feduccia 
(1996), Taylor e Perlo (1998) consideram a perda da capacidade de voo uma condição neotênica, que evolui rapidamente e envolve poucas modificações genéticas.

Os ralídeos compõem a maior família de Gruiformes, representados por 33 gêneros atuais, sendo 13 deles monotípicos, e 135 espécies (Taylor \& Perlo, 1998). Diversas classificações anteriores foram propostas para a família, demonstrando sua complexidade taxonômica. Sharpe (1894) propõe 50 gêneros e 165 espécies; Peters (1934) considera 52 gêneros e 138 espécies; Olson (1973) reduz o número de gêneros para 35 e não produz uma lista de espécies. Morony et al. (1975) consideram 152 espécies; Ripley (1977) reduz bruscamente o número de gêneros para 18 e 122 espécies; Sibley \& Ahlquist (1990) listam 34 gêneros e 142 espécies, enquanto Taylor (1996) considera 33 gêneros e 133 espécies. Ainda, este último autor cita 33 espécies como ameaçadas, dentre elas, 16 provavelmente extintas desde 1.600 .

Com exceção do estudo de Hackett et al. (2008), os demais autores suportam a hipótese filogenética que a família seja monofilética, não havendo discussões sobre a inclusão ou exclusão de seus representantes para outros táxons (Livezey, 1998; Fain et al., 2007). Entretanto, o contexto histórico da organização das espécies em subfamílias apresenta controvérsias. Peters (1934) divide os Rallidae em duas subfamílias: Fulicinae, representados por espécies do gênero Fulica, e Rallinae, contendo todas as demais espécies. Verheyen (1957) propõe cinco subfamílias, porém, sem justificativas anatômicas convincentes para esta divisão. Brodkorb (1967) sugere três subfamílias: Rallinae, Gallinulinae e Fulicinae, também de maneira arbitrária e sem fundamentação morfológica.

Com base em métodos de hibridação DNA-DNA, Sibley \& Ahlquist (1985, 1990) sugerem que os representantes do gênero Sarothrura sejam incluídos em uma família a parte, Sarothruridae, e em sua própria superfamília Sarothruroidea, devido a divergirem do restante do grupo há cerca de 60 milhões de anos, no Paleoceno. No entanto, a maioria dos trabalhos baseados em dados morfológicos (Olson, 1973; Livezey, 1998) suportam a hipótese de que Sarothrura seja relacionado aos gêneros Rallina, Coturnicops e Micropygia. 
A classificação mais recente baseada em caracteres osteológicos proposta por Olson (1973) e corroborada por Livezey (1998) reduz o número de subfamílias para somente duas: Himantornithinae, contendo apenas uma espécie do Velho Mundo e Rallinae, incluindo todas as demais espécies. Previamente a Peters (1934), apenas Gray (1871) validou o gênero Himantornis em sua própria subfamília.

Olson (1973) e Ripley (1977) consideram Himantornis o ralídeo mais distinto devido à plumagem juvenil diferenciada e caracteres osteológicos cranianos e póscranianos semelhantes a Psophia. Taylor \& Perlo (1998) também apontam Himantornis como o único representante de Rallidae a não possuir uma glândula uropigiana e por convergência, apresenta asas eutáxicas (quinta secundária presente), observadas apenas no gênero Amaurolimnas.

\subsection{Taxonomia}

A etimologia da palavra "ralídeo" provém da obra francesa L' Histoire de La nature des oiseaux (Belon, 1555 apud Ripley, 1977), que descreve Coturnix coturnix como "rei dos faisões" devido a seus hábitos migratórios. A palavra inglesa "rail", traduzida para o português, significa trilho, e diversos autores, como Ripley, 1977, relacionaram "rail" a denominação "fino como um trilho", devido à forma do corpo curta e compressa lateralmente. Entretanto, em sua descrição, Ray (1713 apud Ripley, 1977) argumenta que a palavra "rail" pode ter sido originada do sentido de realeza em francês, réel.

O conhecimento dos ralídeos teve início desde que os primeiros catalogadores e naturalistas começaram a publicar compêndios nos séculos dezesseis, dezessete e dezoito. A obra Synopsis Methodica Avium (Ray, 1713) cita seis gêneros e doze espécies, entre elas as carquejas, galinhas-d'água, Rallus aquaticus e Crex crex, além de citar erroneamente os jaçanãs, membros da ordem Charadriiformes, devido as suas semelhança morfológicas. Todas são descritas como aves semelhantes a faisões (Phasianidae), capazes de nadar, mas sem membranas interdigitais. 
O gênero tipo Rallus, empregado por Linnaeus (1758) foi utilizado para a espécie da região Paleártica Rallus aquaticus, cujo epíteto específico esta relacionado ao seu hábitat. Outros ralídeos originalmente descritos por Linnaeus (1758), como Porphyrio porphyrio, Crex crex, Porzana carolina, Gallinula chloropus e Fulica atra fortalecem a percepção dos ralídeos como aves de comportamentos crípticos que habitam manguezais e áreas alagadas (Livezey, 2003).

Os representantes da avifauna Neotropical são bastante comprometidos com as divergências taxonômicas infrafamiliares. De acordo com Taylor \& Perlo (1998), a família é representada por 50 espécies, distribuídas em 13 gêneros. Três espécies (Laterallus jamaicensis, Porzana spiloptera e Gallinula angulata) foram recentemente incluídas (CBRO, 2009), provavelmente, devido a registros casuais.

O gênero Coturnicops, Gray, 1855, compreende três espécies, C. exquisita e $C$. noveboracensis do Velho Mundo e C. notata, restrita a América do Sul. Da mesma maneira que o gênero monotípico Micropygia, Bonaparte, 1856, são frequentemente relacionados a Sarothrura devido a semelhanças na plumagem e acentuado dimorfismo sexual externo, ausente nos demais representantes da família (Olson, 1973; Ripley, 1977; Taylor, 1996). No entanto, a hipótese filogenética de Livezey (1998) demonstra que estes gêneros são relacionados a certos representantes de Porzana, que não constitui um grupo monofilético.

O gênero Laterallus compreende um grupo heterogêneo e, possivelmente, não monofilético de ralídeos de pequeno porte, restritos ao Novo Mundo. Diferente de Peters (1934) e Ripley (1977), Sharpe (1894) e Stresemann \& Stresemann (1966) incluem a espécie fasciatus no gênero Anurolimnas devido a semelhanças na plumagem com A. castaneiceps. Olson (1973) também sugere a inclusão de viridis em Anurolimnas, argumentando que desta forma o gênero Laterallus provavelmente, formaria um grupo monofilético.

Não existem questionamentos na literatura sobre o monofiletismo de Aramides, Pucheran, 1845 de distribuição Neotropical. No entanto, suas relações evolutivas intrafamiliares ainda não estão bem compreendidas. Ripley (1977) aponta que não existem diferenças morfológicas suficientes para tratar as espécies de ralídeos florestais 
em gêneros distintos, incluindo as espécies do Novo Mundo de Aramides e Amaurolimnas no gênero Eulabeornis. A hipótese filogenética de Livezey (1998) aponta as espécies de Aramides como grupo-irmão de Amaurolimnas, corroborando propostas anteriores (Olson, 1973).

Os representantes do gênero Pardirallus, Bonaparte, 1856 são ralídeos de distribuição restrita à região Neotropical, caracterizados pelo bico longo e amarelo esverdeado (Taylor \& Perlo, 1998). O gênero inclui a espécie de plumagem rajada $P$. maculatus Noddaert, 1738 e duas espécies de coloração uniforme, P. nigricans Viellot, 1819 e P. sanguinolentus Swainson, 1838.

As espécies de Pardirallus são frequentemente incluídas no gênero Rallus, Linné, 1758 por diversos autores (Pinto, 1963; 1978; Sclater, 1868; Ripley \& Beehler, 1985; Sick 1997), porém, estudos filogenéticos apontam que Pardirallus não possui parentesco próximo aos representantes de Rallus (Livezey, 1998; Livezey \& Zusi, 2006).

As relações evolutivas entre as espécies de Pardirallus não são bem compreendidas. Peters (1934) e Hellmayr \& Conover (1942) incluem nigricans e sanguinolentus no gênero Ortygonax e a espécie maculatus no gênero monotípico Pardirallus, devido a sua plumagem com barras brancas ventrais e manchas brancas no corpo. Entretanto, Dickerman \& Parkers (1969) e Dickerman \& Haverschmidt (1971) descrevem que a plumagem negra no juvenil de maculatus é semelhante a sanguinolentus e nigricans, e que a plumagem rajada de branco é evidentemente uma condição derivada recente. Segundo a filogenia proposta por Livezey (1998), as três espécies são proximamente relacionadas, porém, foram demonstradas por meio de uma politomia e suas relações de parentesco não foram esclarecidas.

As espécies popularmente conhecidas como frangos-d'água-azul também têm sua taxonomia discutida. Sclater (1868), Olson (1973) e Taylor \& Perlo (1998) consideram apenas um único gênero, Porphyrio Brisson, 1760, para reunir estas aves de distribuição cosmopolita, caracterizadas pela coloração azul e verde brilhosa, com artelhos longos adaptados à vida paludícola. 
Devido a adaptações morfológicas relacionadas ao ambiente aquático, os representantes de Porphyrio já foram relacionados aos gêneros Gallinula e Fulica e inseridos em sua própria subfamília, Fulicinae, por Sclater (1868). Posteriormente, Verheyen (1957) designa a subfamília Porphyriinae, agrupando apenas as espécies do gênero.

As espécies meridionais alleni, martinica e flavirostris são frequentemente inseridas no gênero Porphyrula Blyth, 1849 devido ao menor porte e bico mais delgado (Peters, 1934; Hellmayr \& Conover 1942; Pinto, 1964; 1978; Livezey, 1998; Sick, 1998). De maneira semelhante, a espécie de grande porte com asas reduzidas da Nova Zelândia, mantelli, é designada em um gênero monotípico, Notornis Owen, 1848 (Owen, 1848; Forbes, 1923; Peters, 1934). De acordo com a filogenia de Livezey (1998), os representantes de Porphyrio formam um clado em que as espécies meridionais são um grupo monofilético, podendo ser designadas ao gênero Porphyrula.

De distribuição cosmopolita, porém com um número considerável de espécies na região Neotropical, os gêneros Gallinula e Fulica têm sido historicamente relacionados desde catálogos anteriores ao século XX (Linnaeus, 1758; Sharpe, 1894). Gallinula Brisson, 1760, caracterizado por sua plumagem de coloração escura, branca nos flancos e bico colorido com escudo frontal (Taylor \& Perlo, 1998), foi primariamente descrito por tautonimia como Fulica Linné, 1758. Além disso, autores como Sclater \& Salvin (1868) já trataram estes dois gêneros em uma subfamília à parte, Fulicinae, e a maioria das análises filogenéticas suportam a hipótese de que sejam grupo-irmão (Livezey, 1998; Livezey \& Zusi, 2003; Fain et al., 2007).

Estudos baseados em dados morfológicos (Boyd \& Alley, 1947; Fjeldså, 1982), comportamentais (Navas, 1960) e ecológicos (McFarlane, 1975) apontam Fulica rufifrons como a espécie menos especializada do gênero, assim como proposto por estudos filogenéticos morfológicos e moleculares (Livezey, 1998; Livezey \& Zusi, 2006; Fain et al., 2007), em que $F$. rufifrons é o representante mais basal.

Existe extrema controvérsia quanto à taxonomia da espécie Porphyriops melanops Sharpe, 1894, previamente designada como Rallus melanops Vieillot, 1819. Sclater (1868), Peter (1934), Hellmayr \& Conover (1942), Pinto (1978) e Sick (1997) 
consideram melanops em um gênero monotípico, Porphyriops. Entretanto, Olson (1973), Ripley (1977), Ripley \& Beehler (1985) e Taylor \& Perlo (1998) incluem a espécie no gênero Gallinula. As hipóteses filogenéticas demonstram que Porphriops é um ramo basal do clado que compreende as espécies de Gallinula.

\subsection{Osteologia}

Estudos osteológicos são de grande importância para o entendimento da relação de parentesco entre as espécies de ralídeos (Owen, 1882; Shufdeldt, 1919; Olson, 1973; Ripley, 1977; Kuroda, 1993; Livezey, 1998).

A família é caracterizada por apresentar crânio esquizognato, ou seja, os vômeres são completamente fusionados e formam um osso único longo que impede o contato dos ossos maxilopalatino (Sharpe, 1894). Os ossos nasais, que circundam a região posterior da cavidade nasal não se estendem até a sutura frontal - pré-maxilar, condição nomeada holorrina (Ripley, 1977) e na maioria das espécies há uma fina membrana óssea separando as narinas.

O lacrimal é bastante desenvolvido e se articula quase totalmente com o frontal ou com a barra nasal em alguns gêneros. O tamanho do processo supraorbital é variável e o processo descendente pode tocar na barra jugal em alguns representantes (ex: Himantornis). O ectetmoide é moderadamente desenvolvido e não se articula ao lacrimal nos representantes de todos os gêneros, com exceção de Himantornis (Cracraft, 1968). Algumas espécies, como a saracura-matraca (Rallus longirostris) e Porzana carolina apresentam glândulas de sal supraorbitais bastante desenvolvidas, assim como as espécies extintas Atlantisia elpenor e Fulica chathamensis, onde é observada uma estreita ponte interorbital e depressões na região supraorbital do crânio (Bang, 1968).

Os ralídeos possuem esterno longo e estreito, triangular, com um par de processos laterais posteriores equivalentes à metade ou $1 / 3$ do comprimento total do esterno (Sharpe, 1894; Olson, 1973). A cintura pélvica é mais variável devido a espécies com hábitos mergulhadores (ex: Fulica), nas quais é bastante alongada e afilada. Os 
representantes de hábitos mergulhadores também apresentam o tarsometatarso comprimido lateralmente (Olson, 1973; Ripley, 1977).

A perda da capacidade de voo também implica em várias modificações osteológicas, principalmente na redução dos ossos das asas e cintura escapular. A quilha do esterno é completamente ausente ou reduzida e há um aumento considerável do ângulo entre a escápula e o coracoide, como também observado por convergência em aves paleognatas (Owen, 1882; Fedducia, 1996; Livezey, 1990; 2003).

\subsection{Registros fósseis}

Os primeiros fósseis relacionados aos ralídeos datam do Eoceno Inferior, há cerca de 50 milhões de anos. Todas as cinco espécies desse período são baseadas em porções distais do tibiotarso, pouco contribuindo para o esclarecimento de suas relações com espécies atuais (Olson, 1974). Com base em estudos de hibridação DNA-DNA, Sibley \& Ahlquist (1985) sugerem que os ralídeos podem ter se originado há cerca de 86 milhões de anos, equivalente ao Cretáceo Superior. Apenas fósseis do Oligoceno Superior e Mioceno Inferior, há cerca de 20 a 30 milhões de anos, apresentam materiais diagnosticáveis e semelhantes aos ralídeos modernos (Olson, 1977; Mourer-Chauviré et al., 2004; Mayr, 2009).

Ralídeos continentais fósseis são comuns em depósitos do Terciário da Europa, Ásia e América do Norte e a maioria dos fósseis do Plioceno e do Pleistoceno têm sido incluídos em gêneros atuais, assim como uma grande quantidade de fósseis encontrados em ilhas oceânicas (Olson, 1974; Boles, 2005; Mayr, 2009). A maioria destas espécies insulares foi extinta recentemente, há cerca de 500 anos, devido à intensa exploração marinha europeia. 


\section{Objetivos}

- Contribuir com o conhecimento da osteologia comparada das aves da família Rallidae;

- Criar hipóteses de relacionamento filogenético com base nos caracteres osteológicos analisados;

- Comparar as hipóteses alcançadas com reconstruções filogenéticas de trabalhos prévios, verificando a congruência entre os componentes resgatados;

- Sugerir propostas de mudanças no sistema de classificação do grupo de acordo com as hipóteses filogenéticas aqui obtidas.

\section{Justificativa}

A maioria das classificações propostas para a família Rallidae, principalmente referentes às categorias de subfamílias e gêneros, é baseada em trabalhos que utilizaram dados morfológicos externos e comportamentais e ausentes de um método filogenético. Neste aspecto, o estudo comparativo de uma fonte interna de caracteres (esqueleto) sob o ponto de vista filogenético é importante para o conhecimento anatômico do grupo e para a construção de um sistema de classificação mais informativo. 


\section{Materiais e Métodos}

\subsection{Material de estudo}

Foi utilizado neste estudo um total de 100 esqueletos referentes a espécimes das famílias Rallidae e Heliornithidae, totalizando 13 gêneros e 31 espécies pertencentes às seguintes coleções osteológicas: Museu de História Natural de Taubaté (MNHT), Museu de Zoologia da Universidade de São Paulo (MZUSP), Coleção de Aves do Departamento de Zoologia da Universidade de São Paulo (AZUSP) e Museu Nacional do Rio de Janeiro (MNRJ).

A maioria dos espécimes analisados encontrava-se previamente preparado e já incorporado ao acervo dessas coleções. Quando recém-coletadas, as aves foram descarnadas e posteriormente preparadas utilizando larvas de Dermestes sp. no Museu de História Natural de Taubaté. A listagem do material está disponível no Anexo I, que apresenta dados sobre o táxon, instituição de origem, número de tombo, localidade e sexo dos indivíduos, quando disponíveis.

As variações esqueléticas foram descritas utilizando-se a nomenclatura de Baumel \& Witmer (1993), sendo que em alguns casos foi necessário o uso de terminologias adicionais, como as variações morfológicas do osso lacrimal citadas por Cracraft (1968) e as descrições anatômicas de Livezey \& Zusi (2007). A nomenclatura taxonômica adotada está de acordo com Taylor (1996).

Cada estado de caráter foi descrito e fotografado com câmera digital Sony Cybershot DSC-H50 e, quando necessário, observados em estereomicroscópio Opton modelo Tim-2T equipado com câmera digital DCM-35. As medidas do esqueleto foram feitas com paquímetro Zaas de $0,1 \mathrm{~mm}$ de precisão.

Os exemplares demonstrados nas figuras pertencem à coleção osteológica do Museu de História Natural de Taubaté, nos quais os estados discutidos são nomeados e indicados com escalas de $1 \mathrm{~cm}$. As imagens foram editadas utilizando o programa Adobe Photoshop CS2. 


\subsection{Análises filogenéticas}

As hipóteses de relacionamento entre os Rallidae foram inferidas de acordo com as metodologias da Escola de Sistemática Cladista (Hennig 1950; 1966) adotando-se o princípio da parcimônia para a análise dos dados (Wiley, 1981; Farris, 1983; Kitching et al., 1998; Farris, 2008).

Os caracteres provenientes da análise osteológica comparativa entre os terminais foram numerados de acordo com a ordem anatômica proposta na Nomina Anatomica Avium (Baumel et al., 1993). Os diferentes estados de caracteres, referentes às estruturas do esqueleto (homologias primárias sensu de Pinna, 1991) foram codificados em caracteres numéricos $(0,1,2 \ldots)$ que não indicam polaridade de uma série de transformações, sendo esta concluída após o enraizamento dos diagramas obtidos. Caracteres polimórficos, nos quais terminais apresentam mais de um estado de caráter, foram considerados. Os estados foram organizados em uma matriz de caracteres no programa Nexus Data Editor (Page, 1998), disponibilizados no Anexo II.

A raiz foi determinada no terminal Heliornis fulica, devido à maioria dos trabalhos que estudaram as relações filogenéticas destes grupos apontar a família Heliornithidae como grupo-irmão de Rallidae (Livezey, 1998; Ericson et al., 2006; Fain et al., 2007; Livezey \& Zusi, 2007; Hackett et al., 2008).

As análises de parcimônia e a otimização dos cartacteres foram realizadas no programa PAUP (Swofford, 2001) e para a visualização e edição dos diagramas, o programa Treeview (Page, 2001).

A fim de se encontrar os diagramas que melhor representam a distribuição dos estados dos caracteres pelo princípio da parcimônia, foi realizada uma busca heurística com o algoritmo TBR (“Tree-Bissection-Reconnection”), considerado o de melhor eficiência (Kitching et al., 1998), uma vez que o grande número de táxons terminais (>13) não permite uma busca exata das árvores mais parcimoniosas. O número de réplicas nas análises foi alterado de 10 (padrão do programa) para 1000 e em cada ciclo de busca ("Stepwise Addiction"), foram mantidas duas árvores salvas. A adição de terminais foi realizada de forma randômica (“AddSeq=Random”), no intuito de se evitar 
o encontro repetido de árvores subótimas. O número de árvores salvas na memória do programa (MaxTrees) foi aumentado para 100 a cada réplica de busca e a opção de colapso em politomias de ramos não sustentados (comprimento mínimo igual a zero) foi escolhida ("Collapse=MinBrlen").

No caso de homoplasias, no qual há mais de uma possibilidade de otimização dos caracteres na hipótese mais parcimoniosa (ambigüidade), o critério adotado foi ACCTRAN ("accelerated transformation optimization") devido a melhor suportar as hipóteses de homologia primária e maximizar as mudanças homoplásticas de caracteres representadas por reversões ao invés de convergências e paralelismos (de Pinna, 1991).

Os caracteres multiestados (aqueles com mais de dois estados) foram considerados como não-ordenados, uma vez que na literatura não se encontram informações sobre possíveis séries de transformação e as observações obtidas aqui não indicam ordenação para estes estados. Os índices de consistência (IC), retenção (IR) e consistência reescalonado (RC) de cada caráter estão disponíveis no Anexo III.

$\mathrm{Na}$ análise inicial, procurou-se calcular o digrama de consenso estrito, árvore que contém apenas os grupos que ocorrem em todos os possíveis cladogramas. Em seguida, foi calculado o diagrama de consenso de maioria, no qual são considerados grupos presentes em um número pré-especificado de árvores possíveis. O suporte de Bremer (índice de decaimento), que informa o número de passos extras para que um determinado ramo seja colapsado foi calculado no programa Treerot.3v (Sorenson \& Franzosa, 2007).

Com o objetivo de se testar uma possível maior resolução das árvores de consenso, o procedimento de pesagem sucessiva foi utilizado. Este procedimento atribui pesos aos caracteres em função do grau de incongruência em relação aos demais caracteres, utilizando para tal a média dos índices de consistência re-escalonados. Desta forma, é diferente da pesagem a priori, em que a atribuição de pesos é determinada antes da análise, na maioria dos casos de maneira arbitrária (Farris, 1969; Goloboff, 1993). De acordo com Amorim (2002), o procedimento de pesagem sucessiva pode ser mais poderoso como método de recuperação filogenética que a parcimônia simples. 
Após a obtenção de árvores salvas pelo procedimento de pesagem sucessiva, foi calculado um diagrama de consenso-estrito para comparação com as árvores obtidas anteriormente nas análises sem pesagem. 


\section{Resultados discutidos}

\subsection{Caracteres}

Nos 31 táxons terminais, foram encontrados 50 caracteres osteológicos, dos quais 17 são cranianos e 33 pós-cranianos. A codificação dos estados está disponível na matriz de caracteres no anexo II.

A descrição detalhada dos diferentes estados de caráter encontrados nas espécies analisadas e suas ilustrações estão disponíveis nesta seção.

Os Frontale, Os Parietale, Os Lacrimale, Os Ectethmoidale, Os Mesethmoidale

[01] - Fossa glandulae nasalis. (0) - ausente/ (1) - presente

A fossa glandulae nasalis está presente em Rallus longistrostris e Porzana carolina, como uma depressão rasa na superfície dorsal da margem supraorbital da órbita, situada por quase toda a extensão do osso frontal. Nos outros táxons estudados, a fossa é ausente.

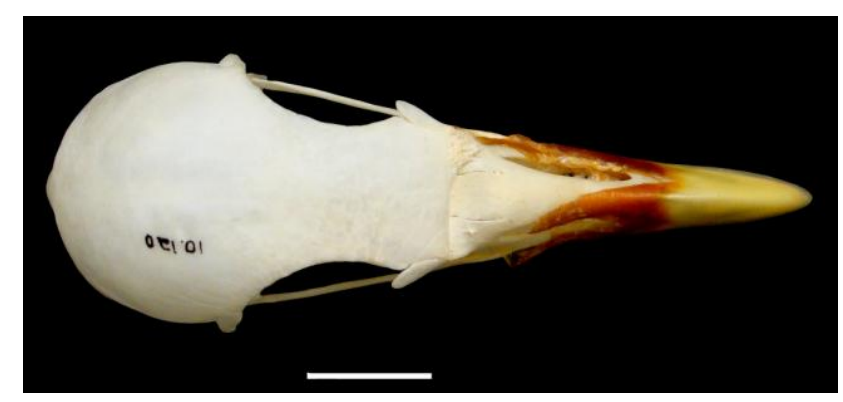

(0) Porphyrio martinica MHNT10.120 


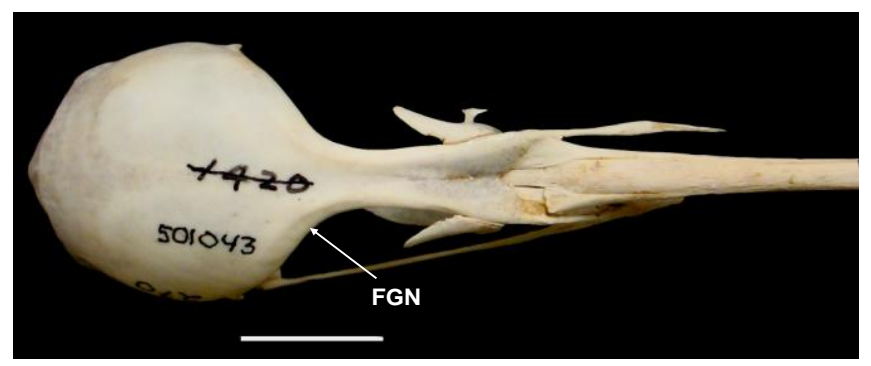

(1) Rallus longirostris MHNT270

FGN - Fossa glandulae nasalis

[02] - Expansão lateral da margo supraorbitalis do os frontale. (0) ausente/ (1) presente

Porphyrio porphyrio possui a margem supraorbital do osso frontal expandida lateralmente, de forma convexa quando observado em vista dorsal. Nos demais táxons, a margem supraorbital é afilada, de forma côncava.

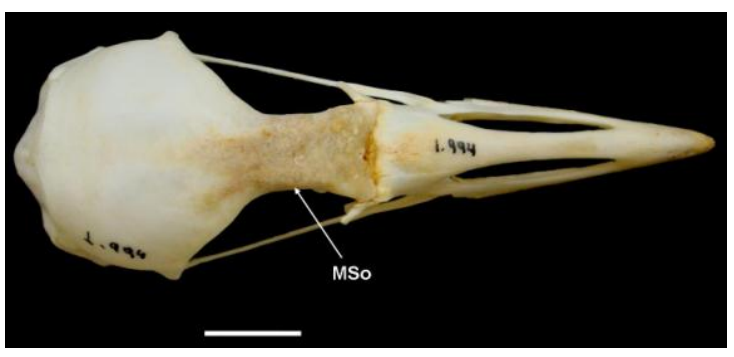

(0) Fulica armilata MHNT1.994

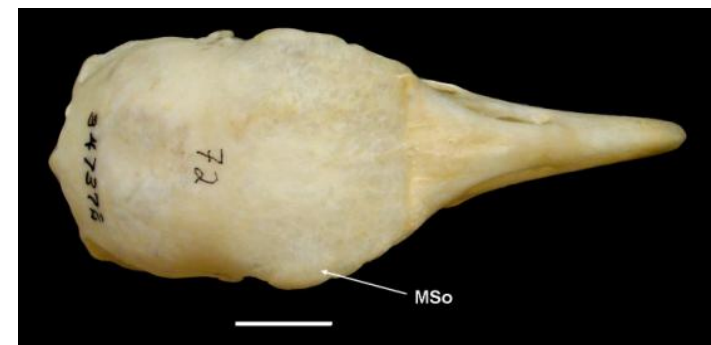

(1) Porphyrio porphyrio MHNT72

MSo - Margo supraorbitalis

[03] - Processus supraorbitalis do os lacrimale. (0) - ausente ou vestigial/ (1) presente

Porphyrio possui o processo supraorbital do lacrimal bastante reduzido ou ausente, enquanto que nos outros táxons analisados o processo está presente, apresentando formas variáveis.

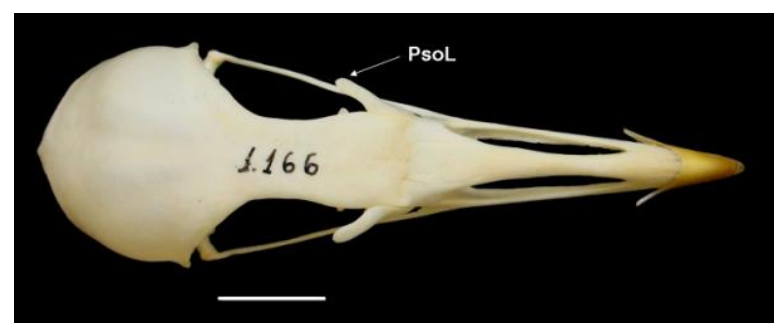

(0) Gallinula tenebrosa MHNT1.166 


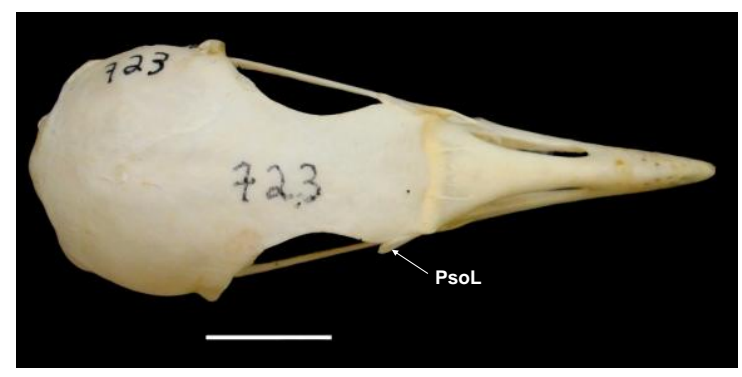

(1) Porphyrio martinica MHNT723

PSoL - Processus supraorbitalis do os lacrimale

[04] - Alongamento caudolateral do processus supraorbitalis do os lacrimale. (0) - ausente/ (1) - presente

Dentre os representantes em que o processo supraorbital do lacrimal é evidente, Aramides apresenta um alongamento caudolateral pronunciado, com a região caudal do processo terminando na porção mediana da margem supraorbital do osso frontal. Nos outros táxons analisados, o alongamento é pouco pronunciado.

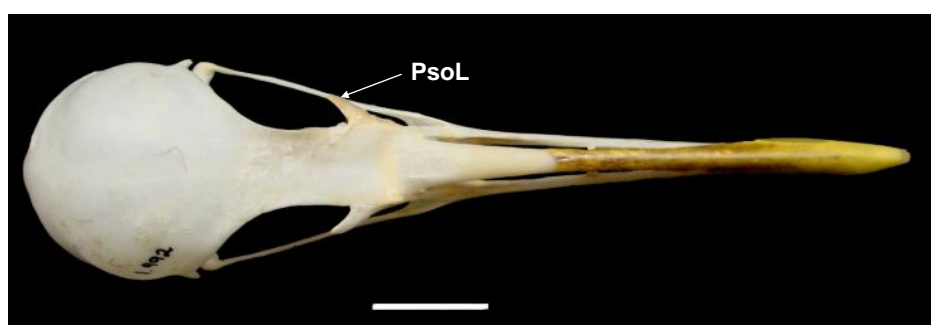

(0) Pardirallus nigricans MHNT1992

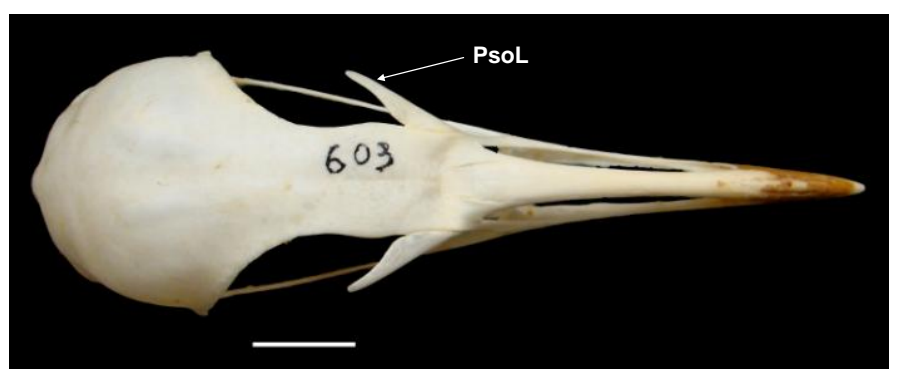

(1) Aramides cajanea MHNT603

PsoL - Processus supraorbitalis do os lacrimale 
[05] - Processo anterior do os lacrimale. (0) - ausente/ (1) - presente

Crex crex e Laterallus viridis possuem um processo anterior curto e arredondado na porção medial do processo descendente do lacrimal. Este caráter ocorre de forma polimórfica em Coturnicops noveboracensis. Nos demais táxons, o processo anterior é ausente.

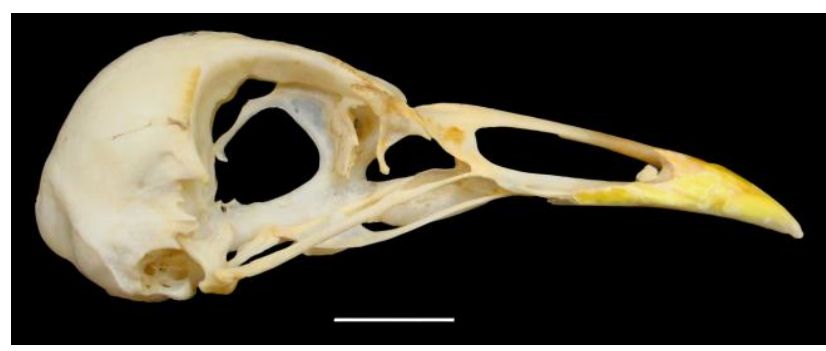

(0) Fulica rufifrons MHNT458

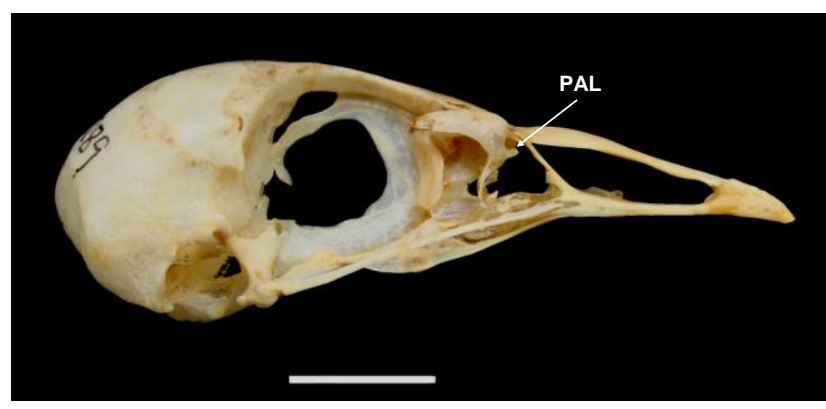

(1) Crex crex MHNT265

PAL - Processo anterior do lacrimal

[06] - Processo posterior do os lacrimale. (0) - ausente/ (1) - presente

Os representantes do gênero Aramides, Pardirallus nigricans e P. maculatus possuem um processo posterior caudal curto situado no meio do processo descendente do lacrimal. Esta estrutura esta ausente nos demais táxons analisados.

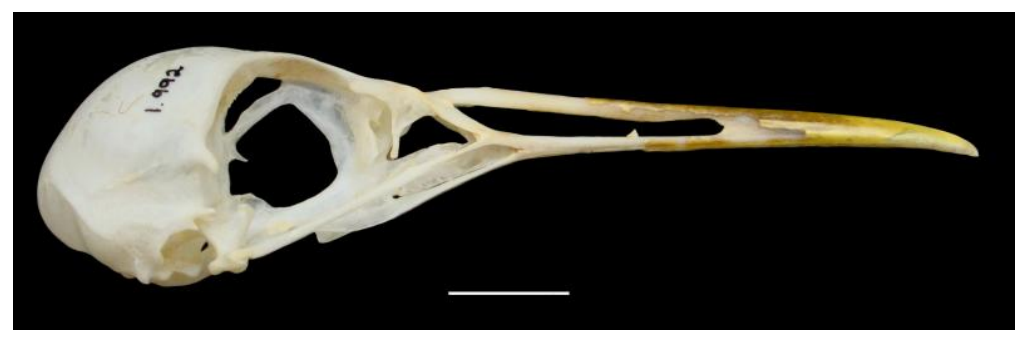

(0) Pardirallus nigrans MHNT1992 


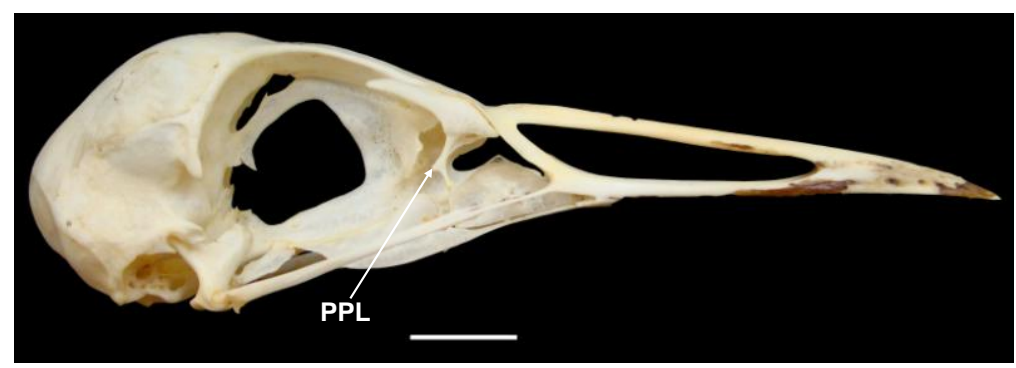

(1) Aramides cajanea MHNT597

PPL - Processo posterior do lacrimal

Os Parasphenoidale, Os Basisphenoidale, Os Laterosphenoidale, Os Squamosum

[07] - Tendões calcificados na fossa temporalis. (0) - ausente/ (1) - presente

Porphyrio porphyrio possui tendões calcificados presos na fossa temporalis que se projetam rostroventralmente em direção à barra jugal. Todos os demais táxons analisados não possuem tendões calcificados na fossa temporal.

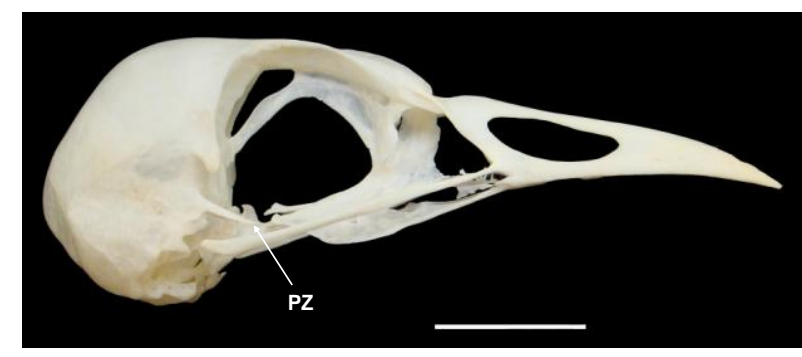

(0) Porphyrio flavirostris MHNT1.425

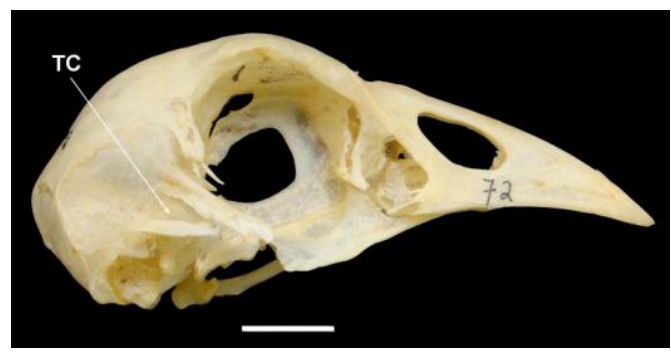

(1) Porphyrio porphyrio MHNT72 PZ - Processus zygomaticus; TC - Tendões calcificados

[08] - Processus zygomaticus. (0) - vestigial/ (1) - curto/ (2) - longo

Nos representantes do gênero Porphyrio martinica e P. flavirostris, o processus zygomaticus é evidentemente afilado e alongado rostroventralmente, com sua extremidade distal localizada mais rostralmente em relação ao processus supraorbitalis. Em $P$. porphyrio os tendões calcificados na região da fossa temporalis ocultam a identificação do processo zigomático.

Nos demais táxons analisados, o processo zigomático é curto e amplo, com sua extremidade distal posicionada ventralmente ao processo supraorbital. 


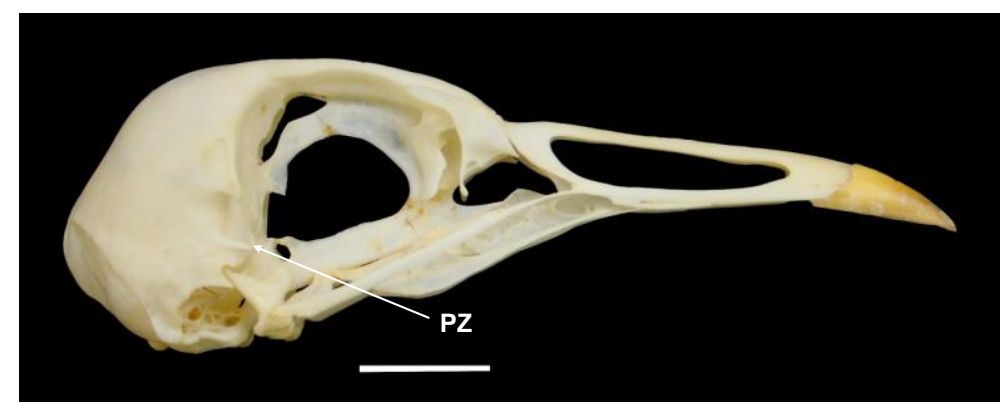

(0) Gallinula tenebrosa MHNT1.166

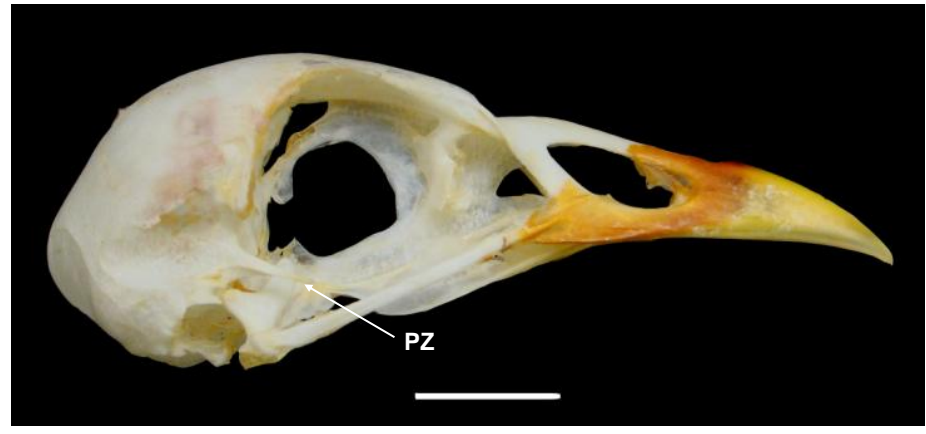

(1) Porphyrio martinica MHNT1.997

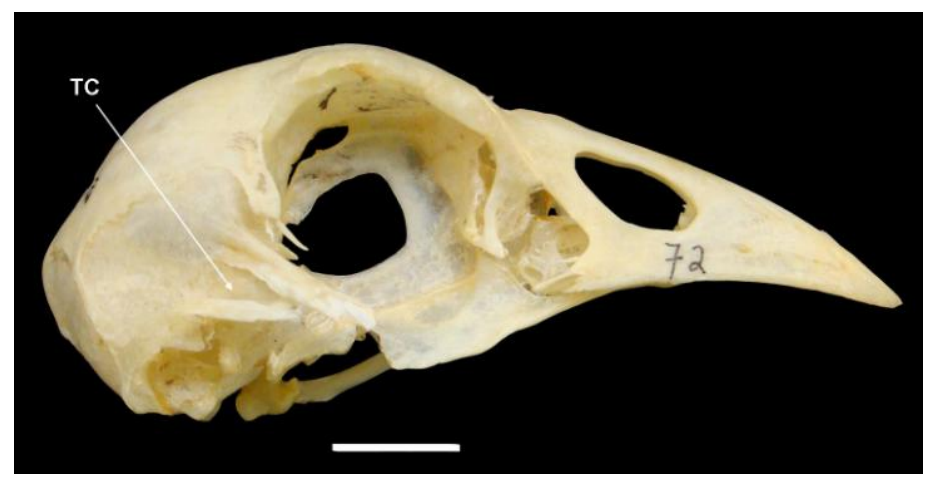

(2) Porphyrio porphyrio MHNT72

PZ - Processus zygomaticus/ TC - Tendões calcificados

Os Basioccipitale, Os Exoccipitale, Os supraoccipitale

[09] - Sulcus veni occipitalis externus. (0) - ausente/ (1) - presente

Nos exemplares analisados, o foramen veni occipitalis externae está localizado lateralmente ao foramen magnum. Aramides e Laterallus possuem um sulco transversal associado ao forâmen, enquanto que nos outros táxons analisados este sulco esta ausente. 


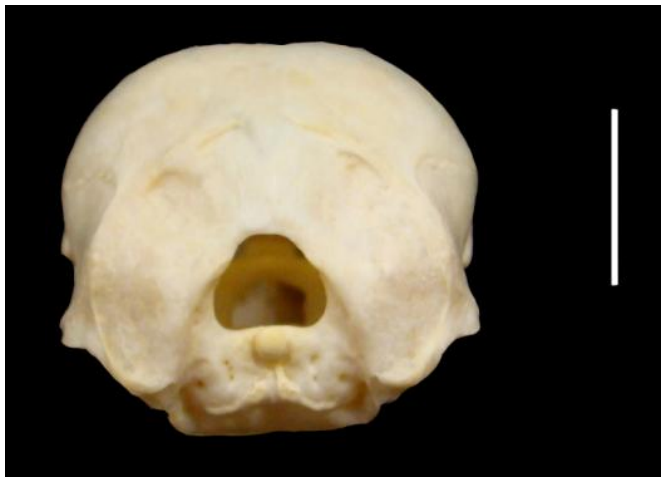

(0) Porphyrio porphyrio MHNT1.369

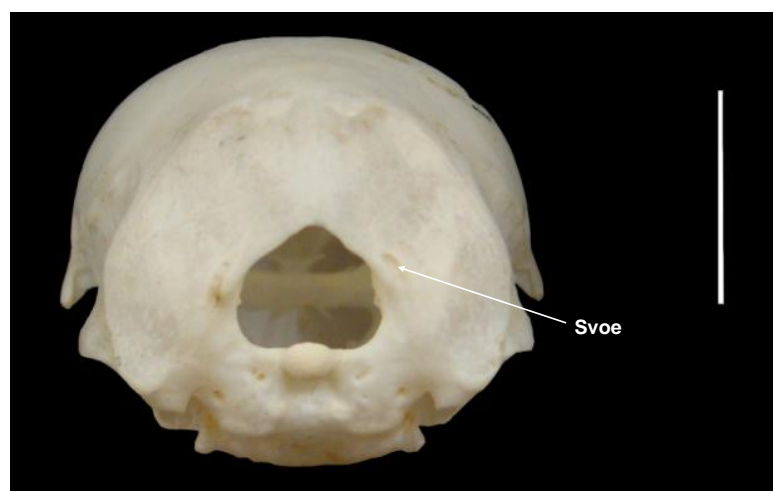

(1) Aramides saracura MHNT1.991

Svoe - Sulcus veni occipitalis externus

Ossa Faciei: Os Nasale, Os Premaxillare, Os Maxillare

[10] - Extensão da apertura nasi ossea. (0) - longa/ (1) - curta

Heliornithidae e os representantes do gênero Porphyrio analisados apresentam o comprimento da apertura nasi ossea equivalente a menos da metade do comprimento total da maxila. Nos demais táxons analisados, o comprimento da abertura nasal é maior do que a metade do comprimento total da maxila.

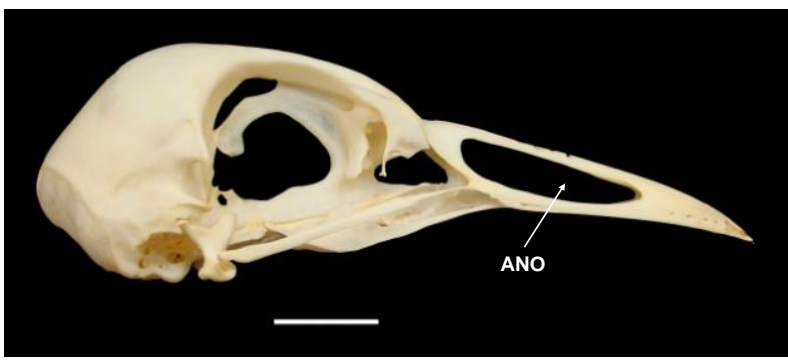

(0) Gallinula tenebrosa MHNT1.166

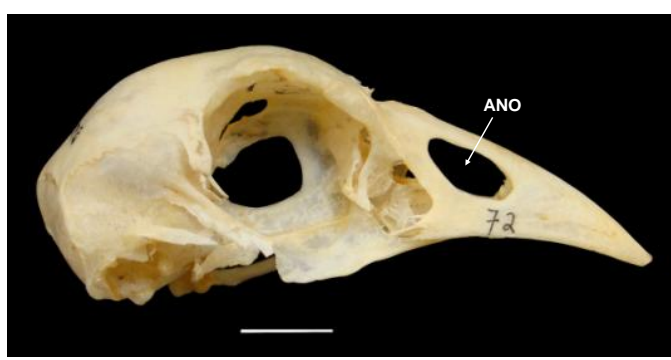

(1) Porphyrio porphyrio MHNT72

\section{ANO - Apertura nasi ossea}

[11] - Forma da porção caudal da apertura nasi ossea. (0) - afilada/ (1) arredondada

A maioria dos ralídeos analisados possui a porção caudal da apertura nasi ossea afilada, estendendo-se caudalmente à zona flexoria craniofacialis, No entanto, Heliornithidae e alguns representantes de Rallidae, como Gallinula e Fulica possuem a porção caudal de forma arredondada. 


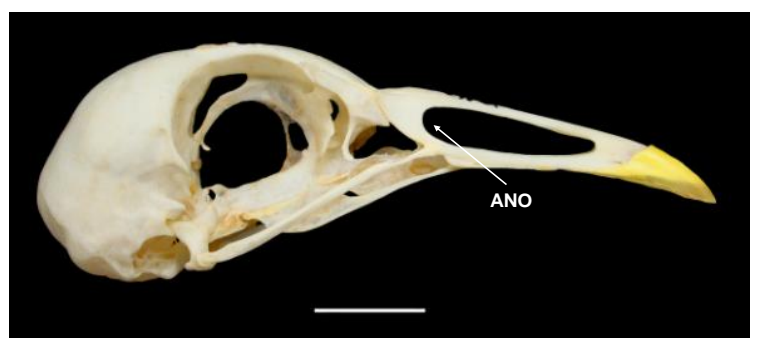

(0) Gallinula chloropus MHNT10.112

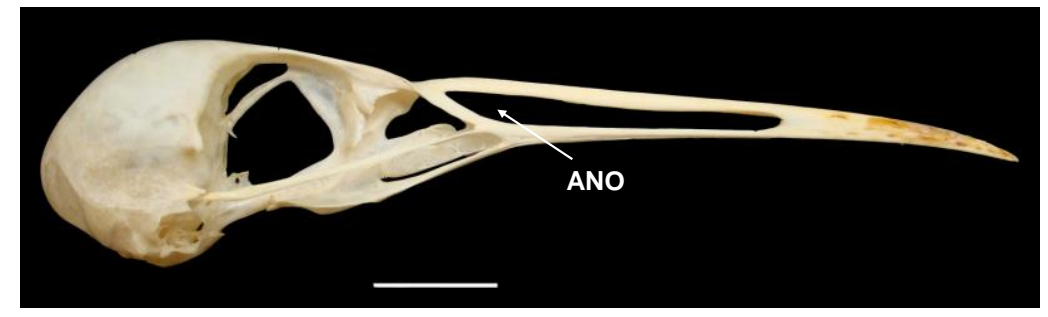

(1) Pardirallus sanguinolentus MHNT1.269

ANO - Apertura nasi ossea

[12] - Espessura do processus maxillaris nasalis (0) - delgado/ (1) - largo

Rallus e Crex possuem o processus maxillaris delgado e o osso lacrimal articulase principalmente ao frontal. Nos demais táxons analisados, o processo é amplo e o osso lacrimal encontra-se mais rostralmente, articulado a porção terminal do processo maxilar.

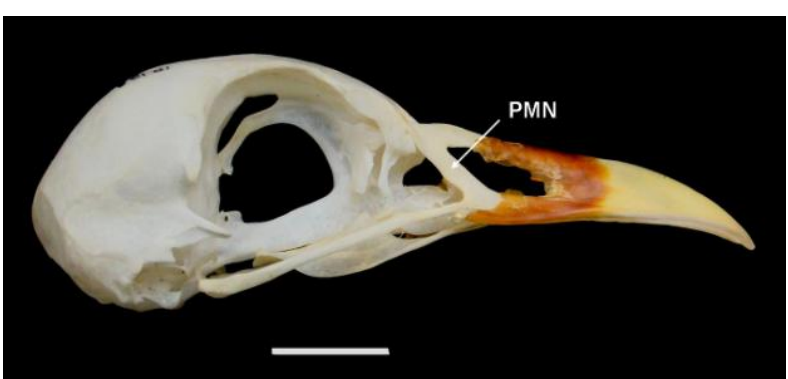

(0) Porphyrio martinica MHNT10.120

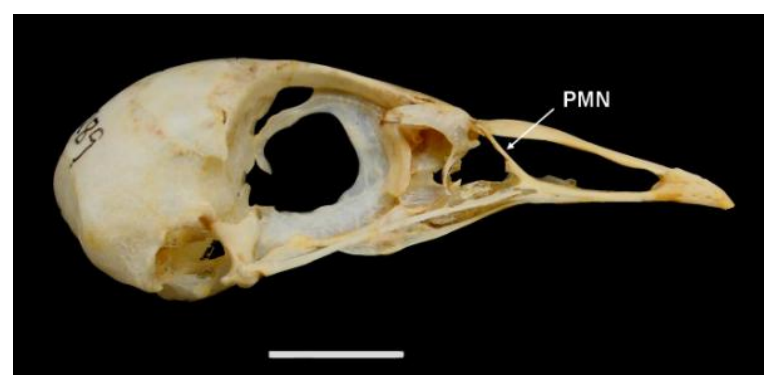

(1) Crex crex MHNT265

PMN - Processus maxillaris nasalis

[13] - Posição do processus maxillaris palatinum. (0) - lateral/ (1) - medial

Heliornis, Crex e os representantes de Porphyrio possuem o processo maxilar palatino posicionado lateralmente, encostado à porção anterior do osso palatino por toda sua extensão, sendo o vômer de fácil visualização. Nos demais táxons, o processo é 
posicionado medialmente, encostando-se ao osso palatino apenas em sua parte mais distal.

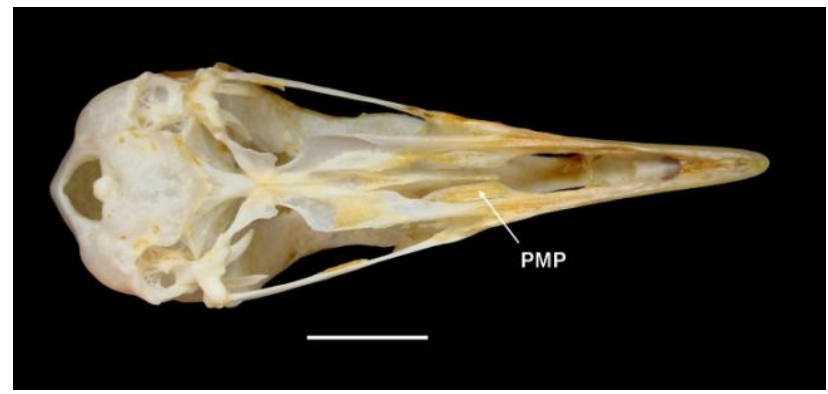

(0) Porphyio martinica MHNT1997

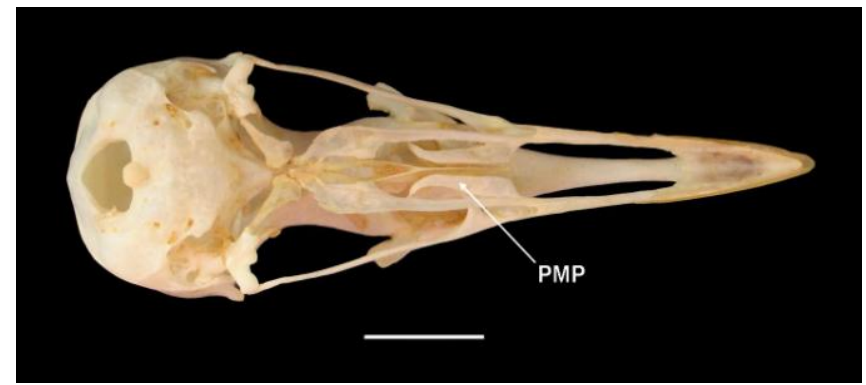

(1) Gallinula chloropus MHNT10.112

PMP - Processus maxillaris palatinum

[14] - Crista tomialis; angulus tomialis maxillaris. (0) - ausente/ (1) - presente

O angulus tomialis maxillaris é uma projeção caudal afilada da crista tomialis localizada ventralmente à articulação entre a barra jugal e o processo maxilar. Está presente em Heliornithidae e em alguns gêneros de ralídeos analisados, tais como Porphyrio, Amaurornis e Crex.

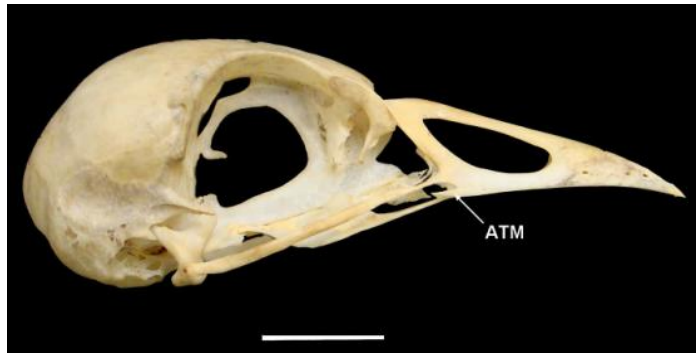

(0) Porphyrio martinica MHNT201

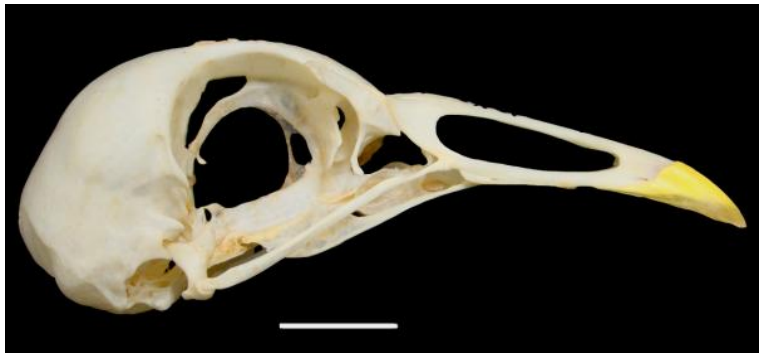

(1) Gallinula chloropus MHNT10.112

ATM - Angulus tomialis maxillaris 
[15] - Angulus caudolateralis do osso palatinum. (0) - arredondado/ (1) - afilado Porphyrio possui o ângulo caudolateral do palatino afilado, enquanto que nos outros táxons analisados ele é arredondado.

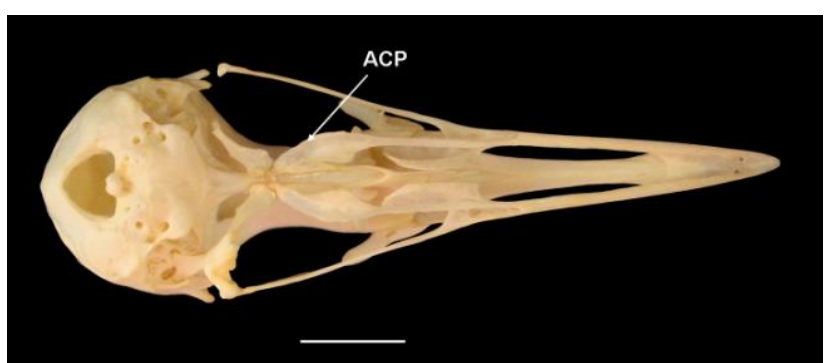

(0) Gallinula tenebrosa MHNT1178

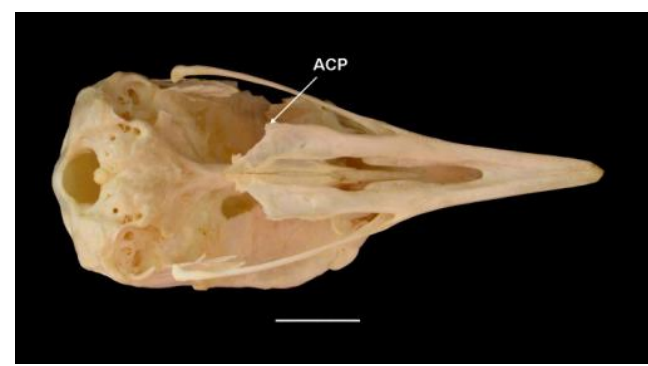

(1) Porphyrio porphyrio MHNT1369

$\mathrm{ACP}-$ Angulus caudolateralis palatinum

Ossa mandibulae

[16] - Processus retroarticularis. (0) - ausente ou vestigial/ (1) - evidente

Em ralídeos, o processus retroarticularis é comparativamente menor em relação ao processo observado em Anseriformes. Livezey \& Zusi, 1997 denominaram esta estrutura de hamulus retroarticularis.

Heliornithidae e Porphyrio possuem o processo de forma reduzida ou ausente, entretanto, nos demais táxons analisados, o processo situa-se na porção caudal da mandíbula, posterior à cotyla lateralis mandibularis, orientado dorsalmente na forma de gancho.

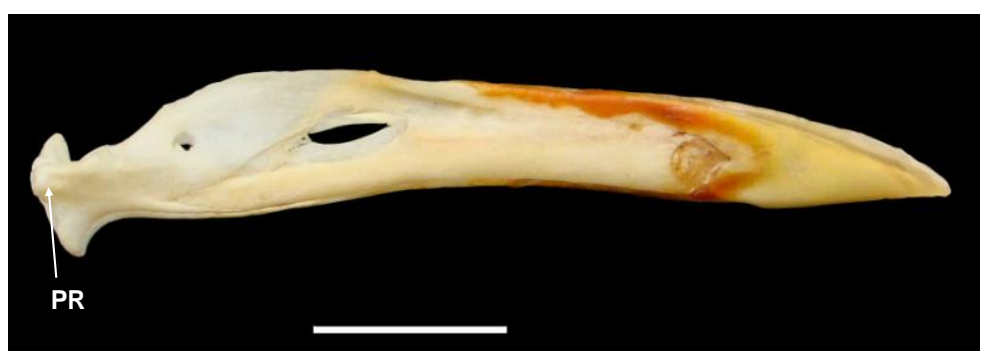

(0) Porphyrio martinica MHNT10120 


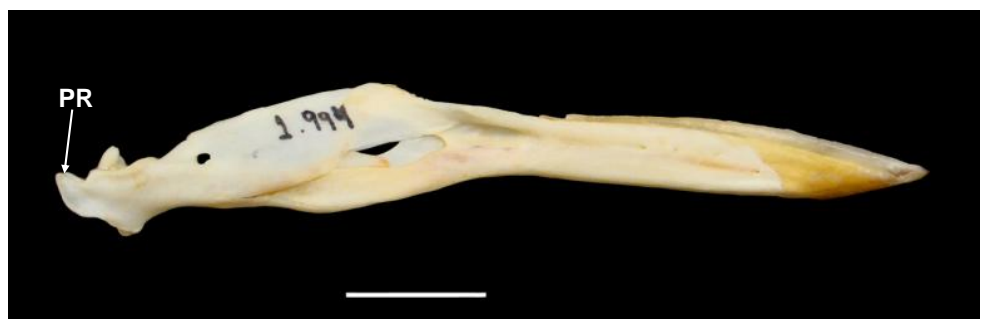

(1) Fulica armilata MHNT1994

PR - Processus retroarticularis

\section{Ossa Acessoria Cranii}

[17] - Concavidade dos ossa sclerae. (0) - pouco evidente/ (1) - pronunciada

Em Fulica a concavidade dos ossa sclerae é bastante pronunciada, com uma proeminência lateral na margem interna que proporciona uma forma cônica. Nos demais táxons, a concavidade e a proeminência na margem interna é vestigial ou ausente.

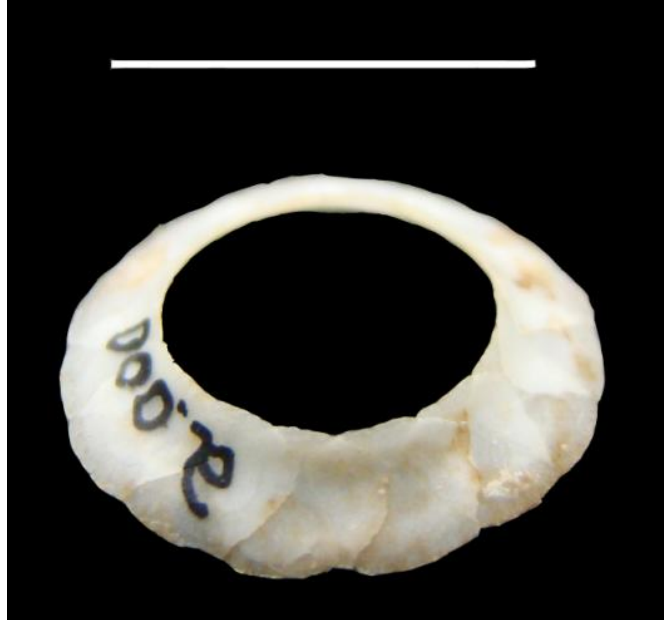

(0) Pardirallus nigricans MHNT2.000

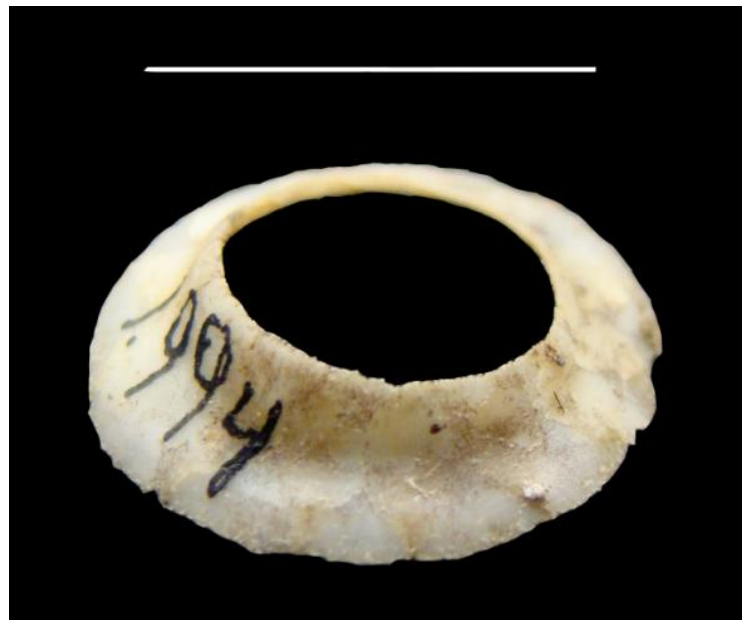

(1) Fulica armilata MHNT1.994

Columna vertebralis: Vertebrae cervicalis

[18] - Lamina arcocostalis. (0) - ausente/ (1) - presente

A lamina arcocostalis é uma fina projeção óssea frequentemente perfurada que se estende ventrolateralmente da face lateral do corpo da vértebra até posições variáveis no processus costalis. Normalmente, está presente a partir da terceira até a nona vértebra 
cervical em todos os representantes de Porphyrio, Aramides cajanea e Heliornis fulica. Nos outros táxons analisados, a lâmina é ausente.

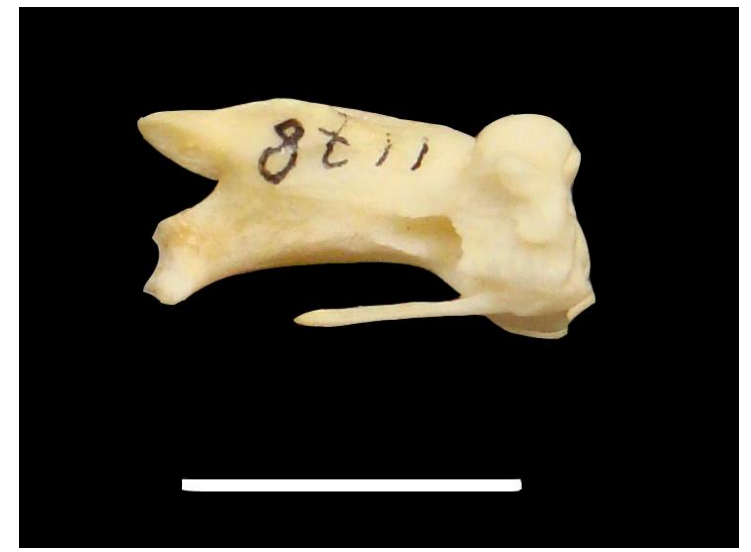

(0) Gallinula tenebrosa MHNT1.178

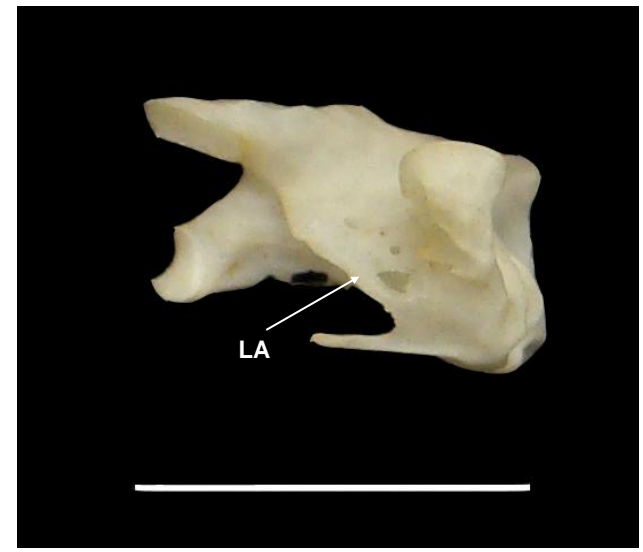

(1) Porphyrio martinica MHNT10120

LA - Lamina arcocostalis

Columna vertebralis: Vertebrae thoracicae

[19] - Foramina pneumatica nas vertebrae thoracicae. (0) - ausente ou vestigial/ (1) - presente

A maioria dos representantes de Rallidae possui um forâmen pneumático na face lateral das vértebras torácicas, localizado dorsocaudalmente à fovea costalis capituli. Heliornithidae e os demais táxons de Rallidae analisados possuem o forâmen vestigial apenas em determinadas vértebras ou ele está completamente ausente.

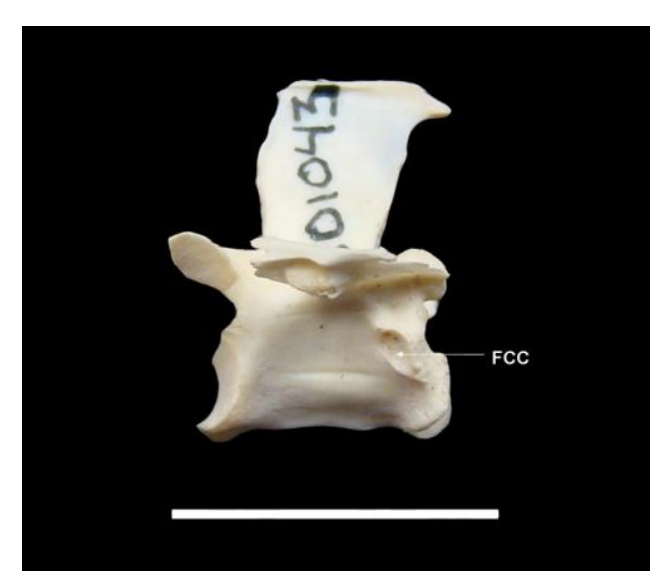

(0) Rallus longirostris MHNT270

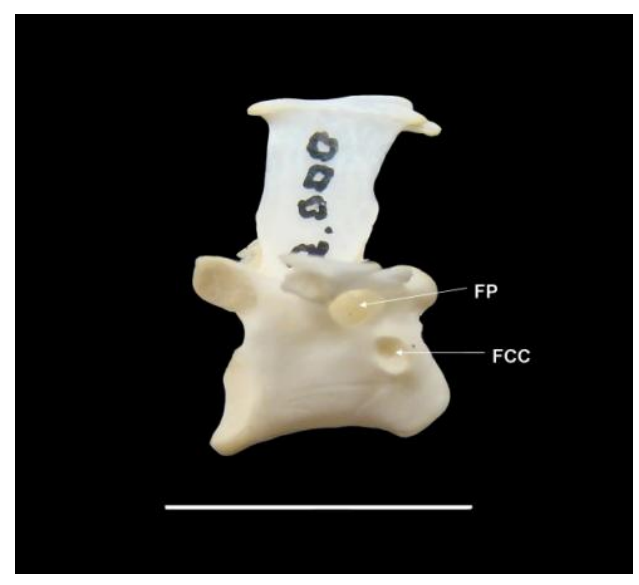

(1) Pardirallus nigricans MHNT2000

FP - Foramina pneumatica; FCC - Fovea costalis capituli 
[20] - Forâmen no primeiro processus transversus associado ao sinsacro. (0) ausente/ (1) - presente

Porphyrio, Amaurornis e Aramides possuem um forâmen no primeiro processo transversal da vértebra sinsacral. Este forâmen é ausente nos demais táxons analisados e ocorre no estado polimórfico em Pardirallus nigricans.

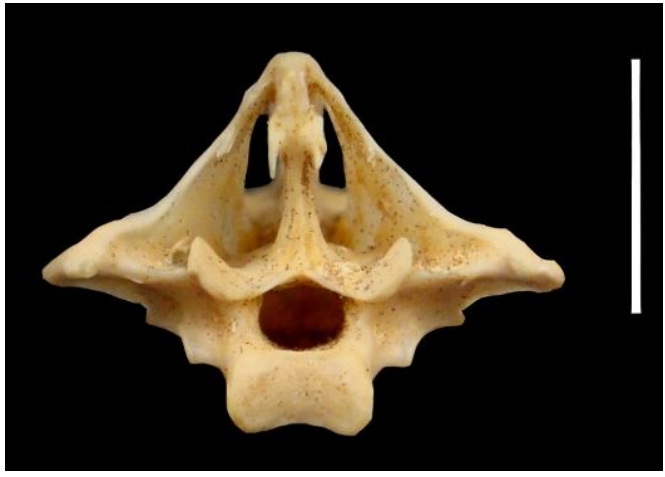

(0) Gallinula chloropus MHNT10.121

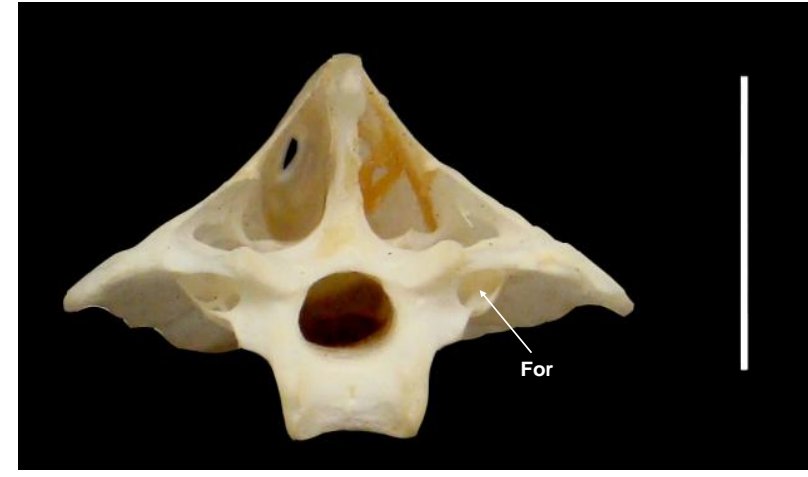

(1) Porphyrio martinica MHNT10.120

For - Foramen

[21] - Depressão medial das vertebrae synsacrales. (0) - ampla e curta/ (1) estreita e longa

Os representantes de Fulica possuem uma depressão medial evidentemente estreita e alongada na face dorsal pós-acetabular do sinsacro, apresentando os foramina intertransversaria vestigiais ou completamente oclusos. Nos demais táxons observados, a depressão medial é vestigial e ampla lateralmente, com os forâmenes intertransversais frequentemente distintos.

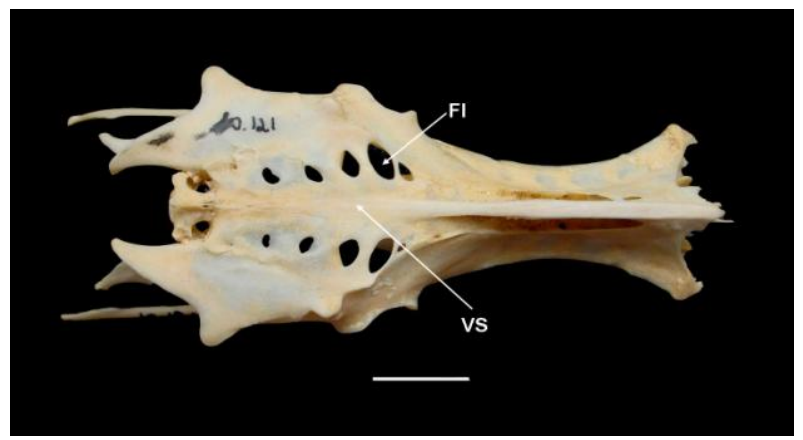

(0) Gallinula chloropus MHNT10.121 


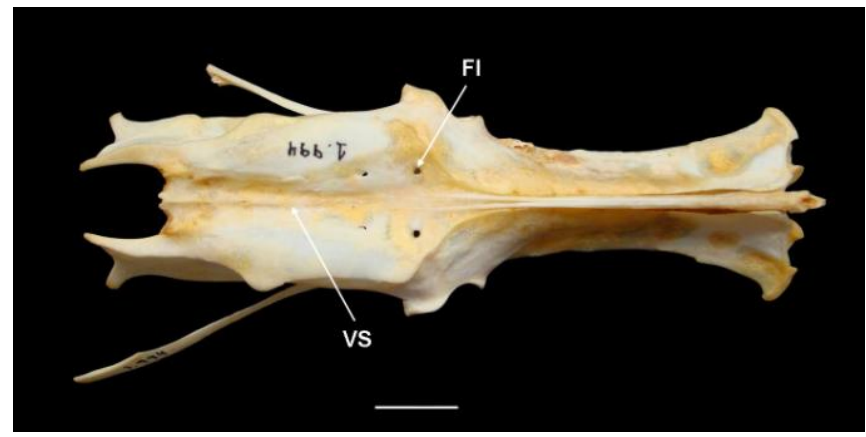

(1) Fulica armilata MHNT1.994

VS - Vertebrae synsacrales; FI - Foramen intersynsacralis

[22] - Número de vertebrae synsacrales associado à ala postacebularis ilii. (0) uma ou duas, variável/ (1) três.

Os representantes de Fulica, com exceção de F. rufifrons, possuem três vértebras sinsacrais associadas à ala pós-acetabular, acomodando dorsalmente a extensão caudal da fossa renalis. Nos demais táxons o número de vértebras sacrais associados à ala postacebularis ilii é variável entre uma a duas vértebras.

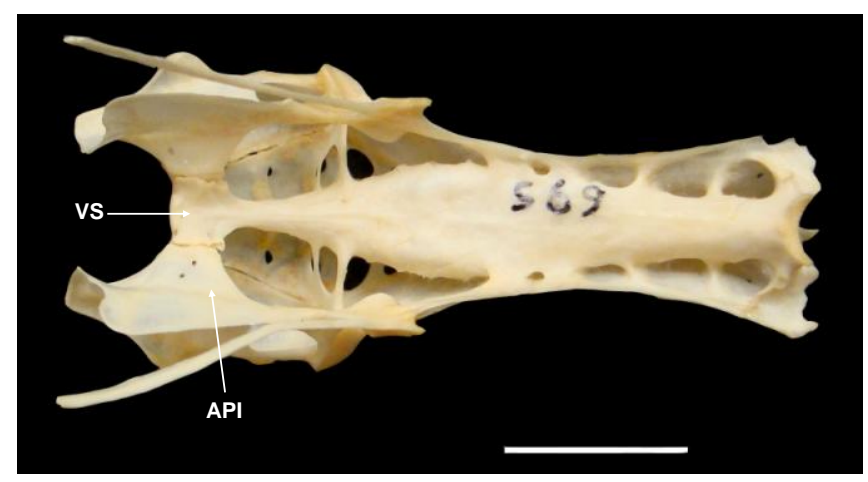

(0) Pardirallus sanguinolentus MHNT695

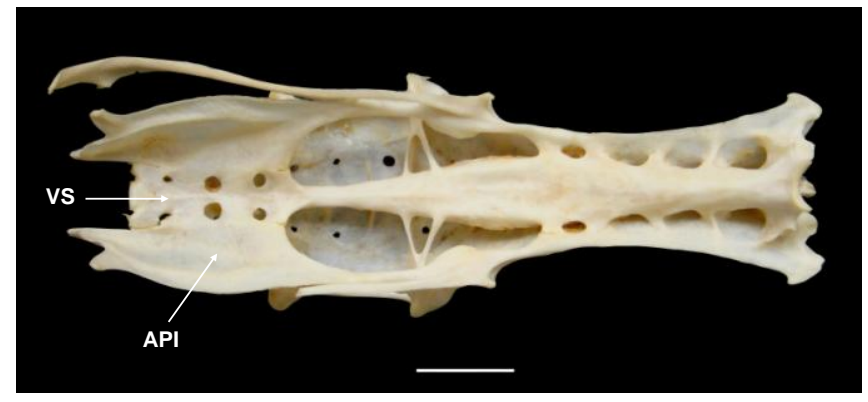

(1) Fulica atra MHNT1.345

VS - Vertebrae synsacralis; API - Ala postacetabularis ilii 
[23] - Extremitas caudalis synsacri. (0) - anquilosada/ (1) - não anquilosada

Os representantes de Fulica possuem as vértebras sinsacrais da extremidade caudal fusionadas à ala postacetabularis ilii. Nos outros táxons analisados é possível observar a sutura entre as vértebras.

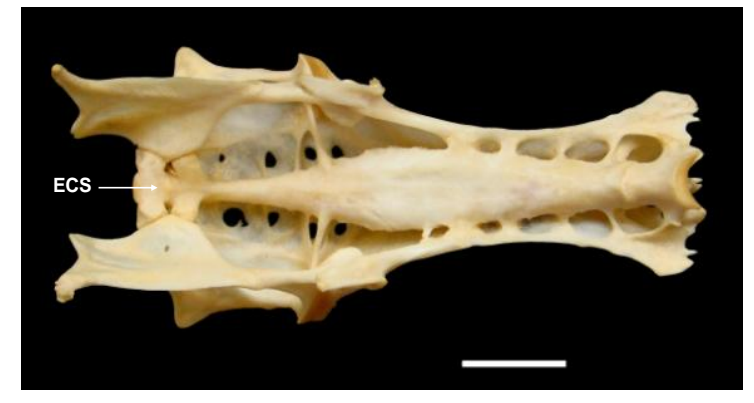

(0) Gallinula chloropus MHNT10.112

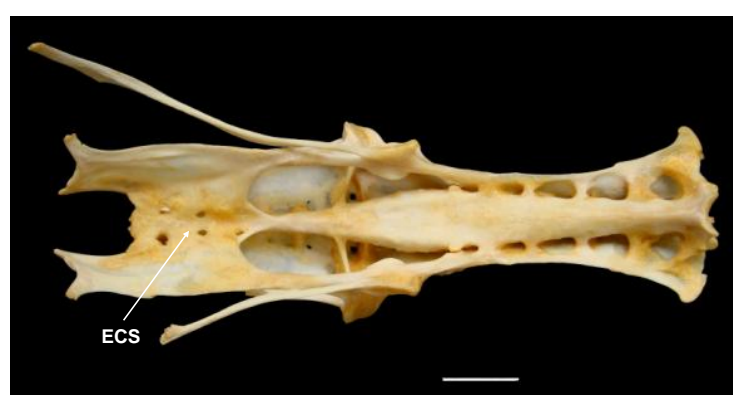

(1) Fulica armilata MHNT1.994

ECS - Extremitas caudalis synsacri

Columna Vertebralis: Vertebrae caudales

[24] - Processus transversus nas vertebrae caudales. (0) - longo/ (1) - curto

Os representantes de Rallidae possuem os processos transversais das vértebras caudais curtos e orientados laterocaudalmente, enquanto que Heliornithidae apresenta estes processos bem alongados lateralmente.

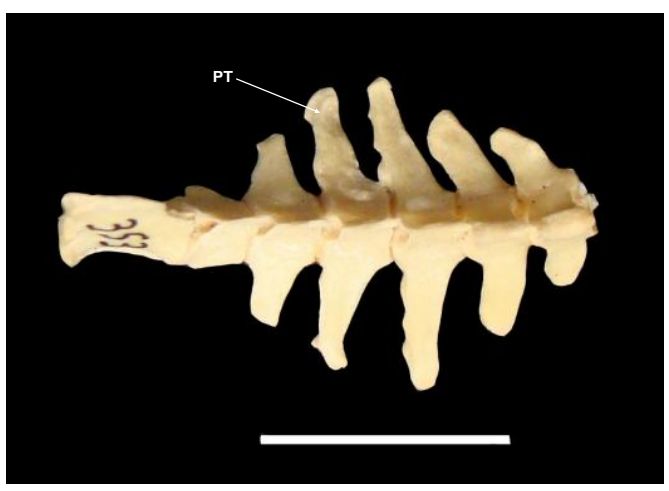

(0) Heliornis fulica MHNT353

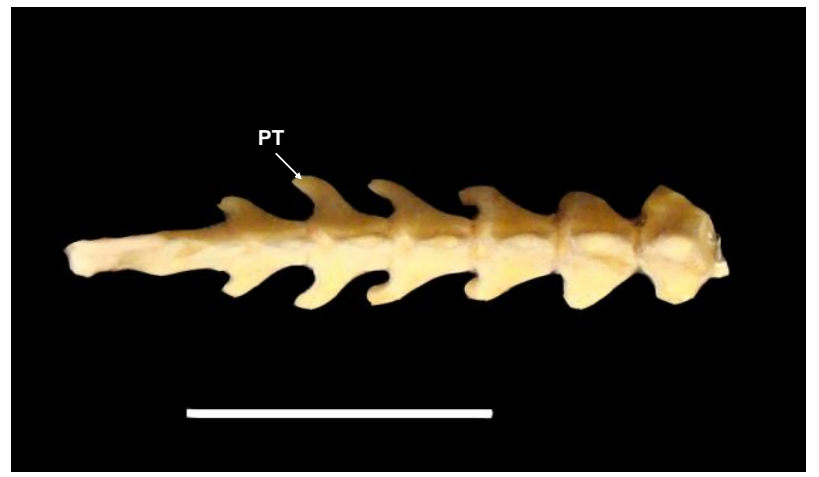

(1) Porphyrio martinica MHNT723

PT - Processus transversus 
Sternum

[25] - Foramen pneumaticum na facies visceralis sterni. (0) - ausente/ (1) presente

Os representantes do gênero Aramides possuem um forâmen pneumático na porção cranial da face visceral do esterno, posterior à pila coracoidea. Nos demais táxons analisados, este forâmen é ausente.

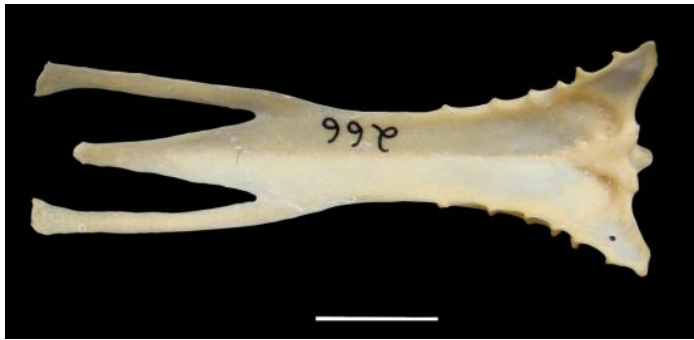

(0) Amaurornis phoenicurus MHNT266

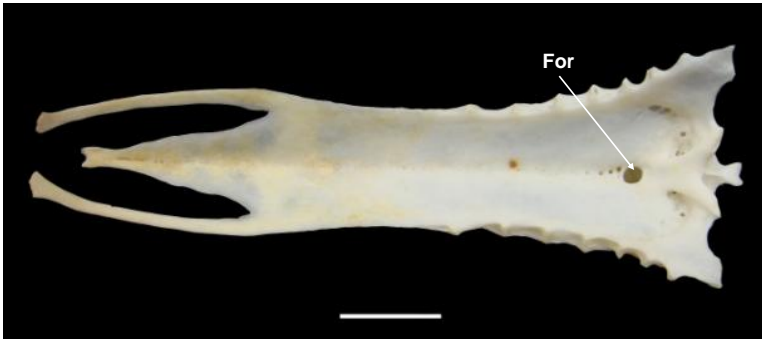

(1) Aramides saracura MHNT1.305

\section{For - Foramen}

[26] - Extensão da margo costalis sterni. (0) - ampla/ (1) - restrita

Gallinula e Porphyrio possuem a margo costalis sterni ampla, ocupando toda a margem lateral do corpo do esterno. Nos outros táxons, a margem costal está restrita à porção cranial do corpo do esterno, ocupando cerca de metade da margem lateral.

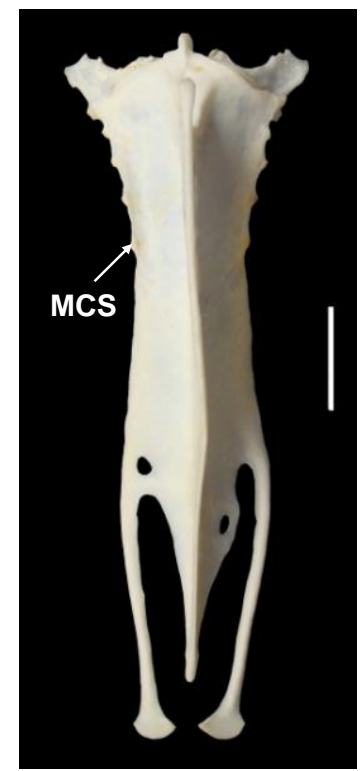

(0) Aramides saracura MHNT10.102

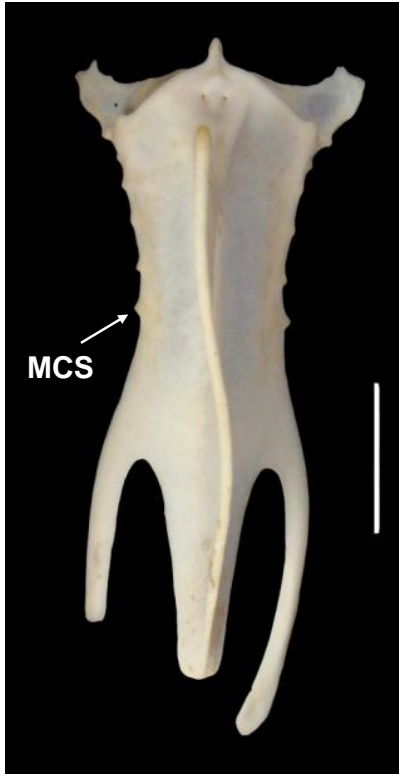

(1) Porphyrio martinica 1.997

MCS - Margo costalis sterni 
[27] - Número de incisurae costales. (0) - cinco/ (1) - seis

Quando observado em vista lateral, o esterno possui uma série de incisurae costales separadas por espaços (processus articularis sternocostalis) onde se articulam as costelas esternais. Os gêneros Coturnicops, Anurolimnas, Laterallus, Gallinula e Porzana possuem cinco incisuras costais, já os outros táxons analisados possuem seis incisuras ou são polimórficos.

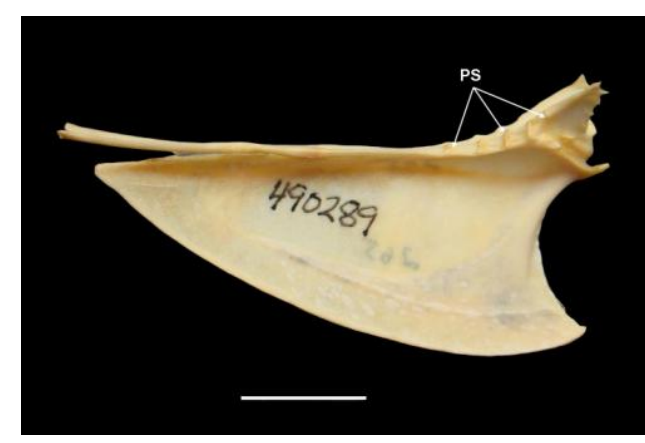

(0) Crex crex MHNT265

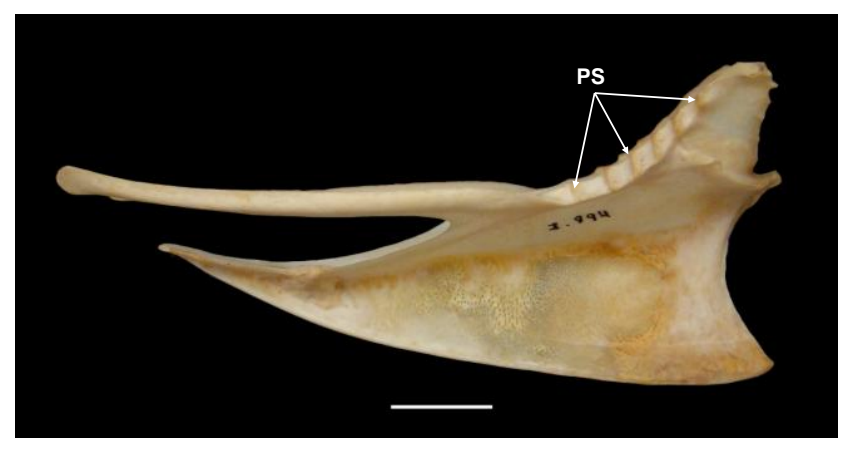

(1) Fulica armilata MHNT1994

[28] - Forma da pila coracoidea. (0) - vestigial/ (1) - forma de T/ (2) - forma de V

A pila coracoidea é um pilar ósseo transversalmente orientado na margem cranial da face dorsal do esterno. Este pilar é evidente na maioria dos ralídeos e pode apresentar duas formas distintas: forma de V (e. g: Laterallus, Porzana, Coturnicops) e forma de T em Gallinula chloropus e G. tenebrosa. Heliornithidae, G. melanops e Fulica possuem o pilar coracóideo vestigial.

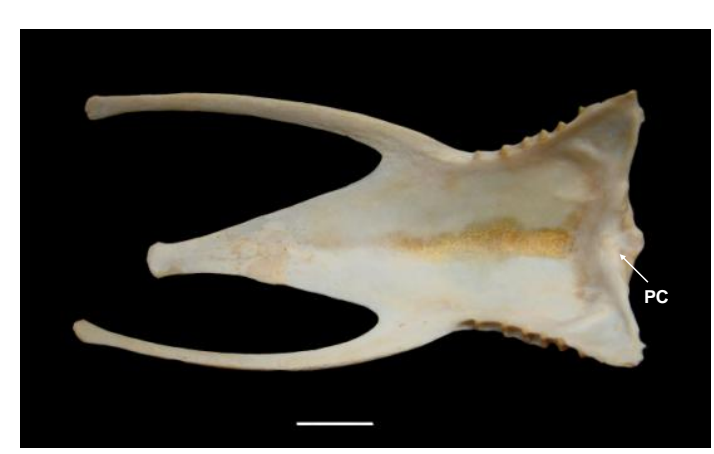

(0) Fulica armilata MHNT1.994

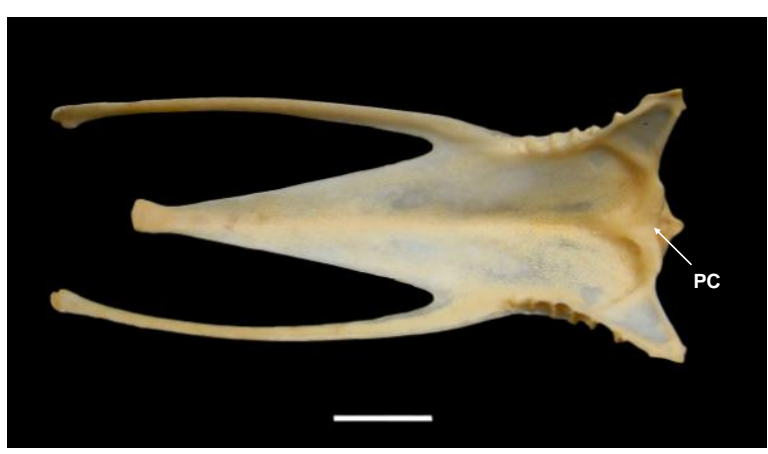

(1) Gallinula chloropus MHNT10.121 


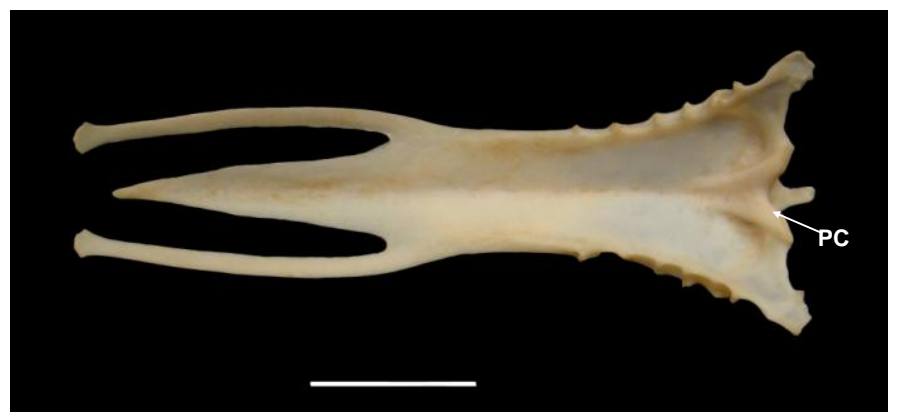

(2) Pardirallus sanguinolentus MHNT765

PC - Pila coracoidea

[29] - Tamanho da incisura lateralis em relação ao corpus sterni. (0) - curto/ (1) - médio/ (2) - grande

A relação entre o comprimento da incisura lateral em relação ao corpo do esterno pode apresentar três estados distintos. O comprimento da incisura é pequeno, correspondendo a cerca de 1/7 do corpo do esterno em Heliornithidae. Os representantes dos gêneros Aramides, Pardirallus e Porphyrio possuem o comprimento da incisura equivalente a 1/3 do comprimento total do esterno, enquanto que Gallinula e Fulica apresentam o tamanho da incisura correspondente à metade do corpo do esterno.

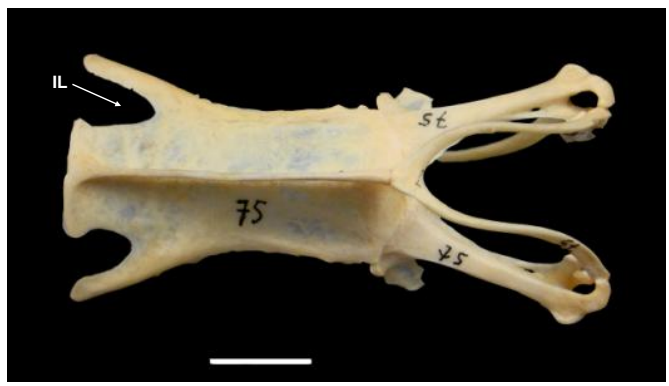

(0) Heliornis fulica MHNT75

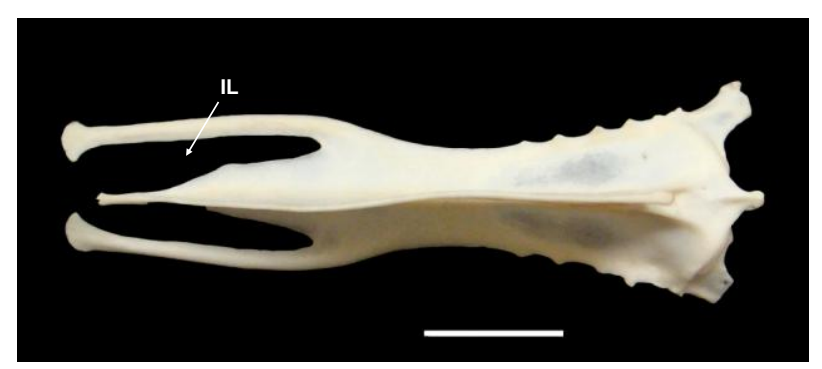

(1) Pardirallus nigricans MHNT1.992

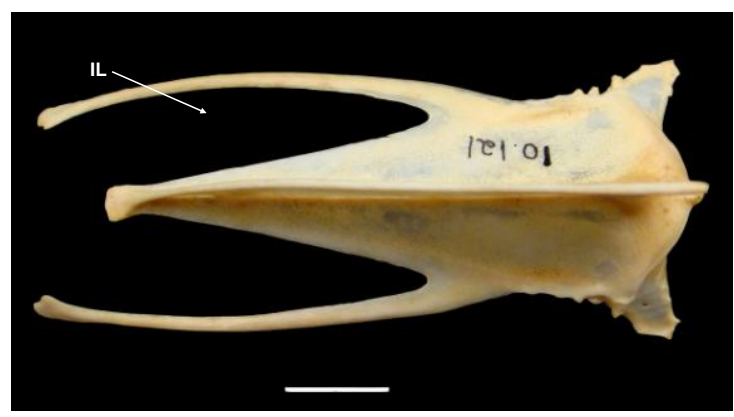

(2) Gallinula chloropus MHNT10.121

$\mathrm{IL}$ - Incisura lateralis 
[30] - Expansão da trabecula medialis. (0) - ausente/ (1) - presente

Heliornithidae possui a poção caudal da trabecula medialis expandida lateralmente, diferente de Rallidae, em que a poção caudal da trabécula é evidentemente afilada.

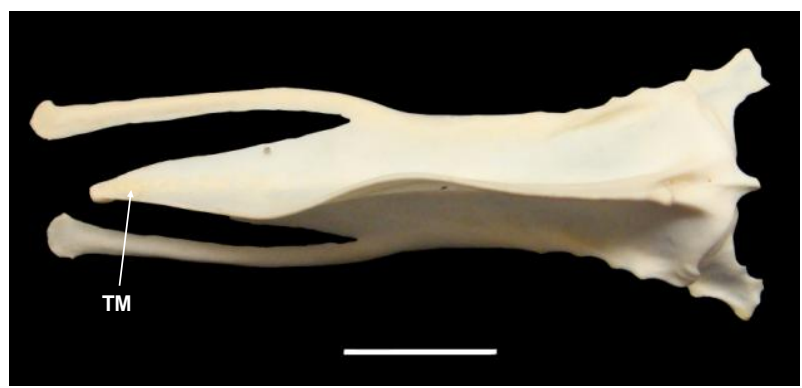

(0) Pardirallus maculatus MHNT1.056

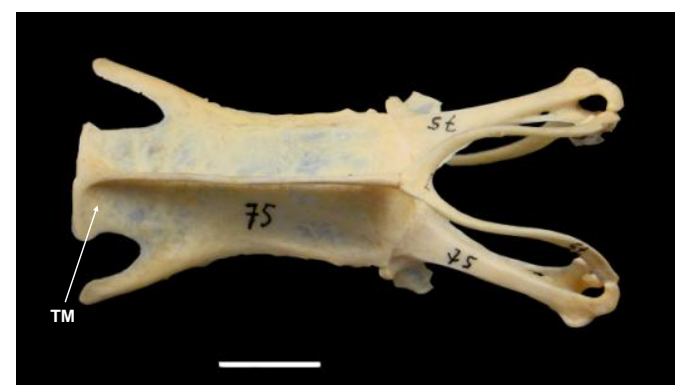

(1) Heliornis fulica MHNT75

TM - Trabecula medialis

[31] - Posição do apex carinae em relação à spina externa. (0) alinhado à spina externa/ (1) posterior à spina externa

Heliornithidae e os representantes de Aramides, Gallinula, Fulica, Crex e Neocrex apresentam o ápice da quilha do esterno alinhado ventralmente à spina externa, de forma que a margem rostral da quilha do esterno é côncava. Nos demais táxons analisados, o apex carinae encontra-se posteriormente em relação à spina externa e a concavidade da margem rostral é menos acentuada. Ambos os estados podem ser visualizados em vista lateral.

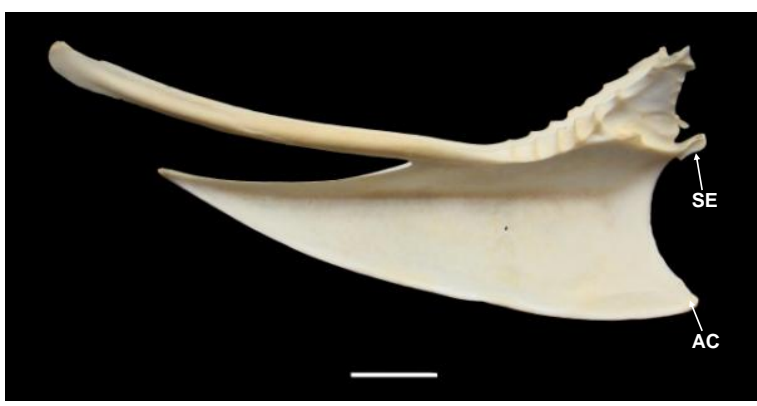

(0) Fulica armilata MHNT1.994

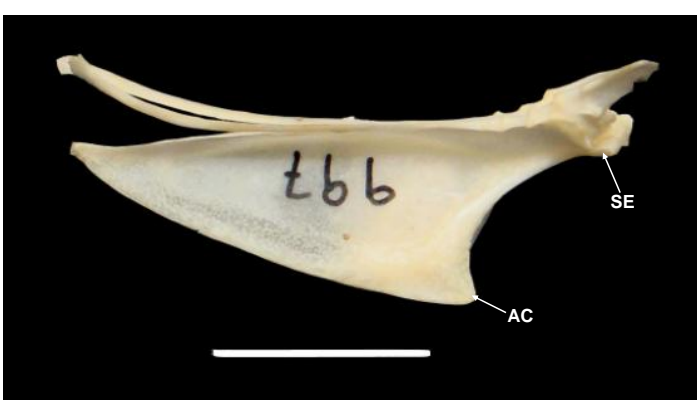

(1) Laterallus melanophaius MHNT997 $\mathrm{AC}$ - Apex carinae; SE - Spina externa 
[32] - Sulcus carinae. (0) - ausente ou vestigial/ (1) - presente

A maioria dos gêneros de ralídeos, como Rallus, Aramides e Pardirallus possui um sulco evidente entre as crista lateralis carinae. Nos demais táxons o sulco é ausente ou bastante reduzido, sendo possível observar a crista medialis entre as cristas laterais por toda a extensão cranial da quilha.

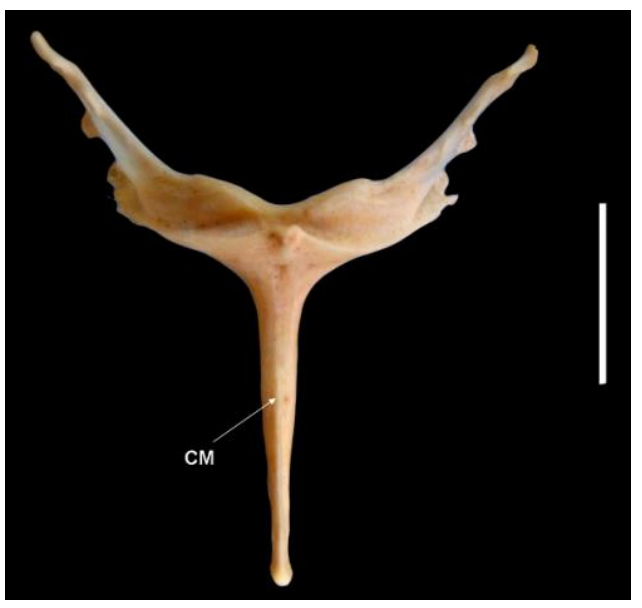

(0) Gallinula chloropus MHNT10.121

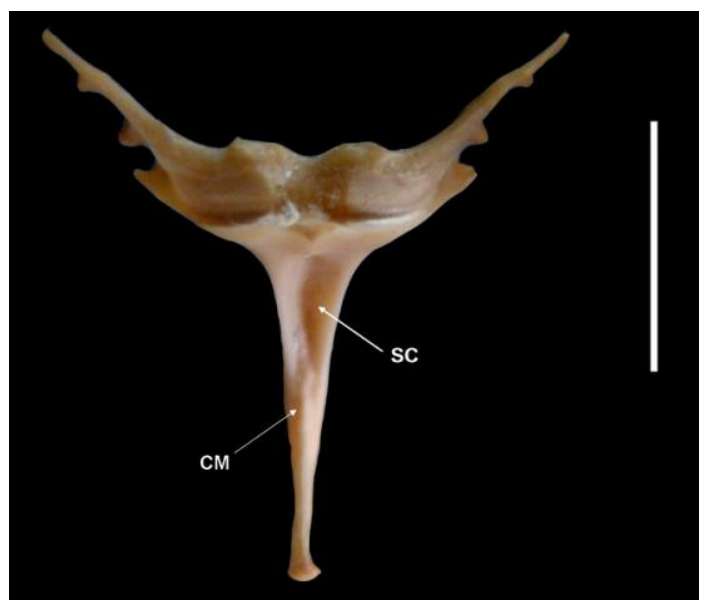

(1) Amaurornis phoenicurus MHNT266

$$
\mathrm{SC}-\text { Sulcus carinae; } \mathrm{CM} \text { - Crista medialis }
$$

Clavicula (Furcula)

$$
\text { [33] - Apophysis furculae. (0) - ausente/ (1) - presente }
$$

Heliornithidae possui um processo ventroposterior curto na poção medial da fúrcula (apophysis furculae) que se articula a uma depressão côncava no apex carinae. Nos membros de Rallidae, a apófise é ausente e a fúrcula não é articulada ao ápice da quilha do esterno.

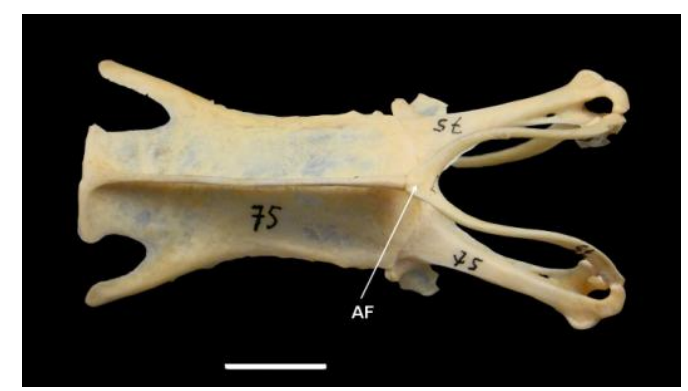

(0) Heliornis fulica MHNT75

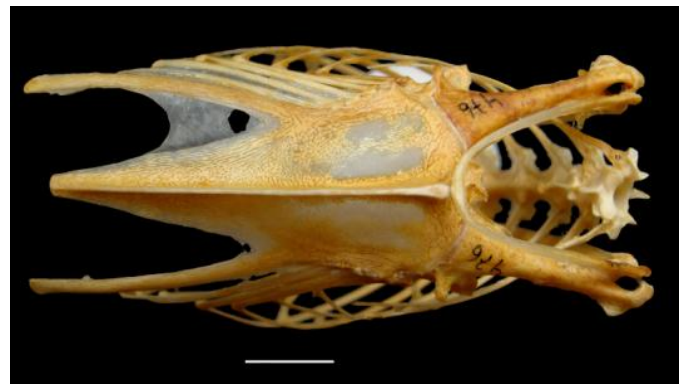

(1) Fulica rufifrons MHNT476

$\mathrm{AF}$ - Aphohysis furculae 
[34] - Extremidade cranial do processus procoracoideus. (0) - ventral ao corpo do coracoide/ (1) - perpendicular ao corpo do coracoide

Heliornithidae apresenta a extremidade cranial do processo procoracoide projetada ventralmente, propiciando um sulco supracoracoide bastante profundo. Nos Rallidae, a extremidade cranial é pouco projetada ventralmente, sendo perpendicular ao corpo do coracoide.

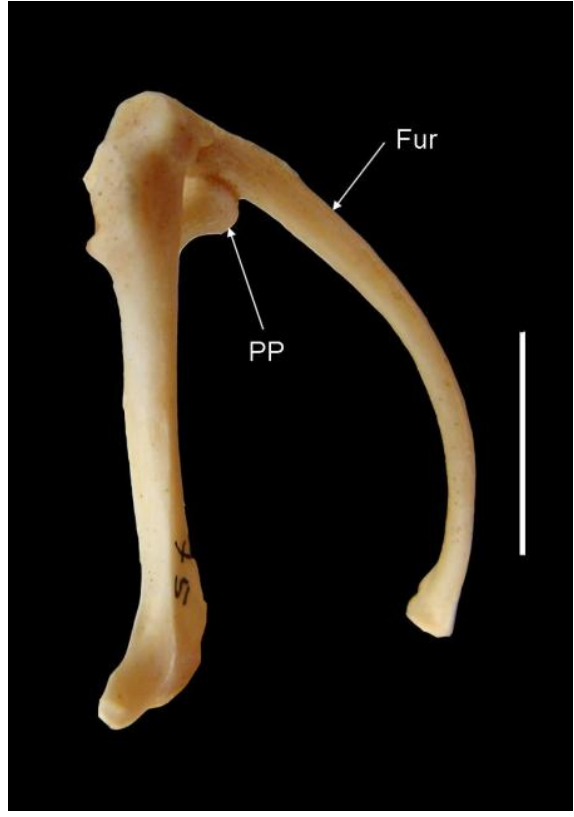

(0) Heliornis fulica MHNT75

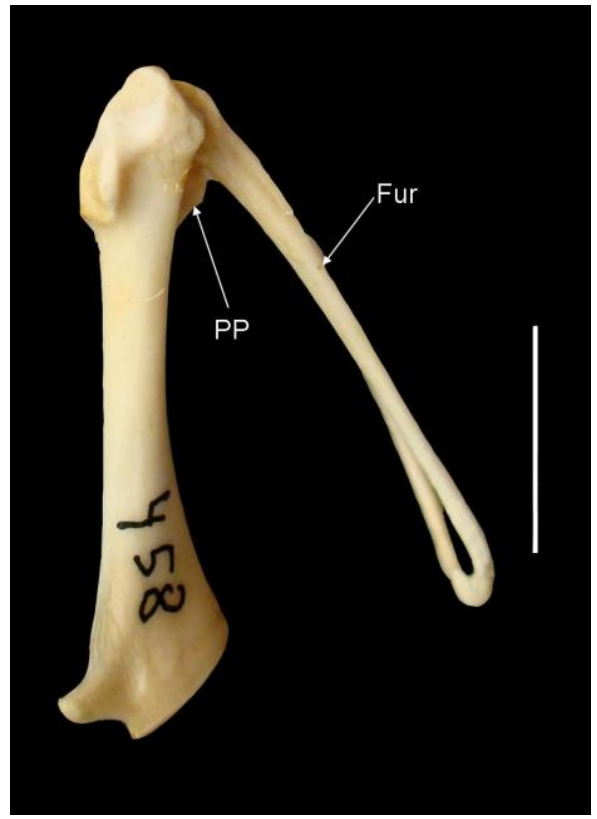

(1) Fulica rufifrons MHNT458 $\mathrm{PP}$ - Processus procoracoideus/ Fur - fúrcula

[35] - Extensão do processus procoracoideus. (0) - curta/ (1) - longa

A projeção da borda medial do coracoide (processus procoracoideus) é curta nos representantes de Rallus, Crex, Coturnicops e Porzana flaviventer, com sua extremidade cranial quase perpendicular à facies articularis clavicularis e o sulcus supracoracoideus pouco evidente. Nos demais táxons, o processo procoracoide é longo, apresentando a extremidade cranial estendida medialmente, evidentemente não perpendicular à facies articularis clavicularis, propiciando um sulco supracoracoide evidente. 


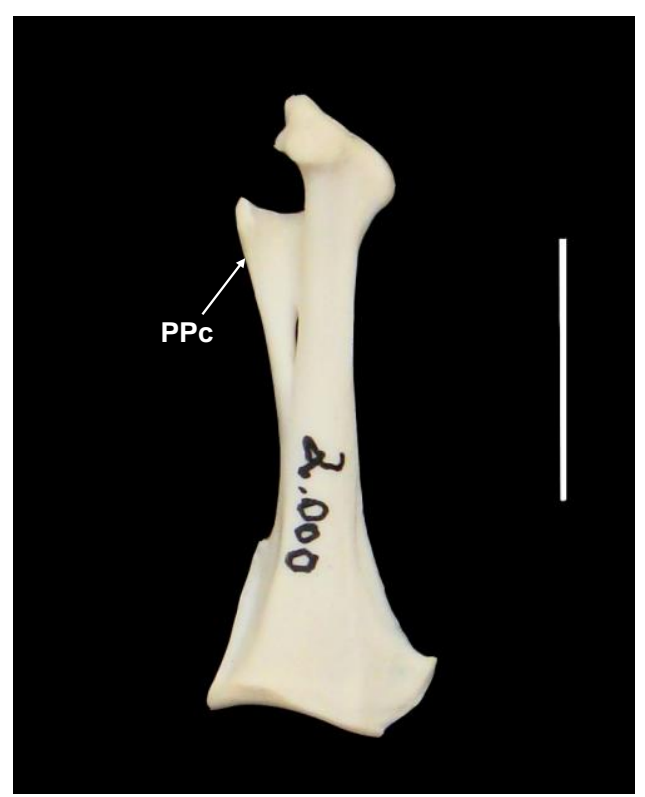

(0) Pardirallus nigricans MHNT2.000

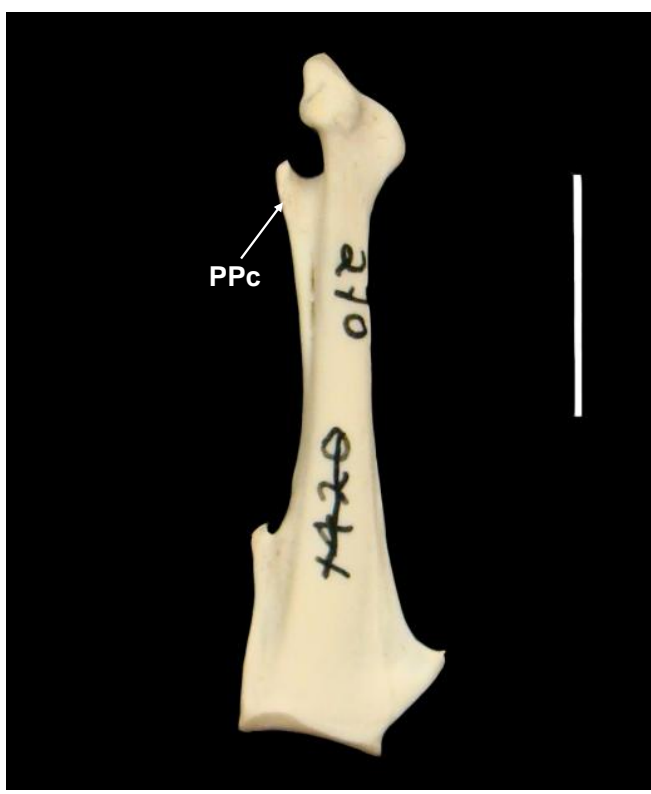

(1) Rallus longirostris MHNT270

PPc - Processus procoracoideus

\section{Humerus}

[36] - Relação entre o comprimento do úmero e o do fêmur. (0) - comprimento semelhante/ (1) - úmero maior que o fêmur/ (2) - úmero menor que o fêmur

Os representantes de Gallinula, Crex, Fulica rufifrons e outros gêneros de Rallidae possuem o comprimento do úmero semelhante ao comprimento do fêmur. Heliornithidae, F. atra, F. americana e $F$. armilata apresentam o comprimento do úmero relativamente maior em relação ao do fêmur. Nos outros táxons, tais como Aramides e Pardirallus, o comprimento do úmero é evidentemente menor do que o do fêmur.

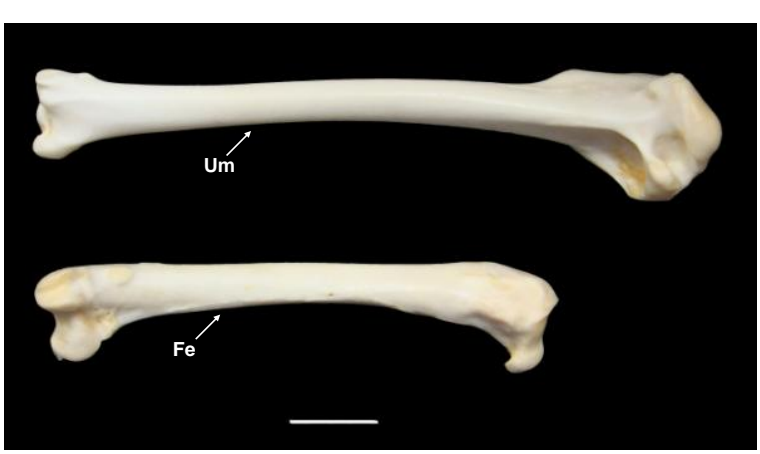

(0) Fulica atra MHNT1.345

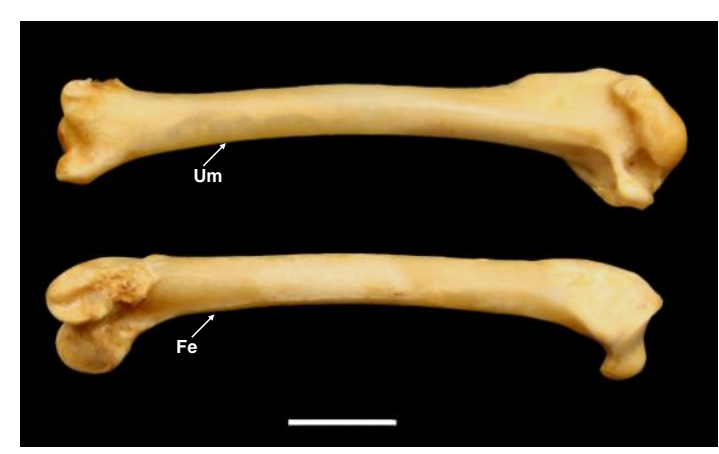

(1) Gallinula chloropus MHNT10.112 


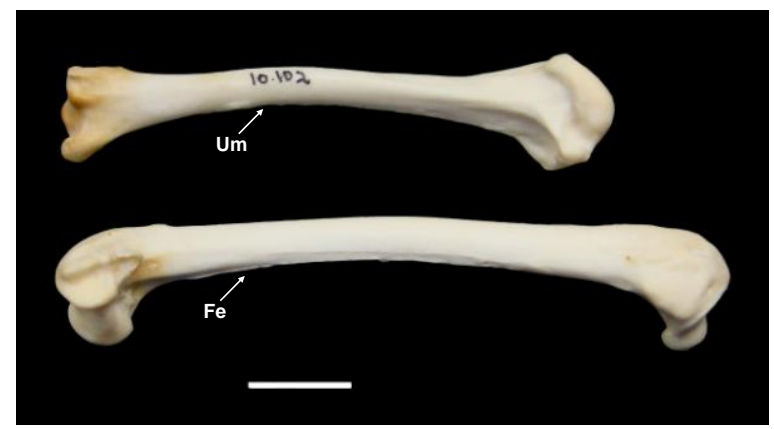

(2) Aramides saracura MHNT10.102

$$
\text { Um - Úmero/ Fe - Fêmur }
$$

Pelvis (Os coxae + Synsacrum)

[37] - Fenestra ischiopubica. (0) - ausente/ (1) - presente

Heliornithidae possui a fenestra ischiopubica localizada ventrocaudalmente ao foramen obturatum, presente devido à anquilose ou articulação entre o processus terminalis ischii e a porção medial do corpo do púbis. Nos outros táxons analisados, a fenestra é ausente.

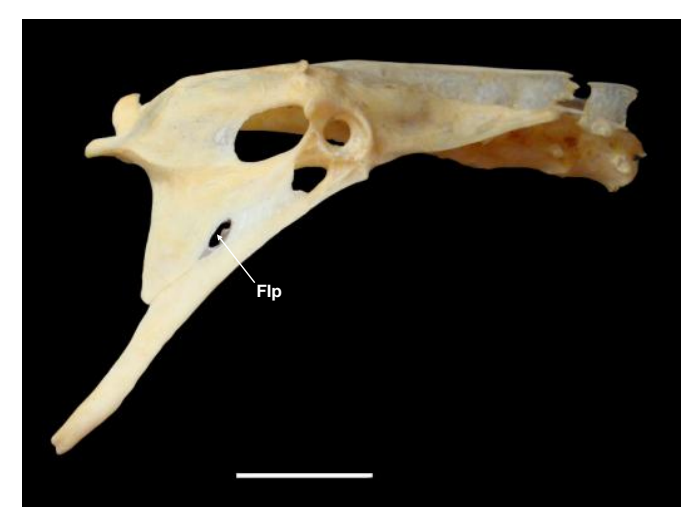

(0) Heliornis fulica MHNT75

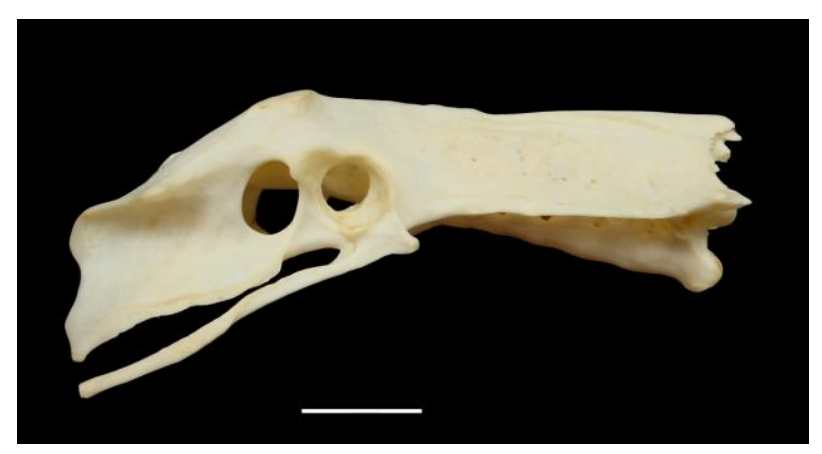

(1) Porphyrio porphyrio MHNT2.369

FIp - Fenestra ischiopubica

[38] - Forma do foramen ilioischiadicum. (0) - oval/ (1) - circular

Heliornithidae, Gallinula melanops e os representantes de Fulica possuem o foramen ilioischiadicum localizado caudalmente ao acetábulo, de forma oval, 
provavelmente devido ao alongamento craniocaudal da pélvis. Nos demais táxons, o forâmen é aproximadamente circular.

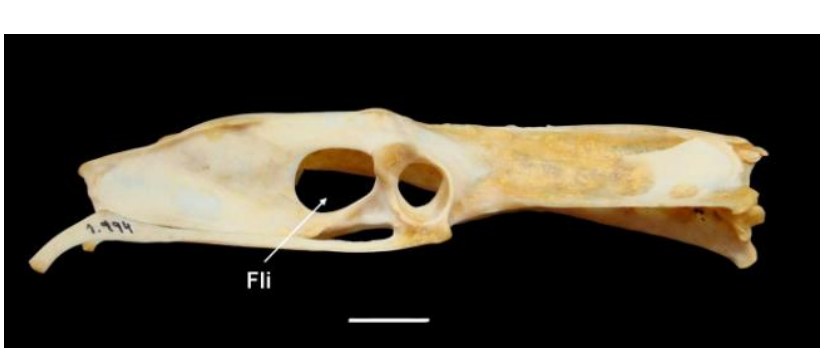

(0) Fulica armilata MHNT1.994

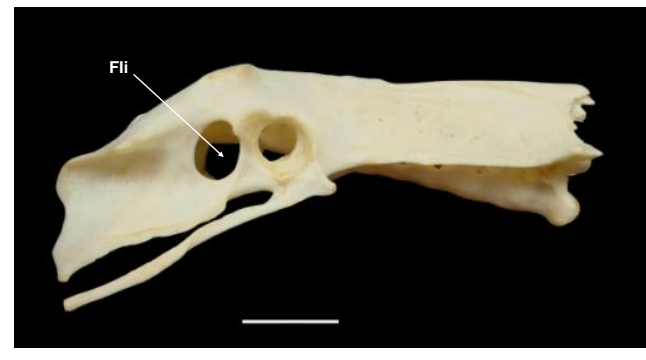

(1) Porphyrio porphyrio MHNT1369

FIi - Foramen ilioischiadicum

[39] - Foramen obturatum. (0) - ausente/ (1) - presente

Heliornithidae possui o foramen obturatum de forma oval situado caudoventralmente ao acetábulo e cranialmente à fenestra ischiopubica. O forâmen é formado devido à anquilose entre a face dorsal do púbis e a borda ventral do ísquio. Nos demais táxons analisados, o forâmen é ausente.

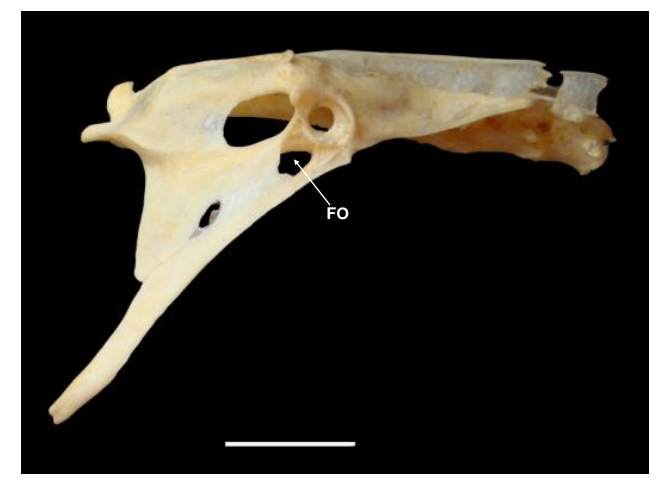

(0) Heliornis fulica MHNT75

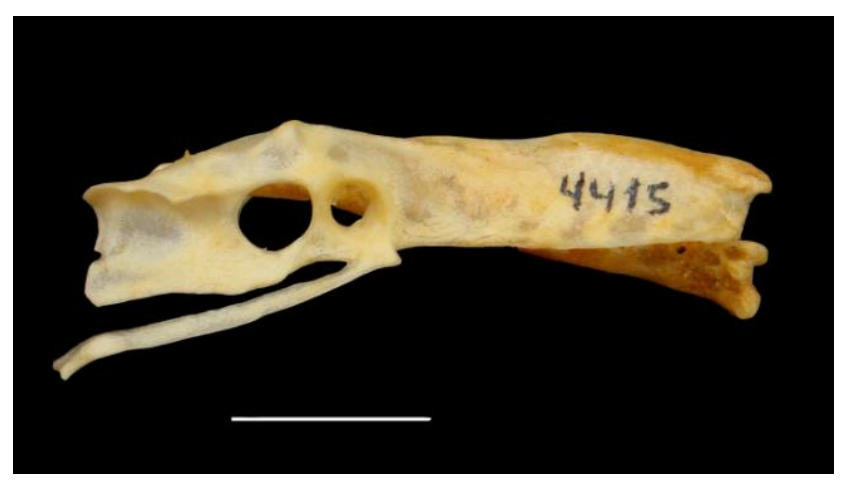

(1) Neocrex erythrops 4.415

\section{FO - Foramen obturatum}

[40] - Pars pudenda fossae. (0) - rasa/ (1) - profunda

A parte caudal da fossa renal (pars pudenda fossae) é rasa nos representantes de Heliornithidae devido à conformidade do processus marginalis caudalis, delgado e expandido lateralmente. Nos Rallidae a fossa é evidentemente profunda. 


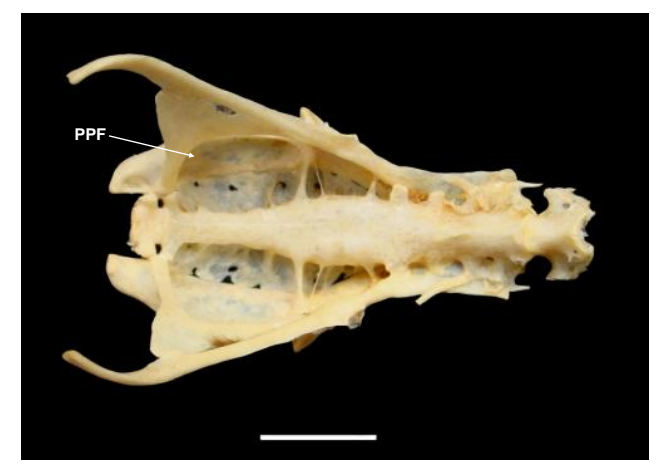

(0) Heliornis fulica MHNT75

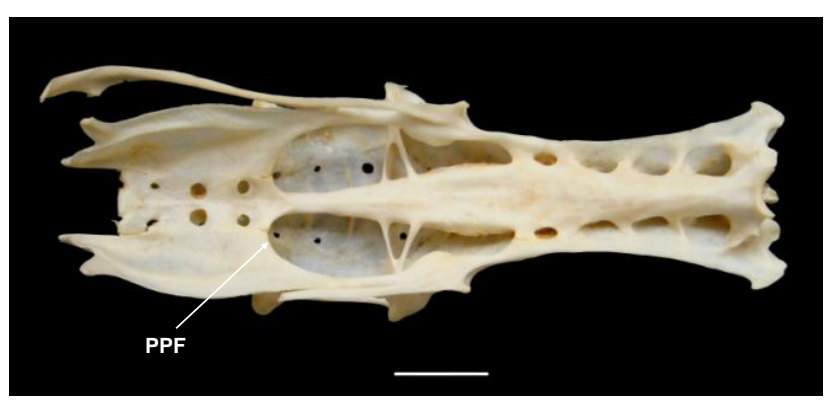

(1) Fulica atra MHNT1.345

PPF - Pars pudenda fossae

[41] - Relação entre o comprimento da região pré-acetabular e pós-acetabular. (0) moderada/ (1) grande

Heliornithidae, Fulica atra, F. americana e $F$. armilata apresentam o comprimento da região pré-acetabular moderado, correspondendo a cerca de metade do comprimento total do sinsacro. Nos outros táxons, a região pré-acetabular é relativamente grande, correspondendo a cerca de $60 \%$.

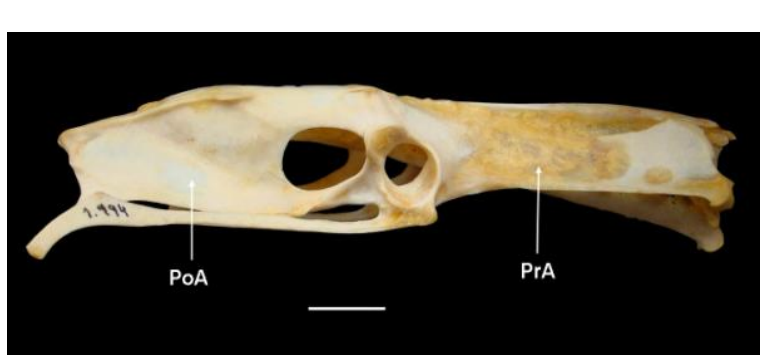

(0) Fulica armilata MHNT1.994

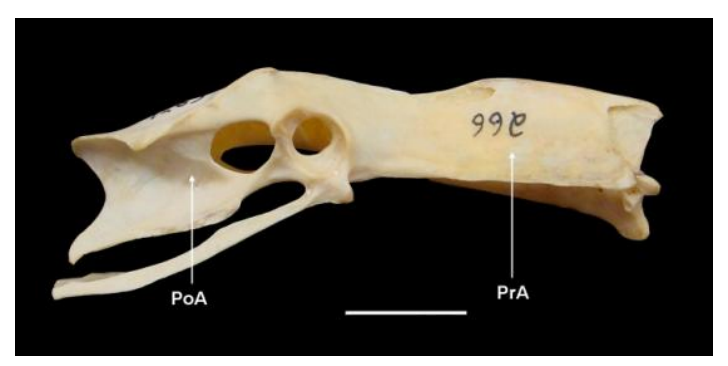

(1) Amaurornis phoenicurus MHNT266

PrA - Região pré-acetabular; PoA - Região pós-acetabular

[42] - Anquilose da crista iliaca dorsalis à crista iliosynsacrales. (0) não anquilosada/ (1) por toda a extensão da crista/ (2) cranial

Todos os representantes de Fulica e Gallinula, com exceção de G. melanops, possuem a crista iliaca dorsalis livre por quase toda a extensão da região préacetabular, sendo anquilosada à crista iliosynsacrales apenas na porção mais cranial do sinsacro. Na maioria dos outros táxons de Rallidae, a crista ilíaca é anquilosada à crista iliosynsacrales por toda a região pré-acetabular. Heliornithidae e G. melanops possuem a crista ilíaca não anquilosada. 


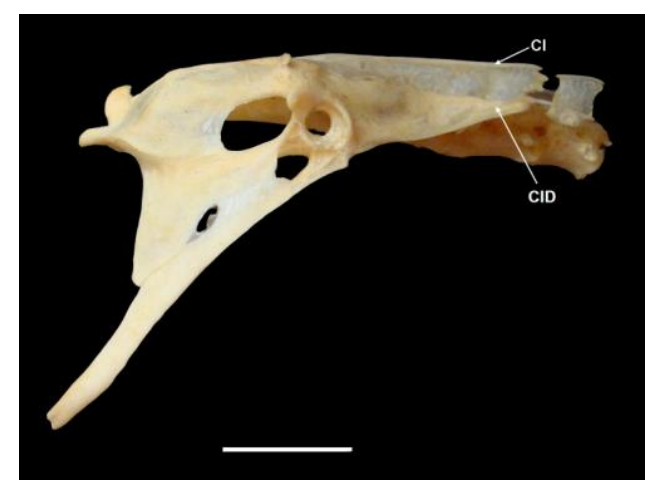

(0) Heliornis fulica MHNT72

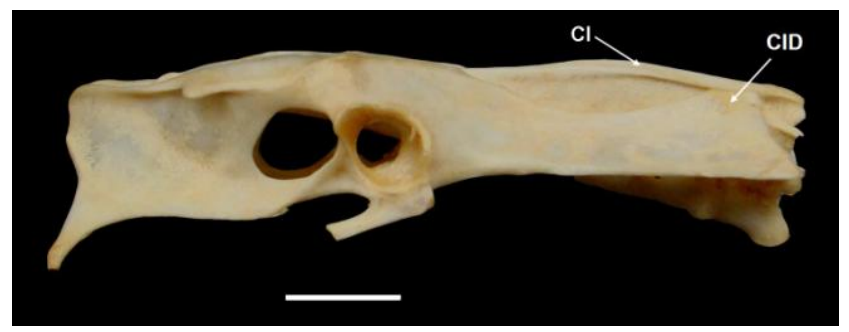

(1) Fulica armilata MHNT1.994

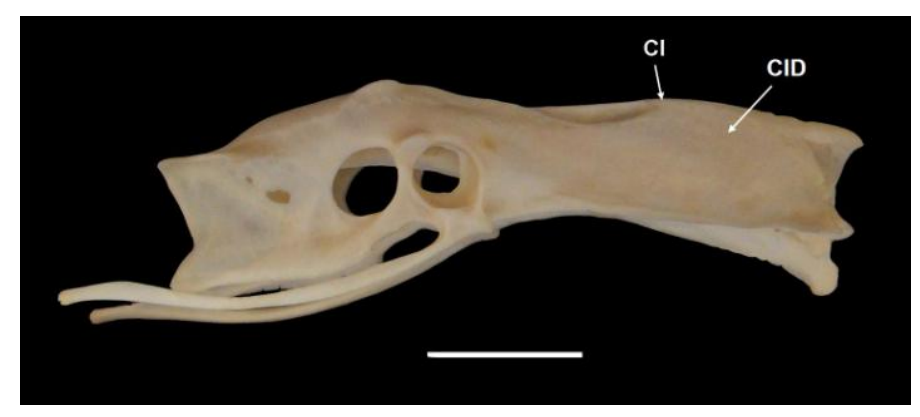

(2) Pardirallus maculatus MHNT1.056

CID - Crista iliaca dorsalis; CI - Crista iliosynsacralis

[43] - Crista dorsolateralis ilii. (0) - vestigial/ (1) - evidente

Todos os representantes de Rallidae possuem a crista dorsolateral ilíaca evidente, expandida lateralmente ou ventrolateralmente, de formas variáveis, e delimitando a superfície dorsal e lateral do ílio. Heliornithidae apresenta a crista bastante vestigial, não expandida lateralmente.

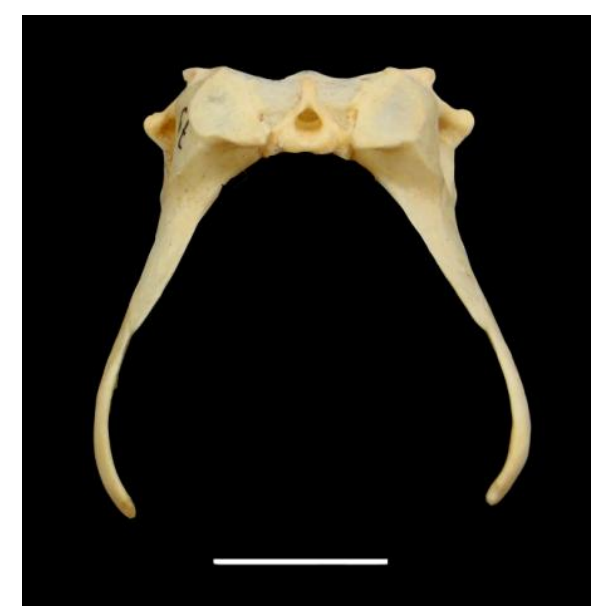

(0) Heliornis fulica MHNT75

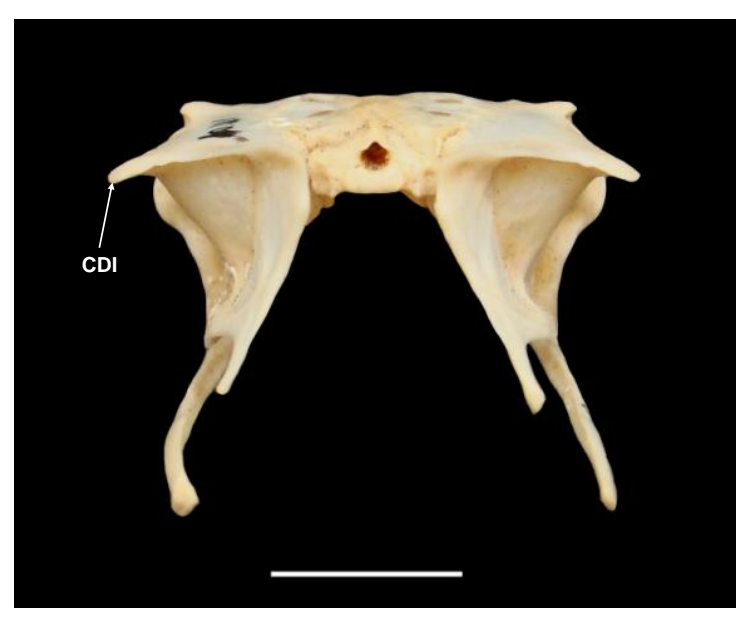

(1) Gallinula chloropus MHNT10.121

CDI - Crista dorsolaterallis ilii 
[44] - Distância entre as spina dorsolateralis ilii. (0) - curta/ (1) - longa

Na maioria dos representantes de Rallidae, com exceção de Porphyrio flavirostris, a spina dorsolateralis ilii é orientada caudalmente e pouco curva, com concavidade medial ausente ou vestigial, propiciando uma curta distância entre as espinhas. Heliornithidae e $P$. flavirostris possuem a spina dorsolaterallis ilii curva, com concavidade medial pronunciada e uma longa distância entre as espinhas.

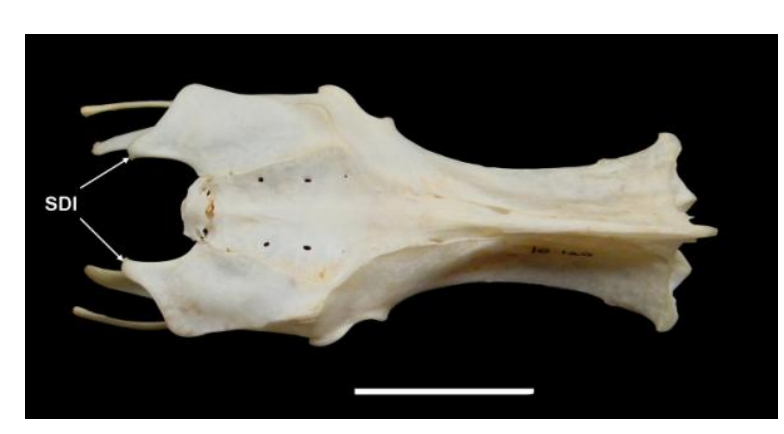

(0) Porphyrio martinica MHNT10.120

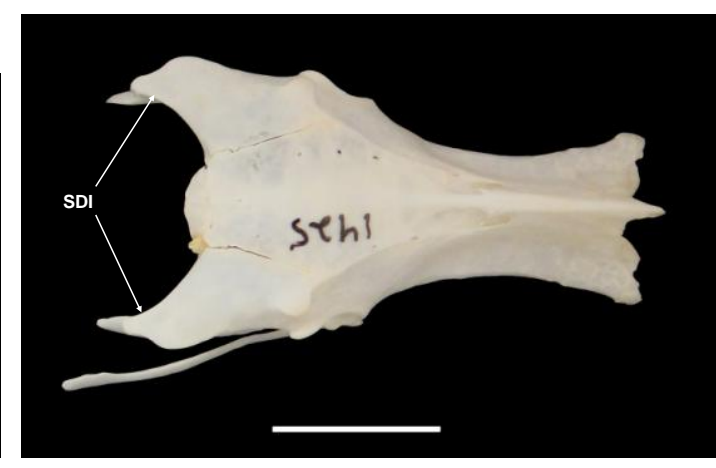

(1) Porphyrio flavirostris MHNT1.425

SDI - Spina dorsolateralis ilii

[45] - Orientação da extremidade caudal do processus terminalis ischii. (0) ausente/ (1) - ventrocaudal/ (2) - caudal

Heliornithidae, Amaurornis phoenicurus e os representantes de Gallinula e Fulica possuem a extremidade caudal do processus terminalis ischii orientada ventrocaudalmente, com sua porção terminal delgada. Em Heliornis, a extremidade é articulada à porção medial do púbis. Nos demais representantes com este estado, observa-se uma leve projeção dorsal da região medial do púbis.

Amaurornis flavirostra e os representantes de Porphyrio possuem a extremidade caudal do processo orientada caudalmente, com sua porção terminal arredondada, mais distante do púbis.

Nos demais táxons analisados, o processus terminalis ischii não é alongado caudalmente e não apresenta orientação evidente. 


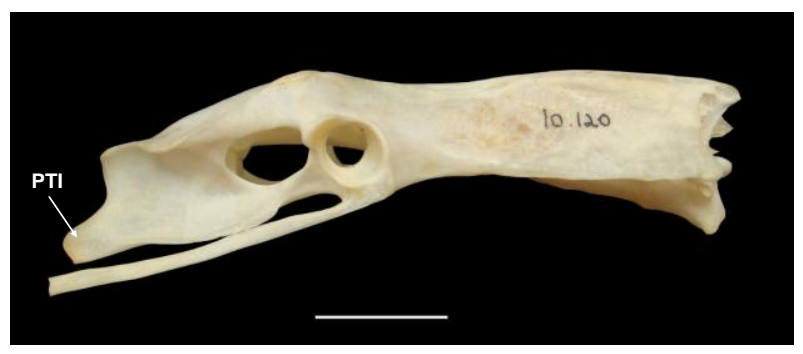

(0) Porphyrio martinica MHNT10.120

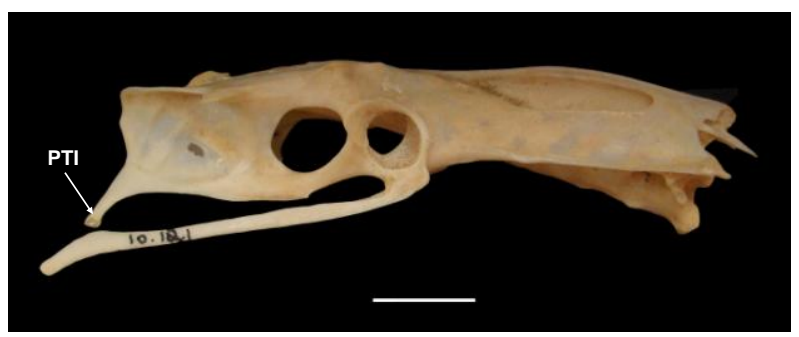

(1) Gallinula chloropus MHNT10.121

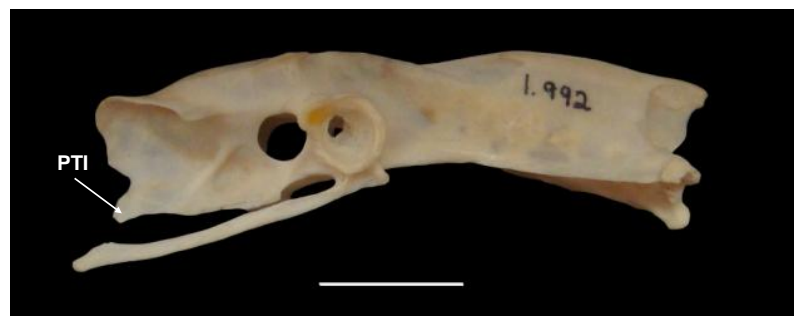

(2) Pardirallus nigricans MHNT1.992

PTI - Processus terminalis ischii

Os Femoris

[46] - Tuberculum musculi gastrocnemius lateralis. (0) - vestigial/ (1) - evidente

Nos representantes de Rallidae, o tuberculum musculi gastrocnemius lateralis localiza-se na face ventral e distal do fêmur, posicionado cranialmente à crista tibiofibularis de forma evidente. Em Heliornithidae, o tubérculo é vestigial. 


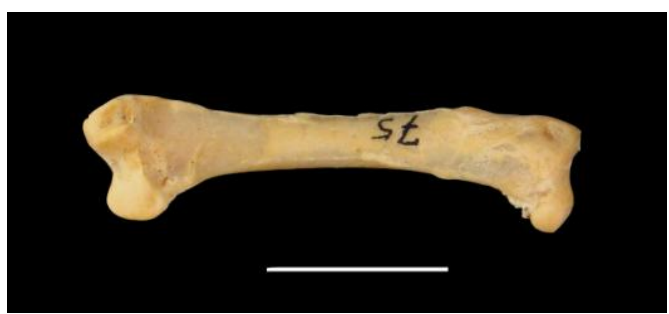

(0) Heliornis fulica MHNT75

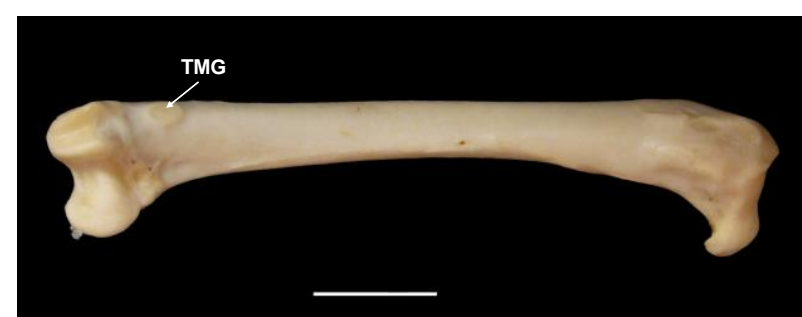

(1) Fulica atra MHNT1.345

TMG - Tuberculum musculi gastrocnemius

\section{Tibiotarsus}

[47] - Elevação da crista cnemialis cranialis. (0) - ausente/ (1) - presente

Heliornithidae e os representantes de Fulica apresentam uma elevação pontiaguda da crista cnemialis cranialis associada ao encurtamento do fêmur, observada também em outros grupos de aves de hábitos mergulhadores. Nos demais táxons analisados, esta elevação é ausente e a extremidade cranial é arredondada.

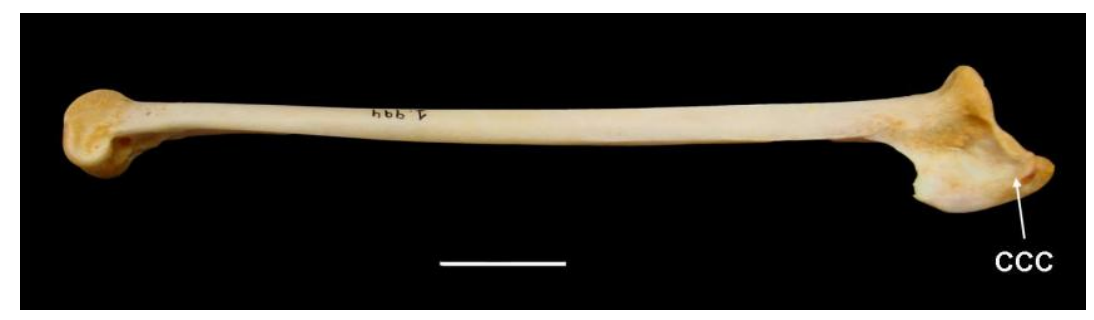

(0) Fulica armilata MHNT1994

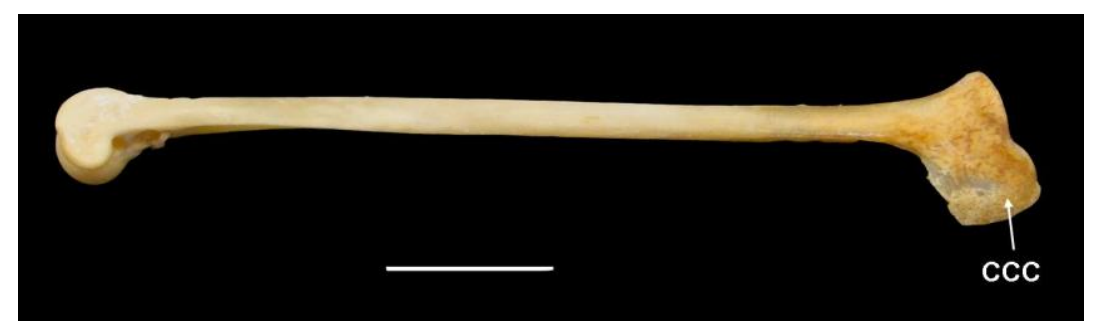

(1) Gallinula melanops MHNT10.112

$\mathrm{CCC}-$ Crista cnemialis cranialis 
[48] - Canalis hypotarsi. (0) - ausente/ (1) - presente

Todos os Rallidae analisados, com exceção de Porphyrio, possuem um canalis hypotarsi na região medial à crista medialis hypotarsi. Quando presente, o canal pode ser observado fechado ou parcialmente fechado, provavelmente devido a fatores ontogenéticos ou variação individual. Em Heliornithidae e nos representantes de Porphyrio, o canal é completamente ausente.

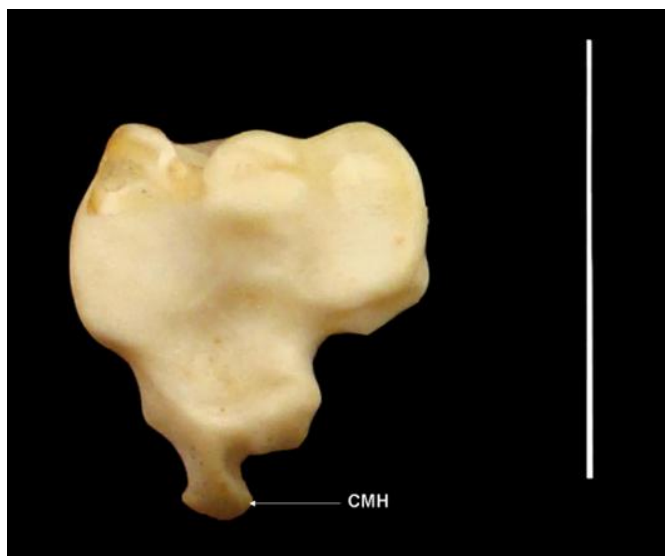

(0) Porphyrio martinica MHNT723

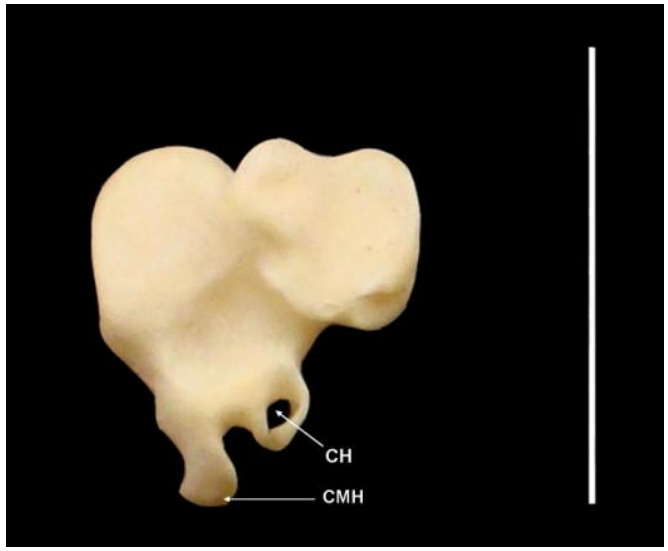

(1) Amaurornis phoenicurus MHNT266

\section{$\mathrm{CH}$ - Canales hypotarsi; $\mathrm{CMH}$ - Crista medialis hypotasi}

[49] - Extensão e profundidade do sulcus flexorius. (0) - proximal e rasa/ (1) extensa e profunda

Heliornithidae e os representantes de Porphyrio possuem o sulcus flexorius longo, ocupando cerca da metade do comprimento da face plantar do tibiotarso. O sulco é evidentemente profundo, propiciando um estreitamento da face medial.

Nos outros táxons analisados, o sulcus flexorius ocupa apenas a parte cranial do tibiotarso e sua profundidade é rasa.

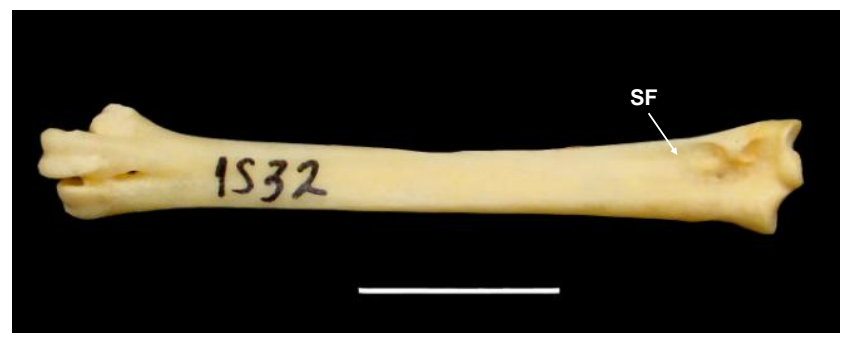

(0) Laterallus melanophaius MHNT1.532

$\mathrm{SF}-$ Sulcus flexorius 


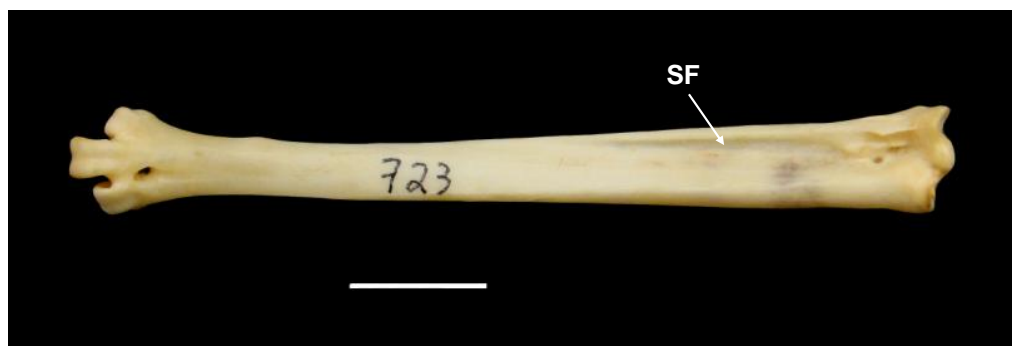

(1) Porphyrio martinica MHNT723

[50] - Concavidade da fossa parahypotarsalis medialis. (0) - vestigial/ (1) pronunciada

Em Heliornithidae e Porphyrio, a fossa parahypotarsalis medialis, localizada caudalmente à crista medialis hypotarsi, apresenta concavidade pronunciada. Nos demais táxons, a concavidade é ausente ou vestigial.

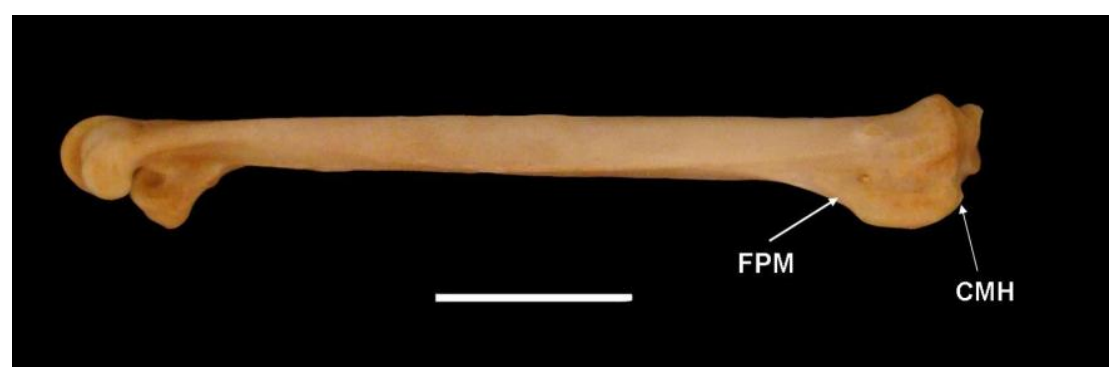

(0) Pardirallus nigricans MHNT1.992

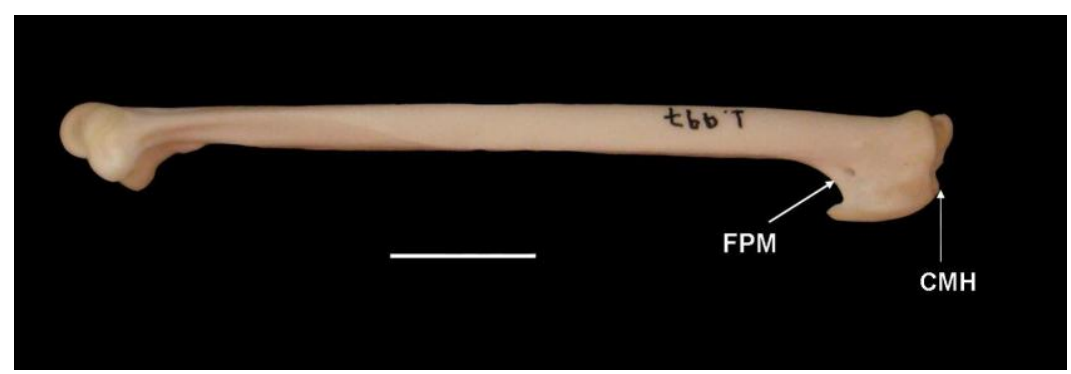

(1) Porphyrio martinica MHNT1.997

FPM - Fossa parahypotarsalis medialis; $\mathrm{CMH}$ - Crista medialis hypotarsi 


\subsection{Análises Filogenéticas}

As análises de parcimônia da matriz contendo 50 caracteres osteológicos e 31 táxons terminais foram realizadas utilizando diferentes ferramentas de otimização e cálculos de consenso, com o intuito de se verificar o produto destas duas diferentes análises.

Em uma primeira análise, direta da matriz e ausente de métodos de pesagem de caracteres, foram obtidas 151 árvores igualmente parcimoniosas com comprimento igual a 99 passos. Os clados representados em 100\% das árvores obtidas são exibidos no diagrama de consenso estrito (Fig. 1) com índice de consistência (IC) igual a 0,56 e índice de retenção (RI) de 0,77. Observou-se uma baixa resolução entre os componentes neste cladograma, o que pode estar relacionado com o número de terminais amostrados e a quantidade de caracteres parcimoniosamente não informativos (autapomorfias) na matriz de dados (13 dos 50 caracteres). A topologia subsequente (Fig. 2), obtida pelo consenso de maioria, exibe todos os clados presentes no mínimo em $50 \%$ das árvores originais.

Em uma segunda análise, com procedimentos de ponderação sucessiva dos caracteres, foram obtidas 14 árvores igualmente parcimoniosas. Além do número consideravelmente menor de árvores, a topologia exibida na árvore de consenso estrito (Fig. 3) resultou em uma melhor resolução se tratando do posicionamento filogenético dos terminais de maior interesse deste estudo, como por exemplo, as relações intraespecíficas dos representantes do gênero Porphyrio e as relações filogenéticas de G. melanops com os gêneros Gallinula e Fulica. Desta forma, essa análise pôde oferecer melhores condições para comparar os dados aqui obtidos com propostas taxonômicas de estudos prévios.

Os caracteres sinapomórficos que sustentam os clados exibidos foram listados com informações sobre seu índice de consistência (IC), as transições dos estados de caracteres e informações sobre ambiguidade e não ambiguidade, representados pelos símbolos --> e ==>, respectivamente, e o valor do suporte de Bremer dos clados exibidos na filogenia. 
Devido à maior resolução obtida na análise de consenso estrito com procedimento de pesagem a posteriori, os clados obtidos nesta topologia (Fig. 3) foram numerados e discutidos abaixo. Os caracteres autapomórficos também foram descritos, a fim de se diagnosticar os táxons estudados com base em caracteres osteológicos.

Clado 1 (Porphyrio porphyrio $+(P$. martinica $+P$. flavirostris $))$

Caráter 4: $(1==>0)$ - Processus supraorbitalis do os lacrimale $(\mathrm{IC}=1,0)$

Caráter 8: $(1$--> 0) - Processus zygomaticus $(\mathrm{IC}=1,0)$

Caráter 19: (0 --> 1) - Foramina pneumatica nas vertebrae thoracicae $(\mathrm{IC}=0,25)$

Caráter 20: $(0==>1)$ - Forâmen no primeiro processus transversus associado ao synsacrum $(\mathrm{IC}=0,33)$

Caráter 26: $(1==>0)$ - Extensão da margo costalis sterni $(\mathrm{IC}=0,50)$

Caráter 29: (0 --> 1) - Tamanho da incisura caudolateralis em relação ao corpus sterni $(\mathrm{IC}=0,40)$

Caráter 31: $(1==>0)$ - Posição do apex carinae em relação à spina externa $(\mathrm{IC}=$ $0,33)$

Caráter 45: (0 --> 2) - Orientação da extremidade caudal do processus terminalis ischii $(\mathrm{IC}=0,40)$

Caráter 49: $(0==>1)$ - Extensão e profundidade do sulcus extensorius $(\mathrm{IC}=1,0)$

Este clado está presente na topologia de consenso estrito com procedimento de pesagem a posteriori e na topologia de consenso estrito sem método de pesagem com valor de suporte de Bremer igual a 2, porém, nesta última, suas relações mais inclusivas não foram completamente resolvidas.

O ramo é sustentado por nove eventos, sendo seis deles homoplásticos e quatro dependentes do critério de otimização. A hipótese obtida neste estudo corrobora com o monofiletismo e a posição basal das aves tradicionalmente chamadas de frangos-d'águaazul na família Rallidae (Olson, 1973; Livezey, 1998). Deste modo, a classificação taxonômica designada por Verheyen (1957), na qual inclui todas as espécies do gênero na subfamília Porhyriinae é sustentada na topologia aqui obtida, porém, isto pode ter ocorrido devido à ausência do terminal Himantopus haematopus na análise, considerado 
por diversos autores como único representante da subfamília Himantornithinae (Olson, 1973; Ripley, 1977; Livezey, 1998; 2003).

A maior discordância pode ser observada nas filogenias baseadas em dados moleculares, nas quais o gênero Porphyrio não exibe uma posição basal e está relacionado aos representantes dos gêneros Gallinula e Fulica (Trewick, 1997) e com o gênero Porzana na análise de Houde (2007). A hipótese de Trewick (1997) corrobora a relação evolutiva entre os gêneros Porphyrio, Gallinula e Fulica argumentada historicamente por taxonomistas (Verheyen, 1957; Brodkorb, 1967) com base em aspectos morfológicos e adaptações para o mergulho.

Clado 2 (Porphyrio martinica + P. flavirostris)

Caráter 8: $(0==>1)$ - Processus zygomaticus $(\mathrm{IC}=1,0)$

Caráter 27: $(0==>1)$ - Número de incisura costales $(\mathrm{IC}=0,25)$

Duas sinapomorfias não-ambíguas e uma homoplástica sustentam a hipótese de relacionamento irmão entre as espécies de frangos-d'água-azul do Novo Mundo. Esta relação pode também ser observada na hipótese filogenética de Livezey (1998). Mesmo sem uma maior representatividade taxonômica do gênero, é possível verificar neste estudo que as espécies de pequeno porte são mais relacionadas entre si do que a Porphyrio porphyrio.

Desta maneira, por se tratar de um grupo monofilético, este clado permite que Porphyrio martinica e Porphyrio flavirostris sejam designadas ao gênero Porphyrula, como proposto em classificações anteriores (Peters, 1934; Hellmayr \& Conover, 1942; Pinto, 1964; 1978). Não foi possível estabelecer aqui uma comparação mais precisa em relação à filogenia molecular de Houde (2007) devido a Porphyrio porphyrio ser o único representante do gênero na análise e na de Trewick (1997), que não contempla a espécie $P$. flavirostris em seu estudo. 
Clado 3 (gênero Gallinula + gênero Fulica)

Caráter 11: (0 --> 1) - Forma da porção caudal da apertura nasi ossea $(\mathrm{IC}=0,25)$

Caráter 14: $(1==>0)$ - Angulus tomialis maxillaris $(\mathrm{IC}=0,33)$

Caráter 26: $(1==>0)$ - Extensão da margo costalis sterni $(\mathrm{IC}=0,50)$

Caráter 28: (2 --> 0) - Forma da pila coracoidea $(\mathrm{IC}=0,67)$

Caráter 42: (1 ==> 2) - Anquilose da crista iliaca dorsalis à crista iliosynsacralis (IC $=0,67)$

Caráter 45: (0 --> 1) - Orientação da extremidade caudal do processus terminalis ischii $(\mathrm{IC}=0,40)$

Seis sinapomorfias sustentam o clado formado pelos membros de Gallinula e Fulica, sendo todas homoplásticas, três não-ambíguas, duas cranianas e quatro póscranianas. A relação entre estes dois gêneros já foi argumentada desde as primeiras classificações da família (Linnaeus, 1758; Sharpe, 1894), sendo frequentemente inseridas na subfamília Fulicinae devido a suas semelhanças anatômicas (Verheyen, 1957; Brodkorb, 1967).

A hipótese de Gallinula grupo-irmão de Fulica obtida neste estudo é corroborada com as filogenias baseadas em dados moleculares (Trewick, 1997, Houde, 2007) e morfológicos (Livezey, 1998), ambas com alto valor de "Bootstrap" para este clado.

As relações de parentesco com outros representantes da família apresentam discordâncias. Trewick (1997) suporta a hipótese de parentesco do clado (Gallinula, Fulica) com o gênero Porphyrio e Houde (2007) sustenta o clado (Porzana (Gallinula, Fulica), enquanto que estudos morfológicos argumentam o parentesco destes gêneros com Amaurornis (Olson, 1973; Livezey, 1998). Neste estudo, o ramo contendo os membros de Gallinula e Fulica é grupo-irmão de um grande clado composto por todos os ralídeos analisados, com exceção da espécie Crex crex e o clado que contém as espécies de Porphyrio.

Desta forma, visto as discordâncias sobre a posição filogenética nos demais estudos e os dados aqui obtidos, as relações desse clado, tão fortemente sustentado 
como um grupo monofilético com os demais componentes da família Rallidae, permanecem ainda mal compreendidas.

Clado 4 (nó basal Gallinula melanops)

Caráter 27: $(0==>1)$ - Número de incisura costalis $(\mathrm{IC}=0,25)$

Caráter 38: $(1==>0)$ - Forma do foramen ilioischiadicum $(\mathrm{IC}=0,50)$

O clado é suportado por dois eventos homoplásticos e não dependentes de otimização, ambos pós-cranianos. Nesta filogenia, a espécie Gallinula melanops é congruente ao nó basal do ramo que suporta os representantes do gênero Fulica como um grupo natural. Esta hipótese sugere que G. melanops é mais relacionada aos membros de Fulica do que às demais espécies de Gallinula, apontando para sua inclusão no gênero Fulica, no entanto, visto que diversos táxons representantes destes gêneros estão ausentes neste trabalho, uma possível proposta de mudança taxonômica é ainda precoce, evidenciando a necessidade de estudos posteriores.

Como pode ser observado na topologia, o monofiletismo do gênero Gallinula não pode ser confirmado, uma vez que o clado 3 apresenta uma tricotomia basal. A maioria dos autores sugere, com base em caracteres morfológicos, que o gênero Fulica é derivado de um ancestral comum ao gênero Gallinula, diferindo deste último apenas por características especializadas para o hábito mergulhador, algo também paralelamente observado em outros grupos de Aves (Olson, 1974; Ripley, 1977; Taylor, 1994).

A posição filogenética de G. melanops encontrada neste estudo foi sugerida por Olson (1974), quando o autor apontou características morfológicas dos membros posteriores de $F$. rufifrons e $G$. melanops para indicar que estas espécies são intermediárias entre os dois gêneros e que não existem caracteres externos que os diferenciem. No entanto, na análise filogenética de Livezey (1998) G. melanops é um terminal basal ao ramo que sustenta as espécies do gênero Gallinula como um grupo monofilético irmão de Fulica. Informações acerca das relações desta espécie não puderam ser testadas nos estudos moleculares dada a ausência na amostragem taxonômica destas análises. 
Clado 5 ((Fulica atra $+F$. americana $+F$. armilata $)+F$. rufifrons $)$

Caráter 17: $(0==>1)$ - Concavidade dos ossa sclerae $(\mathrm{IC}=1,0)$

Caráter 21: $(0==>1)$ - Depressão medial das vertebrae synsacrales $(\mathrm{IC}=1,0)$

Caráter 23: $(1==>0)$ - Extremitas caudalis synsacri $(\mathrm{IC}=1,0)$

Caráter 47: $(0==>1)$ - Elevação da crista cnemialis cranialis $(\mathrm{IC}=0,50)$

O clado está presente nas árvores de consenso estrito de ambas as análises realizadas neste estudo, suportado por um valor de Bremer igual a 2 e quatro sinapomorfias, todas não dependentes de otimização e apenas uma homoplástica. Os componentes deste ramo são representados por aves conhecidas como carquejas, cujo monofiletismo e sua proximidade com Gallinula se mostrou também congruente com análises filogenéticas baseadas em dados moleculares (Trewick, 1997; Houde, 2007) e morfológicos (Livezey, 1998).

Dentre as relações mais inclusivas do gênero, pode-se observar a posição basal de Fulica rufifrons. Esta hipótese é corroborada pela maioria dos autores, fundamentada em dados morfológicos (Olson, 1973; Ripley, 1977; Fjeldsa, 1982; Livezey 1998) e comportamentais (Navas, 1960). Informações sobre as relações dos componentes deste gênero não puderam ser compreendidas nas filogenias moleculares de Trewick (1997) e Houde (2007) devido à baixa representatividade taxonômica do gênero.

Clado 6 (Fulica atra $+F$. americana $+F$. armilata $)$

Caráter 22: $(0==1)$ - Número de vertebrae synsacrales associado à ala postacetabularis ilii $(\mathrm{IC}=1,0)$

Caráter 36: $(0==>1)$ - Relação entre o comprimento do úmero e do fêmur $(\mathrm{IC}=0,33)$

Caráter 41: $(0==>1)$ - Relação entre o comprimento da região pré-acetabular e da pós-acetabular $(\mathrm{IC}=0,50)$

Sustentam este clado, três sinapomorfias, duas homoplásticas e independentes de otimização. Esta hipótese corrobora com o posicionamento basal de F. rufifrons, porém, o relacionamento entre as demais espécies amostradas $(F$. armilata, $F$. americana e $F$. rufifrons) na presente análise é demonstrado por uma politomia. 
Clado 7 (gênero Amaurornis + gênero Aramides + gênero Pardirallus + Porzana carolina + Porzana albicollis)

Caráter 29: (2 ==> 1) - Tamanho da incisura lateralis em relação ao corpus sterni (IC $=0,50)$

Apenas um evento homoplástico e não-ambíguo sustenta este clado. Como pode ser visto na figura 3, os componentes do ramo são representados por uma politomia e suas relações de parentesco não foram completamente resolvidas. O monofiletismo dos gêneros Aramides e Amaurornis foram corroborados com hipóteses de trabalhos prévios, no entanto, os membros de Pardirallus não formam um grupo monofilético no presente estudo. A espécie $P$. maculatus configura-se no nó basal do clado (A. ypecaha (A. saracura, A. cajanea)), não sendo corroborado por trabalhos filogenéticos anteriores. A relação evolutiva entre as espécies de Pardirallus é apresentada por uma politomia em Livezey (1998), e são relacionadas ao gênero monotípico Cyanolimnas, corroborando sugestões anteriores (Olson, 1974; Ripley, 1977). Este gênero é ausente na amostragem taxonômica deste trabalho.

O relacionamento próximo entre os membros dos gêneros Porzana e Aramides é corroborado na filogenia baseada em dados moleculares de Trewick (1997), na qual Porzana constitui um grupo monofilético irmão de Aramides. No entanto, a análise filogenética de Houde (2007) e a hipótese filogenética de Livezey (1998) suportam a hipótese de parentesco de Porzana com os membros de Gallinula e Fulica.

Existe um forte questionamento sobre o monofiletismo do gênero Porzana por diversos autores (Olson, 1974; Ripley, 1977; Taylor, 1996). No presente estudo, $P$. flaviventer configura-se como componente de outro clado, enquanto que na filogenia de Livezey (1998) os representantes de Porzana amostrados aqui constituem um grupo monofilético.

Clado 8 ((Aramides saracura + A. cajanea $)+$ A. ypecaha $)$

Caráter 3: $(0==>1)$ - Alongamento caudolateral do processus supraorbitalis do os lacrimale $(\mathrm{IC}=1,0)$ 
Caráter 9: $(0==>1)-$ Sulcus veni occipitalis externus $(\mathrm{IC}=0,33)$

Caráter 20: $(0$ ==> 1) - Forâmen no primeiro processus transversus associado ao synsacrum $(\mathrm{IC}=0,33)$

Caráter 25: $(0==>1)$ - Foramen pneumaticum na facies visceralis sterni $(\mathrm{IC}=1,0)$

Caráter 31: (0 --> 1) - Posição do apex carinae em relação à spina externa $(\mathrm{IC}=0,33)$

Suportam este clado cinco sinapomorfias, quatro independentes de otimização, três homoplásticas e apenas uma localizada no esqueleto craniano. Este clado também está presente na árvore de consenso estrito sem ponderação sucessiva, com valor de suporte de Bremer igual a 2, no entanto, está representado por uma tricotomia. O monofiletismo do grupo é corroborado na filogenia de Livezey (1998) e suas relações mais inclusivas suportam a hipótese de que A. saracura seja basal aos demais representantes do gênero. No entanto, no presente estudo, uma sinapomorfia homoplástica suporta o clado (A. saracura, A. cajanea), sendo A. ypecaha grupo-irmão deste clado.

O estudo filogenético molecular de Trewick (1997) suporta a hipótese de parentesco entre Aramides e o gênero Porzana. Diversos autores (e. g. Olson, 1973; Ripley, 1977) propõem que os membros de Aramides sejam proximamente relacionados com os gêneros monotípicos Amaurolimnas e Eulabeornis, porém, mesmo no estudo filogenético de Livezey (1998) que apresenta uma ampla amostragem taxonômica, essas relações não puderam ser compreendidas. Devido à ausência destes gêneros nas coleções osteológicas consultadas neste estudo, as relações entre estes táxons não puderam ser testadas.

Clado 9 (Amaurornis phoenicurus + Amaurornis flavisostris)

Caráter 20: $(0==>1)$ - Forâmen no primeiro processus transversus associado ao synsacrum $(\mathrm{IC}=0,33)$

Caráter 45: (0 --> 1) - Orientação na extremidade caudal do processus terminalis ischii $(\mathrm{IC}=0,40)$

Duas sinapomorfias sustentam este clado, ambas homoplásticas e uma nãoambígua. O monofiletismo do gênero é corroborado na análise filogenética de Livezey 
(1998), no entanto, suas relações com outros membros de Rallidae não são claras. No presente estudo, Amaurornis situa-se em um clado representado por uma politomia contendo os gêneros Porzana, Pardirallus e Aramides. Na filogenia de Livezey (1998) o gênero é relacionado aos membros dos gêneros Porzana, Gallinula e Fulica. A relação com Porzana também é sugerida por Olson (1974) baseada em características osteológicas.

Clado 10 (nó basal Coturnicops noveboracensis)

Caráter 9: $(1==>0)-$ Sulcus veni occipitalis externus $(\mathrm{IC}=0,33)$

Caráter 36: (2 --> 0) - Relação entre o comprimento do úmero e do fêmur $(\mathrm{IC}=0,28)$

O clado é suportado por duas sinapomorfias homoplásticas, uma delas nãoambígua. Observa-se que Coturnicops notata configura-se no nó basal que sustenta o clado com os representantes de Rallus amostrados. Desta forma, o gênero não é monofilético. Esta hipótese não é corroborada por Livezey (1998), cujas as espécies de Coturnicops constituem um grupo monofilético e estão inseridas em um grande clado representado pela maioria das espécies do gênero Porzana. Com base em caracteres tegumentares, Olson (1974) propõe que o gênero Coturnicops seja aparentado às espécies de Sarothrura. As hipóteses baseadas em dados moleculares não incluem espécies de Coturnicops em sua amostragem, sendo assim, a relação intragenérica e com os demais representantes de Rallidae ainda não estão claras.

Clado 11 (gênero Rallus)

Caráter 12: $(1==>0)$ - Espessura do processus maxillaris $(\mathrm{IC}=0,50)$

O clado é sustentado por apenas uma sinapomorfia homoplástica e independente de otimização. Como pode ser observado na topologia da figura 3, os representantes de Rallus não são proximamente relacionados com os membros do gênero Pardirallus, sendo congruente com os dados obtidos na filogenia de Livezey (1998). Desta forma, o arranjo taxonômico adotado por diversos autores, que incluem as espécies de Pardirallus no gênero Rallus (Pinto, 1963; 1978; Sclater, 1868; Ripley \& Beehler, 
1985; Sick, 1997) não é recomendado, por não corroborar com as topologias alcançadas em estudos filogenéticos.

No presente estudo, o gênero é monofilético, porém suas relações mais inclusivas não foram resolvidas. Olson (1974) sugere que Rallus não é um grupo monofilético, assim como na análise filogenética de Livezey (1998) e na topologia obtida por Trewick, (1997) baseada em dados moleculares. A proximidade filogenética com o gênero Gallirallus é corroborada nesses trabalhos, no entanto, exemplares deste gênero não estão amostrados nesta análise.

\section{Autopomorfias}

\section{Terminal Heliornis fulica}

Caráter 11: (0 --> 1) - Forma da porção caudal da apertura nasi ossea $(\mathrm{IC}=0,25)$

Caráter 24: $(1==>0)$ - Processus transversus das vertebrae caudalis $(\mathrm{IC}=1,0)$

Caráter 28: $(2==0)$ - Forma da pila coracoidea $(\mathrm{IC}=0,67)$

Caráter 30: $(0==>1)$ - Expansão da trabecula medialis $(\mathrm{IC}=1,0)$

Caráter 33: $(0==>1)$ - Apophysis furculae $(\mathrm{IC}=1,0)$

Caráter 34: $(1==>0)$ - Extremidade cranial do processus procoracoideus $(\mathrm{IC}=1,0)$

Caráter 36: $(0==>1)$ - Relação entre o comprimento do úmero e do fêmur $(\mathrm{IC}=0,33)$

Caráter 37: $(0==>1)-$ Fenestra ischiopubica $(\mathrm{IC}=1,0)$

Caráter 38: $(1==>0)$ - Forma do foramen ilioischiadicum $(\mathrm{IC}=0,50)$

Caráter 39: $(0==>1)-$ Foramen obturatum $(\mathrm{IC}=1,0)$

Caráter 40: $(1==>0)$ - Pars pudenda fossae $(\mathrm{IC}=1,0)$

Caráter 41: $(0==>1)$ - Relação entre o comprimento da região pré-acetabular e pósacetabular $(\mathrm{IC}=0,50)$

Caráter 42: (1 ==> 0) - Anquilose da crista iliaca dorsalis a crista iliosynsacralis (IC $=0,66)$.

Caráter 43: $(1==>0)-$ Crista dorsolateralis ilii $(\mathrm{IC}=1,0)$

Caráter 45: (0 --> 1) - Orientação da extremidade caudal do processus terminalis ischii $(\mathrm{IC}=0,40)$

Caráter 47: $(0==>1)$ - Elevação da crista cnemialis cranialis $(\mathrm{IC}=0,50)$ 
Terminal Laterallus melanophaius

Caráter 35: $(0==>1)$ - Extensão do processus procoracoideus $(\mathrm{IC}=0,33)$

Terminal Porzana flaviventer

Caráter 32: $(1==>0)-$ Sulcus carinae $(\mathrm{IC}=0,25)$

Terminal Coturnicops notata

Caráter 36: $(0==>2)$ - Relação entre o comprimento do úmero e do fêmur (IC = 0,33)

Terminal Rallus longirostris

Caráter 1: $(0==>1)$ - Fossa glandulae nasalis $(\mathrm{IC}=0,50)$

Terminal Anurolimnas viridis

Caráter 5: $(0==>1)$ - Processo anterior do os lacrimale $(\mathrm{IC}=0,50)$

Caráter 18: $(0==>1)-$ Lamina arcocostalis $(\mathrm{IC}=0,33)$

Caráter 29: (1 ==> 2) - Tamanho da incisura lateralis em relação ao corpus sterni (IC $=0,40)$

Terminal Porzana albicollis

Caráter 32: $(1==>0)-$ Sulcus carinae $(0,25)$

Terminal Amaurornis flavirostris

Caráter 45: (1 --> 2) - Orientação da extremidade caudal do processus terminalis ischii $(\mathrm{IC}=0,40)$

Terminal Aramides cajanea

Caráter 18: $(0==>1)-$ Lamina arcocostalis $(\mathrm{IC}=0,33)$

Terminal Porzana carolina

Caráter 1: $(0==>1)$ - Fossa glandulae nasalis $(\mathrm{IC}=0,50)$

Terminal Gallinula melanops

Caráter 19: $(1==>0)$ - Foramina pneumatica nas vertebrae thoracicae $(\mathrm{IC}=0,25)$

Caráter 42: ( $2==0)$ - Anquilose da crista iliaca dorsalis à crista iliosynsacralis (IC $=0,66)$. 


\section{Terminal Crex crex}

Caráter 5: $(0==>1)$ - Processo anterior do os lacrimale $(\mathrm{IC}=0,50)$

Caráter 12: $(1==>0)$ - Espessura do processus maxillaris $(\mathrm{IC}=0,50)$

Caráter 35: (1 ==> 0) - Extensão do processus procoracoideus $(\mathrm{IC}=0,33)$

Terminal Porphyrio porphyrio

Caráter 2: $(0==>1)$ - Expansão lateral da margo supraorbitalis do os frontale $(\mathrm{IC}=$ $1,0)$

Caráter 7: $(0==>1)$ - Tendões calcificados na fossa temporalis $(\mathrm{IC}=1,0)$

Caráter 11: (0 --> 1) - Forma da porção caudal da apertura nasi ossea $(\mathrm{IC}=0,25)$

Caráter 15: $(0==>1)-$ Angulus caudolateralis do os palatinum $(\mathrm{IC}=1,0)$

Terminal Porphyrio flavirostris

Caráter 16: $(0==>1)-$ Processus retroarticularis $(\mathrm{IC}=0,5)$

Caráter 32: $(0==>1)-$ Sulcus carinae $(\mathrm{IC}=0,25)$

Caráter 44: $(0==>1)$ - Distância entre as spina dorsolateralis ilii $(\mathrm{IC}=1,0)$ 




Figura 1: Consenso estrito de 151 hipóteses igualmente parcimoniosas. $\mathrm{L}=99, \mathrm{IC}=$ $0,56, \mathrm{IH}=0,43, \mathrm{IR}=, 0,77 \mathrm{CR}=0,43$. Os valores sobre os nós referem-se ao suporte de Bremer. 


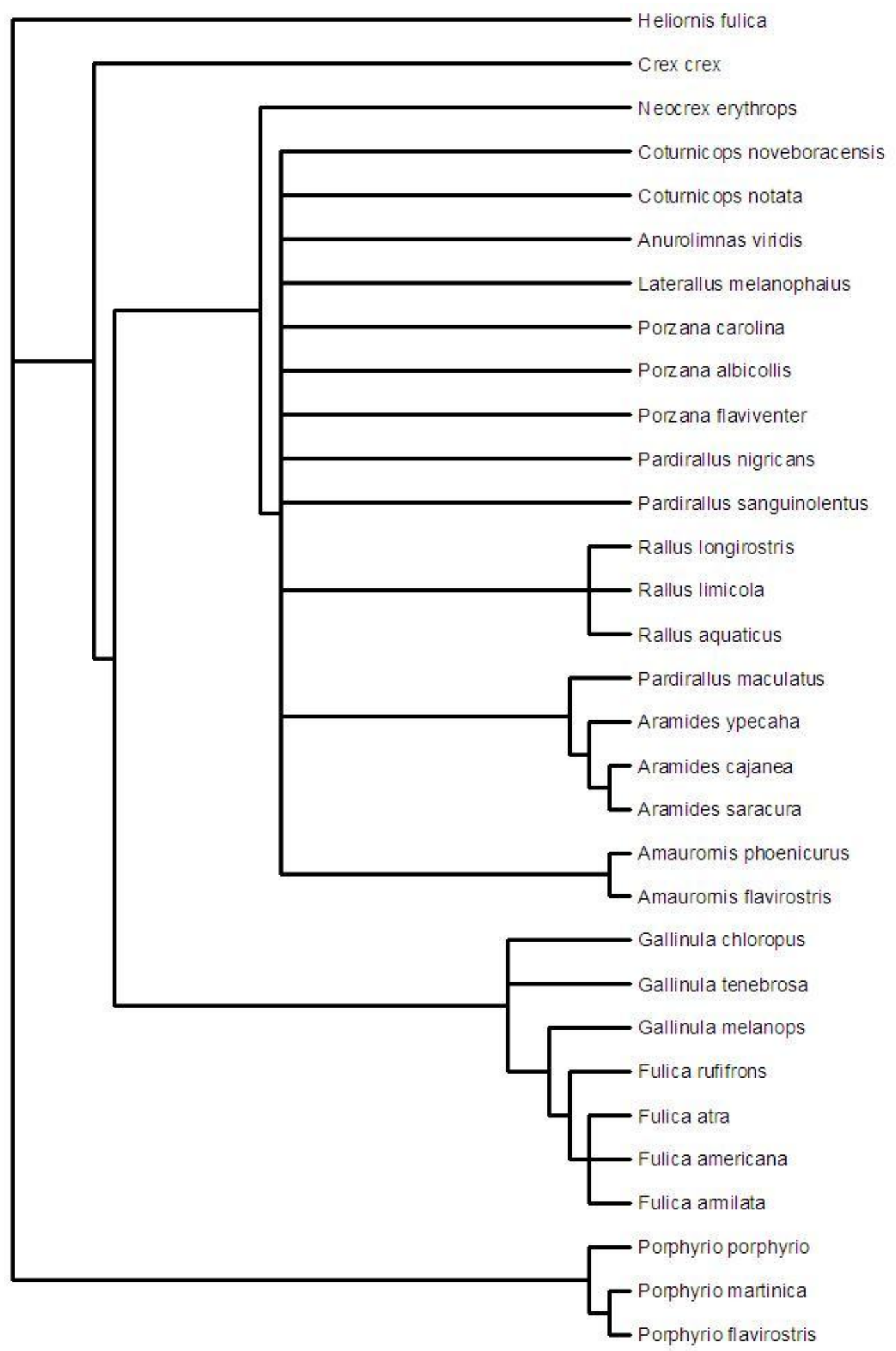

Figura 2: Consenso de maioria $(50 \%)$ de 151 hipóteses igualmente parcimoniosas. $\mathrm{L}=$ 99, $\mathrm{IC}=0,56, \mathrm{IH}=0,43, \mathrm{IR}=, 0,77 \mathrm{CR}=0,43$. 


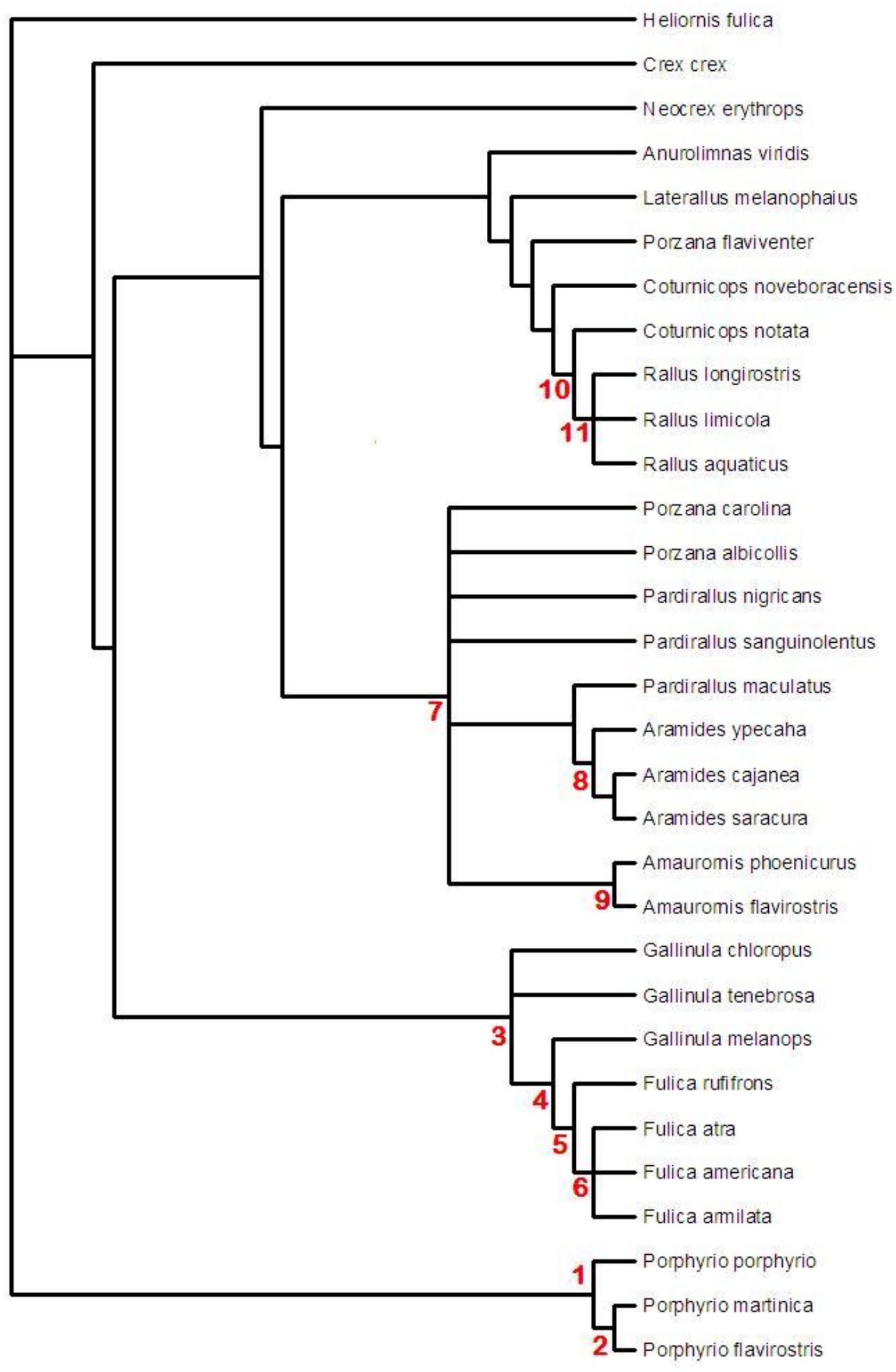

Figura 3: Consenso estrito com método de pesagem posterior dos caracteres das 14 árvores igualmente parcimoniosas obtidas. Os números em vermelho referem-se aos clados discutidos acima. 


\section{Discussão Geral}

Com a finalidade de se esclarecer as relações filogenéticas entre os membros de Rallidae amostrados e testar a monofilia de gêneros representados exclusivamente no Neotrópico, foram demonstradas três topologias submetidas a diferentes métodos de otimização e consenso, no qual forneceram hipóteses de relacionamento entre os terminais.

Observando a topologia de consenso estrito, ausente de critério de pesagem $a$ posteriori dos caracteres, nota-se uma topologia de baixa resolução, no entanto, os clados formados são altamente congruentes com os disponíveis na literatura. Quando vista a árvore de consenso de maioria, um número maior de componentes foi resgatado, pelo fato destes clados estarem presentes em pelo menos $50 \%$ das 151 árvores igualmente parcimoniosas geradas na análise. Diversos agrupamentos visualizados na topologia de consenso de maioria são congruentes quando comparados à árvore de consenso estrito, submetida ao critério de pesagem dos caracteres, como por exemplo os clados $1,3,8$ e 10 .

O método de pesagem posterior dos caracteres certamente contribui para uma melhor resolução entre os componentes amostrados, permitindo que a hipótese filogenética aqui obtida pudesse ser comparada de forma mais significativa com outras filogenias disponíveis na literatura. Além disso, com exceção do clado 7 em que a relação entre alguns terminais é representada por uma politomia, a árvore de consenso estrito apresenta a mesma topologia das árvores 59, 60, 71, 84 e 87 das 151 árvores igualmente parcimoniosas, demonstrando ser coerente com o conjunto de dados.

$\mathrm{Na}$ árvore de consenso estrito com pesagem posterior dos caracteres, pode ser observada uma politomia basal de ramos (Heliornis fulica, Porphyrio, demais membros de Rallidae). Isso se deve à longa distância filogenética entre os terminais amostrados e à raiz do cladograma, uma vez que diversos táxons estão ausentes na análise. No entanto, a amostragem taxonômica se mostrou adequada para o problema proposto a ser estudado, pois a hipótese que se está testando é o monofiletismo de alguns gêneros, ou 
seja, o posicionamento filogenético de espécies dentro de diferentes gêneros historicamente relacionados, e não particularmente o monofiletismo da família Rallidae.

Quando comparadas as hipóteses filogenéticas baseadas em dados moleculares com a hipótese apresentada neste estudo, nota-se que as maiores discordâncias referemse à posição fillogenética dos membros do gênero Porphyrio na família Rallidae. Enquanto que aportes morfológicos sustentam a hipótese de que os frangos-d`água-azul sejam grupo-irmão dos demais membros da subfamília Rallinae (Livezey, 1998), congruente com a hipótese aqui apresentada, as filogenias moleculares (Trewick, 1997; Houde, 2007) suportam uma posição mais inclusiva e seu relacionamento com o gênero Gallinula.

Certamente, algumas relações de parentesco, como por exemplo, a relação entre as espécies de Aramides e Amaurolimnas concolor e a proximidade dos gêneros Coturnicops e Micropygia, não puderam ser compreendidas em sua totalidade neste trabalho devido à baixa representatividade taxonômica de alguns gêneros nas coleções osteológicas consultadas.

Visto os dados obtidos no presente estudo, constata-se que os caracteres osteológicos são filogeneticamente informativos para hipóteses de relacionamento dos membros de Rallidae, além disso, os caracteres levantados neste trabalho podem ser incluídos a matriz de estudos baseados em outros componentes morfológicos ou moleculares. 


\section{Conclusões}

As relações filogenéticas entre os representantes de Rallus não puderam ser totalmente compreendidas, no entanto observa-se na topologia que o gênero não é proximamente relacionado às espécies de Pardirallus, não corroborando classificações que incluem os membros de Pardirallus no gênero Rallus.

O posicionamento filogenético dos representantes do gênero Porphyrio como um grupo-irmão de todos os outros representantes da subfamília Rallinae foi corroborado no presente trabalho, assim como outras hipóteses filogenéticas com base em caracteres morfológicos.

As relações evolutivas interespecíficas dos membros de Porphyrio foram esclarecidas, sendo a espécie $P$. martinica grupo-irmão de $P$. flavirostris, o que corrobora a hipótese de relacionamento próximo dos representantes de pequeno porte do gênero. Desta forma, a validade do gênero Porphyrula é consolidada, corroborando classificações anteriores.

O posicionamento basal da espécie Gallinula melanops em relação as espécies do gênero Fulica aqui encontrado, sugere uma mudança taxonômica, no entanto, visto que as relações mais profundas deste clado estão representadas por uma tricotomia e que não foram amostradas todas as espécies reconhecidas para estes gêneros, tornam-se necessários estudos filogenéticos adicionais utilizando outras fontes de caracteres.

Segundo as informações filogenéticas obtidas, Fulica rufifrons é um terminal basal de um clado que contém as demais espécies do gênero amostradas.

Conclui-se que os caracteres osteológicos contribuíram para o compreendimento das relações de parentesco entre os terminais amostrados e a constatação de determinados gêneros como entidades monofiléticas, corroborando estudos filogenéticos anteriores e indicando mudanças nomenclaturais. 


\section{Resumo}

A família Rallidae é representada por aves cosmopolitas popularmente conhecidas como saracuras, sanãs, carquejas, galinhas-d’água e frangos-d’água. Compreende cerca de 135 espécies distribuídas em 33 gêneros, dos quais 13 são monotípicos. As relações filogenéticas baseadas em caracteres morfológicos e dados moleculares indicam diferentes afinidades entre os membros da família, principalmente na posição dos gêneros Rallus, Porphyrio, Gallinula e Fulica. Neste estudo, focado em espécies Neotropicais da família, uma nova análise filogenética baseada em caracteres osteológicos é proposta. Uma amostra de 100 esqueletos de 13 gêneros e 31 espécies foi analisada. No total 50 caracteres foram codificados, dos quais 17 são cranianos e 33 pós-cranianos para a construção de uma matriz e subseqüente análise filogenética de acordo com o princípio da parcimônia. Foram calculados árvores de consenso estrito e consenso de maioria. A primeira gerou 151 árvores igualmente parcimoniosas com 99 passos. A análise com método de pesagem sucessiva dos caracteres obteve melhores resoluções entre as espécies amostradas. A topologia do cladograma permite a validade de determinados gêneros como entidades monofiléticas, como Rallus, Porphyrio, Aramides, Gallinula e Fulica. O posicionamento de Porphyrio como um ramo basal dentro da subfamília Rallinae foi suportado e suas relações interespecíficas demonstram que as espécies do Novo mundo são mais proximamente relacionadas do que $P$. porphyrio, permitindo a inclusão taxonômica de Porphyrula. A relação próxima entre as espécies do gênero Gallinula e Fulica foi corroborada, no entanto, G. melanops é um ramo basal do clado que inclui as espécies de Fulica, indicando que uma mudança taxonômica é necessária. A relação entre as espécies de Rallus e Pardirallus é distante e não suporta a inclusão das espécies de Pardirallus em Rallus. As maiores discordâncias da filogenia proposta em comparação com estudos moleculares referem-se à posição interna dos membros de Porphyrio e suas relações com outros gêneros. 


\section{Abstract}

The family Rallidae is represented by cosmopolitan birds commonly known as woodrails, crakes, coots, gallinules and swamp hens. It comprises around 135 species, distributed in 33 genera, of which 13 are monotypics. The phylogenetic relationships based on morphological characters and molecular parameters indicate different affinities among family species, mainly the position of the genera Rallus, Porphyrio, Gallinula and Fulica. In this study, focused on the Neotropical species of the family, a new phylogenetic analysis based on osteological characters is proposed. A sample of 100 skeletons of 13 genera and 31 species was analyzed. A total of 50 characters was codified, of which 17 were cranial and 33 post-cranial to provide a matrix construction and a subsequent phylogenetic analysis according to the principle of parsimony. A strict consensus and a majority rule consensus tree were calculated. The former generated 151 equally parsimonious trees with 99 steps. The successive weighting approach analyses of characters obtained better resolutions around the sampled species. The cladogram topology allows the acceptance of some genera as valid monophyletic groups, such as Rallus, Porphyrio, Aramides, Gallinula and Fulica. The position of Porphyrio as a basal branch within the subfamily Rallinae was supported and the interspecific relationships show that New World species were more closely related than $P$. porphyrio, allowing the taxonomic inclusion of Porphyrula. The close relationship between the species of Gallinula and Fulica was corroborated, but G. melanops is a basal branch of a clade that includes Fulica species, indicating that a taxonomic change is needed. The relationship of Rallus and Pardirallus is distant and so does not support the inclusion of Pardirallus species in Rallus. The major discordances of the proposed phylogeny in comparison with molecular studies concern the internal position of the Porphyrio members and their relationships with other genera. 


\section{Referências Bibliográficas}

Amorin, D. S. 2002. Fundamentos de sistemática filogenética. Ed. Holos, 156 p.

Bang, B. G. 1968. Olfaction in Rallidae (Gruiformes), a morphological study of thirteen species. Journal of Zoology of London, v. 156, p. 97-107.

Bartlett, A. D. 1862. Note on the habits and affinities of the kagu (Rhinochetus jubatus). Proceedings of the Zoological Society of London, 1862, p. 218-219.

Baumel, J. J.; Witmer, L. 1993. Osteology. In: Baumel, J. J.; King, A. S.; Breazlie, J. E.; Evans, H. E.; Vanden Berge, J. C. (eds) Handbook of Avian Anatomy: Nomina Anatomica Avium, 2. ed. Cambridge, Publications of Nuttal Ornithologists Club, p. 45-132.

Beddard, F. E. 1898. The structure and classification of birds. London: Longmans \& Green, 548 p.

Boles, W. E. 2005. A new flightless gallinule (Aves; Rallidae: Gallinula) from the Oligo-Miocene of Riversleigh, northwestern Queensland, Australia. Records of Australian Museum, v. 57, p. 179-190.

Boyd, H. J.; Alley, R. 1948. The function of the head coloration of the nesting Coot and other nestling Rallidae. Ibis, v. 90, p. 582-593.

Brodkorb, P. 1967. Catalogue of fossils birds. 3. Ralliformes, Ichryornithiformes, Charadriiformes. Bulletin of Florida State Museum (Biological Science), v. 11, p. 99-200.

Comitê Brasileiro de Registros Ornitológicos (CBRO). 2009. Lista de Aves do Brasil. Versão 09/08/2009. Disponível em http://cbro.org.br/CBRO/listapri.htm (Acesso em 07/12/2009). 
Cracraft, J. 1968. The lacrimal-ectethmoid bone complex in birds: a single character analysis. American Midland Naturalist, v. 80, n. 2, p. 316-359.

Cracraft, J. 1982. Phylogenetic relationships and transantartic biogeography of some gruiform birds. Geobios, v. 6, p. 393-402.

Cracraft, J.; Barker, F. K.; Braun, M.; Harshman J.; Dyke, G. J.; Feinstein, J.; Stanley, S.; Cibois, A.; Schikler, P.; Beresford, P.; Garcia-Moreno, J.; Sorenson, M. D.; Yuri, T.; Mindell, D. P. 2004. Phylogenetic relationships among modern birds (Neornithes): toward an avian tree of life. In: Cracraft, J.; Donoghue, M. (eds) Assembling tree of life. Oxford University Press, New York, p. 468-489.

de Pinna M. C. C. 1991. Concepts and tests of homology in the cladistic paradigm. Cladistics, v. 7, p. 367-394.

Diamond, J. 1991. A new species of rail from the Solomon Islands and convergent evolution of insular flightlessness. Auk, v.108, p. 461-470.

Dickerman, R. W.; Haverschmidt, F. 1971. Further notes on the juvenal plumage of the Spotted Rail (Rallus maculatus). Wilson Bulletin, v. 87, p. 412-413.

Dickerman, R, W.; Parkes, K. C. 1969. Juvenal plumage of the Spotted Rail. Wilson Bulletin, v. 81, p. 207-209.

Dyke, G. J.; van Tuinen, M. 2004. The evolutionary radiation of modern birds (Neornithes): reconciling molecules, morphology and the fossil record. Zoological Journal of the Linnean Society, v. 141, p. 153-177.

Ericson, P. G.; Anderson, C. L.; Briton, T.; Elzanowski, A.; Johansson, U. S.; Kallersjo, M.; Ohlson, J.; Parsons, T. J.; Zuccon, D., Mayr, G. 2006. Diversification of Neoaves: integration of molecular sequence data and fossils. Biology Letters, v.2 p. 543-547. 
Fain, M. G.; Krajewski, C.; Houde, P. 2007. Phylogeny of "core Gruiformes" (Aves: Grues) and resolution of the Limpkin - Sungrebe problem. Molecular Phylogenetics and Evolution, v. 43. p. 515-529.

Farris, J. S. 1969. A successive approximations approach to character weighting. Systematic Zoology, v.18, n. 4, p. 374-385.

Farris, J. S. 1983. The logical basis of phylogenetic analysis. In: Platnick, N. I.; Funk, V. A. (eds) Advances in cladistics 2. Proceedings of the second meeting of the Willi Hennig Society. p. 7-36. New York, Columbia University Press.

Farris, J. S. 2008. Parsimony and explanatory power. Cladistics, v. 4, p. 1-23.

Fedducia, J. A. 1996. The origin and evolution of birds. Yale, Yale University Press, $420 \mathrm{p}$.

Forbes, H. O. 1923. The ralline genus Notornis, Owen. Nature, v. 112, p. 726.

Fjeldså, J. 1982. Biology and systematic relations of the Andean Coot Fulica Americana ardesiaca (Aves, Rallidae). Steenstrupia, vol. 8, p. 1-21.

Fürbringer, M. 1888. Untersuchungen zur Morphologie und Systematik der Vögel, zugleich ein Beitrag zur Anatomie der Stütz - und Bewegungsorgane. Amsterdam: T. J. Van Holkema.

Goloboff, P. A. 1993. Estimating character weights during tree search. Cladistics, v. 11, p. 83-91.

Gray, G. R. 1871. Hand-list of genera and species of birds, distinguishing those contained in the British Museum, part 3. London: British Museum (Natural History).

Hackett, S. J.; Kimball, R. T.; Reddy, S.; Bowie. R. C. K.; Braun, E. L.; Braun, M. J.; Chojnowski, J. L.; Cox, W. A.; Han, J.; Harshman, J.; Huddleston, C. J.; Marks, B. 
D.; Miglia, K. J.; Moore, W. S.; Sheldon, F. H.; Steadman, D. W.; Witt, C. C.; Yuri, T. 2008. A phylogenomic study of birds reveals their evolutionary history. Science, v. 320, p. 1763-1768.

Hellmayr, C. E.; Conover, B. 1942. Catalogue of birds of the Americas part 1. Chicago, Field Museum of Natural History, v. 13, n. 4, 359 p.

Hennig, W. 1950. Grünzuge einer Theorie der phylogenetischen Systematik. Berlin, Deutsche Zentralverlag, $370 \mathrm{p}$.

Hennig, W. 1966. Phylogenetic systematics. Urbana, University of Illinois Press, 263 p.

Kitching, I. J.; Forey, P. L.; Humphries, C. J.; Williams, D. M. 1998. Cladistics - the theory and practice of parsimony analysis. Oxford, Oxford University Press, 228 p.

Kuroda, N. 1993. Morpho-anatomy of the Okinawa Rail Rallus okinawae. Journal Yamashina Institute of Ornithology, v. 25, p. 12-27.

Linnaeus, C. 1758. Systema naturae per regna tria nature, secundum classes, ordines, genera, species, cum characteribus, differentiis, synonimys, locis. Regnum animale Stockholm, Laurentii Salvii, v. 1, ed. 10, p. 81-86.

Livezey, B. C. 1990. Evolutionary morphology of flightlessness in the Auckland Islands teal. Condor, v.92, p. 639-673.

Livezey, B. C. 1998. A phylogenetic analysis of the Gruiformes (Aves) based on morphological characters, with an emphasis on the rails (Rallidae). Philosophical Transaction, Biological Sciences, v. 353, n. 1378, p. 2077-2151.

Livezey, B. C. 2003. Evolution of flightlessness in rails (Gruiformes: Rallidae), phylogenetic, ecomorphological and ontogenetic perspectives. Ornithological Monographs, v. 53, p. 651. 
Livezey, B. C.; Zusi, R. L. 2006. Higher-order phylogenetics of modern Aves based on comparative anatomy: I. Methods and characters. Bulletin of Carnegie Museum of Natural History, n. 37, 544 p.

Livezey, B. C.; Zusi R. L. 2007. Higher-order phylogeny of modern birds (Theropoda, Aves: Neornithes) based on comparative anatomy: II. Analysis and discussion. Zoological Journal of the Linnean Society, v.149, n.1, p.1-95.

Lowe, P. R. 1931. On the relations of Gruimorphae to the Charadriimorphae and Rallimorphae, with special reference to the taxonomic position of Rostratulidae, Jacanidae, and Burhinidae; with a suggested new order (Telmatomorphae). Ibis, vol. 73, p. 491-534.

Mayr, G. 2009. Paleogene fossil birds. Springer-Verlag Berlim Heidelberg, 262 p.

McFarlane, R. W. 1975. Notes on the Giant Coot (Fulica gigantea). Condor, v. 77, p. 324-327.

Morony, J. J.; Bock, W. J.; Farrand, J. Jr. 1975. Reference list of the birds of the world. New York: American Museum of Natural History, 207 p.

Mourer-Chauviré, C.; Berthet, D.; Hugueny, M. 2004. The late Oligocene birds of the Créchy quarry (Allier, France), with a description of two new genera (Aves: Pelecaniformes: Phalacrocoracidae, and Anseriformes: Anseranatidae). Senckenberg Lethaea, v. 84, p. 303-315.

Navas, J. R. 1960. Comportamiento aggressivo de Fulica armillata Viellot. Revista del Museo Argentino de Ciencias naturales “Bernadino Ricadavio”, v. 6, p. 103-129.

Olson, S. L. 1973. A classification on the Rallidae. Wilson Bulletin, v. 85, n. 4, p. 381416.

Olson, S. L. 1974. The Pleistocene rails of North America. Condor, v. 76, p. 169-175. 
Olson S. L. 1977. A synopsis of the fossil Rallidae. P. 339-373 in Ripley, S. D. Rails of the world: a monograph of the family Rallidae. Boston: Godine.

Owen, R. 1848. On the remains of the gigantic and presumed extinct wingless and terrestrial birds of New Zealand (Dinornis and Palapteryx), with indications of two other genera (Notornis and Nestor). Proceedings of the Zoological Society of London, 1848, p. 1-11.

Owen, R. 1882. On the sternum of Notornis and on sternal characters. Proceedings of the Zoological Society of London, 1882, p. 689-697.

Page, R. D. M. 1998. Nexus data editor, v.0.5 http://taxonomy.zoology.gla.ac.uk/rod/

Page, R. D. M. 2001. TreeView, v1.6 http://taxonomy.zoology.gla.ac.uk/rod/

Peters, J. L. 1934. Check-list of birds of the world. Harvard University Press, Cambridge, v. 2, 401 p.

Pinto, O. M. 1963. Ornitologia brasiliense. São Paulo, Imprensa Oficial do Estado, 182 p.

Pinto, O. M. 1978. Novo catálogo das aves do Brasil - primeira parte: Aves não Passeriformes e Passeriformes não Oscines, com exclusão da família Tyrannidae. São Paulo, Empresa Gráfica da Revista dos Tribunais, 446 p.

Ray, J. 1713. Synopsis methodica avium. London.

Ripley, S. D. 1977. Rails of the world. Boston; Godine, 406 p.

Ripley, S. D.; Beehler, B. M. 1985. Rails of the world, a compilation of new information, 1975-1983 (Aves: Rallidae). Smithsonian Contribution Zoology, v. 417 , p. $1-28$. 
Sclater, P. L. 1868. Synopsis of the American rails (Rallidae). Proceedings of the Zoological Society of London, 1868 p. 442-470.

Seebohm, H. 1895. Classification of birds; an attempt to diagnose the subclasses, orders, suborders, and families of existing birds. Supplement. London: R. H. Porter.

Sharpe, R. B. 1894. Catalogue of the Fulicariae (Rallidae and Heliornithidae) and Alectorides (Aramidae, Eurypygidae, Mesithidae, Rhinochetidae, Gruidae, Psophiidae, and Otididae) in the collection of the British Museum. London, British Museum (Natural History), v. 13, p. 353.

Shufeldt, R. W. 1919. The osteology of the giant gallinule of the Philippines, Porphyrio pulverulentus Temminck. Philippine Journal of Science, v. 14, p. 87-104.

Sibley, C. G.; Ahlquist. J. E. 1985. The relationships of some groups of African birds, based on comparisons of the genetic material, DNA. Proceedings International Symposium of African Vertebrates, p. 115-162.

Sibley, C. G.; Ahlquist J. E. 1990. Phylogeny and classification of birds: a study in molecular evolution. New Haven. Yale University Press, 976 p.

Sibley, C. G.; Monroe, B. L. Jr. 1990. Distribution and taxonomy of birds of the world. New Haven: Yale University Press, 1111 p.

Sick, H. 1997. Ornitologia brasileira. Rio de Janeiro, Ed. Nova Fronteira, 862 p.

Slikas, B.; Olson, S. L.; Fleischer, R. C. 2002. Rapid, independent evolution of flightlessness in four species of Pacific Island rails (Rallidae): an analysis based on mitochondrial sequence data. Journal of Avian Biology, v. 33, n. 1, p. 5-14.

Sorenson, M. D; Franzosa, E. A. 2007. Treerot, version 3. Boston University, Boston, MA. http://people.bu.edu/msoren/TreeRot.html. 
Stang, A. T.; McRae, S. B. 2009. Why some rails have white tails: the evolution of white undertail plumage and anti-predator signaling. Evolutionary Ecology, v. 23, p. 943-961.

Stresemann, E; Stresemann, V. 1966. Die Mäuser der Vögel. Journal of Ornithology, v. 107, p. 1-439.

Swofford, D. L. 2001. PAUP*: Phylogenetic analysis using parsimony (* and other methods), v 4.0b. Sinnauer, Sunderland.

Taylor, B. 1996. Family Rallidae (rails, gallinules and coots), p. 109-209. In del Hoyo, J. Elliot, A.; Sargatal, J. (eds). Handbook of the birds of the world. Barcelona, Lynx Editions.

Taylor, B.; van Perlo, B. 1998. Rails - A guide to the rails, crakes, gallinules and coots of the world. London, Pica Press, 600 p.

Trewick, S. A. 1997. Flightlessness and phylogeny amongst endemic rails (Aves: Rallidae) of the New Zealand region. Philosophical Transactions: Biological Sciences, v. 352, n. 1352, p. 429-446.

Verheyen, R. 1957. Contribution au demembrent de l'ordo artificial des Gruiformes (Peters, 1934). Les Ralliformes. Bulletin Institute Royal des Sciences Naturelles de Belgique, v. 33, p. 44.

Wiley, E. O. 1981. Phylogenetics: the theory and practice of phylogenetic systematics. New York, John Wiley \& Sons, 349 p. 
Anexo I - Relação de exemplares utilizados para análises osteológicas. AZUSP - Coleção de Aves do Departamento de Zoologia da Universidade de São Paulo; MHNT - Museu de História Natural de Taubaté; MNRJ - Museu Nacional do Rio de Janeiro; MZUSP - Museu de Zoologia da Universidade de São Paulo.

\begin{tabular}{|c|c|c|c|c|}
\hline Instituição & Número & Táxon & Sexo & Procedência \\
\hline MHNT & 848 & Coturnicops noveboracensis & q & Kansas - EUA \\
\hline MHNT & 862 & Coturnicops noveboracensis & $\hat{0}$ & Kansas - EUA \\
\hline MHNT & 240 & Coturnicops notatus & $?$ & Tremembé-SP \\
\hline MHNT & 282 & Coturnicops notatus & $?$ & Tremembé-SP \\
\hline MHNT & 1325 & Coturnicops notatus & q & Tremembé-SP \\
\hline MHNT & 1248 & Anurolimnas viridis & q & Santarém-PA \\
\hline MHNT & 222 & Laterallus melanophaius & q & Tremembé-SP \\
\hline MHNT & 997 & Laterallus melanophaius & q & Tremembé-SP \\
\hline MHNT & 1989 & Laterallus melanophaius & 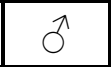 & São Paulo-SP \\
\hline MHNT & 270 & Rallus longirostris & q & Panamá \\
\hline MHNT & 275 & Rallus limicola & $\pi$ & Kansas - EUA \\
\hline MHNT & 869 & Rallus limicola & $0^{\lambda}$ & Kansas - EUA \\
\hline MHNT & 1449 & Rallus aquaticus & $?$ & $\begin{array}{c}\text { Bialowieza - Polônia } \\
\text { (cativeiro) }\end{array}$ \\
\hline MHNT & 1638 & Rallus aquaticus & q & $\begin{array}{c}\text { Bialowieza - Polônia } \\
\text { (cativeiro) }\end{array}$ \\
\hline MHNT & 265 & Crex crex & $?$ & Matruh - Egito \\
\hline AZUSP & 1522 & Aramides cajanea & $?$ & Sem procedência \\
\hline MHNT & 205 & Aramides cajanea & q & Rio Xingú - PA \\
\hline MHNT & 597 & Aramides cajanea & q & Rio Caiapó - TO \\
\hline MHNT & 603 & Aramides cajanea & 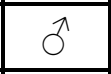 & Cocalinho - MT \\
\hline MHNT & 10101 & Aramides cajanea & q & São Paulo - SP \\
\hline MZUSP & 89165 & Aramides cajanea & $?$ & Sem procedência \\
\hline MZUSP & 89163 & Aramides cajanea & 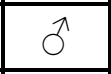 & Embu-guaçu - SP \\
\hline MHNT & 739 & Aramides saracura & $q$ & São Paulo - SP \\
\hline MHNT & 1305 & Aramides saracura & $\sigma^{\lambda}$ & Taubaté - SP \\
\hline MHNT & 1991 & Aramides saracura & $\sigma^{\pi}$ & São Paulo - SP \\
\hline MHNT & 1988 & Aramides saracura & q & São Paulo - SP \\
\hline MHNT & 10102 & Aramides saracura & q & São Paulo - SP \\
\hline MHNT & 716 & Aramides ypecaha & q & Mozarlândia - GO \\
\hline MHNT & 948 & Aramides ypecaha & $?$ & Mozarlândia - GO \\
\hline
\end{tabular}




\begin{tabular}{|c|c|c|c|c|}
\hline Instituição & Número & Táxon & Sexo & Procedência \\
\hline MHNT & 266 & Amaurornis phoenicurus & $\hat{0}$ & Índia \\
\hline MHNT & 1792 & Amaurornis phoenicurus & $?$ & São Paulo - SP (cativeiro) \\
\hline MHNT & 273 & Amaurornis flavirostris & $?$ & EUA (cativeiro) \\
\hline MHNT & 264 & Porzana carolina & q & New Jersey - EUA \\
\hline MHNT & 74 & Porzana albicollis & $\hat{0}$ & Tremembé - SP \\
\hline MHNT & 229 & Porzana albicollis & $\pi$ & Tremembé - SP \\
\hline MHNT & 1532 & Porzana albicollis & $\hat{0}$ & Tremembé - SP \\
\hline MZUSP & 89164 & Porzana albicollis & $?$ & Dourado - SP \\
\hline MHNT & 209 & Porzana flaviventer & q & Tremembé - SP \\
\hline MHNT & 878 & Porzana flaviventer & $q$ & Tremembé - SP \\
\hline MHNT & 4415 & Neocrex erythrops & $\hat{0}$ & Tremembé - SP \\
\hline MHNT & 230 & Pardirallus maculatus & $0^{\pi}$ & Tremembé - SP \\
\hline MHNT & 1056 & Pardirallus maculatus & $\pi$ & Tremembé - SP \\
\hline MHNT & 1111 & Pardirallus maculatus & q & Tremembé - SP \\
\hline MZUSP & 89149 & Pardirallus maculatus & $?$ & Tremembé - SP \\
\hline MZUSP & 89159 & Pardirallus maculatus & q & São Bernado do Campo - SP \\
\hline MHNT & 365 & Pardirallus nigricans & $\pi$ & Taubaté - SP \\
\hline MHNT & 720 & Pardirallus nigricans & q & Taubaté - SP \\
\hline MHNT & 1992 & Pardirallus nigricans & $q$ & São Paulo - SP \\
\hline MHNT & 2000 & Pardirallus nigricans & $\hat{0}$ & São Paulo - SP \\
\hline MZUSP & 89151 & Pardirallus nigricans & $?$ & Sem procedência \\
\hline MZUSP & 89152 & Pardirallus nigricans & $\hat{0}$ & São Paulo - SP \\
\hline MZUSP & 89153 & Pardirallus nigricans & $?$ & São Paulo - SP \\
\hline MHNT & 695 & Pardirallus sanguinolentus & $q$ & Tremembé - SP \\
\hline MHNT & 1269 & Pardirallus sanguinolentus & q & Tremembé - SP \\
\hline MHNT & 72 & Porphyrio porphyrio & q & EUA (cativeiro) \\
\hline MHNT & 1369 & Porphyrio porphyrio & $?$ & Poznan - Polônia (cativeiro) \\
\hline AZUSP & 156 & Porphyrio martinica & $?$ & Sem procedência \\
\hline AZUSP & 1387 & Porphyrio martinica & $\sigma^{\pi}$ & Depave - SP (cativeiro) \\
\hline AZUSP & 1604 & Porphyrio martinica & $q$ & Sem procedência \\
\hline MHNT & 201 & Porphyrio martinica & q & Tremembé - SP \\
\hline MHNT & 723 & Porphyrio martinica & 0 & Tremembé - SP \\
\hline MHNT & 1997 & Porphyrio martinica & q & Peruíbe - SP \\
\hline MHNT & 10120 & Porphyrio martinica & 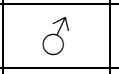 & Praia Grande - SP \\
\hline MZUSP & 89160 & Porphyrio martinica & $0^{\pi}$ & São Paulo - SP \\
\hline MZUSP & 89162 & Porphyrio martinica & $q$ & Sem procedência \\
\hline
\end{tabular}




\begin{tabular}{|c|c|c|c|c|}
\hline Instituição & Número & Táxon & Sexo & Procedência \\
\hline MHNT & 1525 & Porphyrio flavirostris & $\widehat{0}$ & Bauru - SP \\
\hline AZUSP & 5 & Gallinula chloropus & 우 & São Paulo - SP \\
\hline AZUSP & 1527 & Gallinula chloropus & $?$ & Sem procedência \\
\hline MHNT & 301 & Gallinula chloropus & $\overline{0}$ & Taubaté - SP \\
\hline MHNT & 321 & Gallinula chloropus & $q$ & Tremembé - SP \\
\hline MHNT & 324 & Gallinula chloropus & q & Tremembé - SP \\
\hline MHNT & 1075 & Gallinula chloropus & 우 & Tremembé - SP \\
\hline MHNT & 10112 & Gallinula chloropus & $\overline{0}$ & São Paulo - SP \\
\hline MHNT & 10121 & Gallinula chloropus & $\hat{o}$ & São Paulo - SP \\
\hline MZUSP & 89156 & Gallinula chloropus & $?$ & São Paulo - SP \\
\hline MZUSP & 89157 & Gallinula chloropus & q & São Paulo - SP \\
\hline MZUSP & 89158 & Gallinula chloropus & 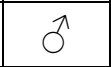 & Água Funda - SP \\
\hline MZUSP & 89166 & Gallinula chloropus & $?$ & Chicago - EUA (cativeiro) \\
\hline MZUSP & 89167 & Gallinula chloropus & $?$ & Niterói - RJ \\
\hline MZUSP & 89168 & Gallinula chloropus & $\widehat{0}$ & São Paulo - SP (cativeiro) \\
\hline MZUSP & 89169 & Gallinula chloropus & $?$ & São Paulo - SP \\
\hline MZUSP & 89170 & Gallinula chloropus & $\hat{0}$ & Água Funda - SP \\
\hline MZUSP & 90332 & Gallinula chloropus & $\pi$ & Sem procedência \\
\hline MHNT & 1166 & Gallinula tenebrosa & q & Austrália \\
\hline MHNT & 1178 & Gallinula tenebrosa & $\pi$ & Austrália \\
\hline MHNT & 73 & Gallinula melanops & q & Tremembé - SP \\
\hline MHNT & 225 & Gallinula melanops & $q$ & Tremembé - SP \\
\hline MHNT & 1345 & Fulica atra & $\pi$ & Krakow - Polônia \\
\hline MHNT & 274 & Fulica americana & $\pi$ & Massassuchets - EUA \\
\hline MHNT & 1994 & Fulica armilata & q & Santa Catarina - SC \\
\hline MHNT & 4767 & Fulica armilata & $\pi$ & Santa Catarina - SC \\
\hline MNRJ & 871 & Fulica armilata & $\pi$ & Maricá - RJ \\
\hline MHNT & 458 & Fulica rufifrons & $q$ & Chasconus - Argentina \\
\hline MHNT & 476 & Fulica rufifrons & $?$ & Chasconus - Argentina \\
\hline MHNT & 75 & Heliornis fulica & $\pi$ & Rio Caiapó - TO \\
\hline MHNT & 353 & Heliornis fulica & q & Rio Caiapó - TO \\
\hline MZUSP & 89174 & Heliornis fulica & $q$ & Dourado-SP \\
\hline MZUSP & 2022 & Heliornis fulica & $?$ & Sem procedência \\
\hline MZUSP & 2108 & Heliornis fulica & $\pi$ & Dourado - SP \\
\hline
\end{tabular}


Anexo II - Matriz de caracteres

\begin{tabular}{|c|c|c|c|c|c|c|c|c|c|c|}
\hline Táxon/Caráter & 1 & 2 & 3 & 4 & 5 & 6 & 7 & 8 & 9 & 10 \\
\hline Heliornis fulica & 0 & 0 & 1 & 0 & 0 & 0 & 0 & 1 & 0 & 1 \\
\hline Coturnicops noveboracensis & 0 & 0 & 1 & 0 & $0 / 1$ & 0 & 0 & 1 & 0 & 0 \\
\hline Coturnicops notata & 0 & 0 & 1 & 0 & 0 & 0 & 0 & 1 & 0 & 0 \\
\hline Anurolimnas viridis & 0 & 0 & 1 & 0 & 1 & 0 & 0 & 1 & 1 & 0 \\
\hline Laterallus melanophaius & 0 & 0 & 1 & 0 & 0 & 0 & 0 & 1 & 1 & 0 \\
\hline Rallus longirostris & 1 & 0 & 1 & 0 & 0 & 0 & 0 & 1 & 0 & 0 \\
\hline Rallus limicola & $?$ & 0 & $?$ & $?$ & $?$ & $?$ & 0 & 1 & 0 & 0 \\
\hline Rallus aquaticus & 0 & 0 & 1 & 0 & 0 & 0 & 0 & 1 & 0 & 0 \\
\hline Crex crex & 0 & 0 & 1 & 0 & 1 & 0 & 0 & 1 & 0 & 0 \\
\hline Aramides cajanea & 0 & 0 & 1 & 1 & 0 & 1 & 0 & 1 & $0 / 1$ & 0 \\
\hline Aramides saracura & 0 & 0 & 1 & 1 & 0 & 1 & 0 & 1 & 1 & 0 \\
\hline Aramides ypecaha & 0 & 0 & 1 & 1 & 0 & 1 & 0 & 1 & 1 & 0 \\
\hline Amaurornis phoenicurus & 0 & 0 & 1 & 0 & 0 & 0 & 0 & 1 & 0 & 0 \\
\hline Amaurornis flavirostris & 0 & 0 & 1 & 0 & 0 & 0 & 0 & 1 & 0 & 0 \\
\hline Porzana carolina & 1 & 0 & 1 & 0 & 0 & 0 & 0 & 1 & 0 & 0 \\
\hline Porzana albicollis & 0 & 0 & 1 & 0 & 0 & 0 & 0 & 1 & $0 / 1$ & 0 \\
\hline Porzana flaviventer & 0 & 0 & 1 & 0 & 0 & 0 & 0 & 1 & 1 & 0 \\
\hline Neocrex erythrops & $?$ & 0 & $?$ & 0 & $?$ & $?$ & 0 & $?$ & 0 & $?$ \\
\hline Pardirallus maculatus & 0 & 0 & 1 & 0 & 0 & 1 & 0 & 1 & 0 & 0 \\
\hline Pardirallus nigricans & 0 & 0 & 1 & 0 & 0 & $0 / 1$ & 0 & 1 & 0 & 0 \\
\hline Pardirallus sanguinolentus & 0 & 0 & 1 & 0 & 0 & 0 & 0 & 1 & 0 & 0 \\
\hline Porphyrio porphyrio & 0 & 1 & 0 & 0 & 0 & 0 & 1 & 0 & 0 & 1 \\
\hline Porphyrio martinica & 0 & 0 & 0 & 0 & 0 & 0 & 0 & 2 & 0 & 1 \\
\hline Porphyrio flavirostris & 0 & 0 & 0 & 0 & 0 & $?$ & 0 & 2 & 0 & 1 \\
\hline Gallinula chloropus & 0 & 0 & 1 & 0 & 0 & 0 & 0 & 1 & 0 & 0 \\
\hline Gallinula tenebrosa & 0 & 0 & 1 & 0 & 0 & 0 & 0 & 1 & 0 & 0 \\
\hline Gallinula melanops & 0 & 0 & 1 & 0 & 0 & 0 & 0 & 1 & 0 & 0 \\
\hline Fulica atra & 0 & 0 & $?$ & 0 & $?$ & $?$ & 0 & 1 & 0 & 0 \\
\hline Fulica americana & 0 & 0 & 1 & 0 & 0 & 0 & 0 & 1 & 0 & 0 \\
\hline Fulica armilata & 0 & 0 & 1 & 0 & 0 & 0 & 0 & 1 & 0 & 0 \\
\hline Fulica rufifrons & 0 & 0 & 1 & 0 & 0 & 0 & 0 & 1 & 0 & 0 \\
\hline
\end{tabular}




\begin{tabular}{|c|c|c|c|c|c|c|c|c|c|c|}
\hline Táxon/Caráter & 11 & 12 & 13 & 14 & 15 & 16 & 17 & 18 & 19 & 20 \\
\hline Heliornis fulica & 1 & 1 & 0 & 1 & 0 & 0 & 0 & 1 & 0 & 0 \\
\hline Coturnicops noveboracensis & 0 & 1 & 1 & 0 & 0 & 1 & 0 & 0 & 0 & 0 \\
\hline Coturnicops notata & 0 & 1 & 1 & 0 & 0 & 1 & $?$ & 0 & 0 & 0 \\
\hline Anurolimnas viridis & 0 & 1 & 1 & 1 & 0 & 1 & 0 & 1 & 1 & 0 \\
\hline Laterallus melanophaius & 0 & 1 & 1 & 0 & 0 & 1 & 0 & 0 & 0 & 0 \\
\hline Rallus longirostris & $?$ & 0 & 1 & $?$ & 0 & 1 & $?$ & 0 & 0 & 0 \\
\hline Rallus limicola & $?$ & 0 & $?$ & $?$ & $?$ & 1 & 0 & 0 & 0 & 0 \\
\hline Rallus aquaticus & 0 & 0 & 1 & 0 & 0 & 1 & $?$ & 0 & 0 & 0 \\
\hline Crex crex & 0 & 0 & 0 & 1 & 0 & 0 & 0 & 0 & 0 & 0 \\
\hline Aramides cajanea & 0 & 1 & 1 & $0 / 1$ & 0 & 1 & 0 & 1 & 1 & 1 \\
\hline Aramides saracura & 0 & 1 & 1 & 0 & 0 & 1 & 0 & 0 & 1 & 1 \\
\hline Aramides ypecaha & 0 & 1 & 1 & 0 & 0 & 1 & 0 & 0 & 1 & 1 \\
\hline Amaurornis phoenicurus & 0 & 1 & $0 / 1$ & 1 & 0 & 1 & 0 & 0 & 1 & 1 \\
\hline Amaurornis flavirostris & 0 & 1 & 1 & 1 & 0 & 1 & $?$ & 0 & 1 & 1 \\
\hline Porzana carolina & 0 & 1 & $?$ & 0 & $?$ & 1 & $?$ & 0 & $?$ & 0 \\
\hline Porzana albicollis & 0 & 1 & $0 / 1$ & 1 & 0 & 1 & 0 & 0 & 1 & 0 \\
\hline Porzana flaviventer & 1 & 1 & 1 & 0 & 0 & 1 & 0 & 0 & 0 & 0 \\
\hline Neocrex erythrops & $?$ & $?$ & $?$ & $?$ & $?$ & $?$ & $?$ & 0 & 1 & 0 \\
\hline Pardirallus maculatus & 0 & 1 & 1 & 0 & 0 & 1 & 0 & 0 & 1 & 0 \\
\hline Pardirallus nigricans & 0 & 1 & 1 & 0 & 0 & 1 & 0 & 0 & 1 & $0 / 1$ \\
\hline Pardirallus sanguinolentus & 0 & 1 & 1 & 0 & 0 & 1 & $?$ & 0 & 1 & 0 \\
\hline Porphyrio porphyrio & 1 & 1 & 0 & 1 & 1 & 0 & $?$ & 1 & 1 & 1 \\
\hline Porphyrio martinica & 0 & 1 & 0 & 1 & 0 & 0 & 0 & 1 & 1 & 1 \\
\hline Porphyrio flavirostris & 0 & 1 & $?$ & 1 & 0 & 1 & $?$ & 1 & 1 & 1 \\
\hline Gallinula chloropus & 1 & 1 & 1 & 0 & 0 & 1 & 0 & 0 & 1 & 0 \\
\hline Gallinula tenebrosa & 1 & 1 & 1 & 0 & 0 & 1 & $?$ & 0 & 1 & 0 \\
\hline Gallinula melanops & 1 & 1 & 1 & 0 & 0 & 1 & 0 & 0 & 0 & 0 \\
\hline Fulica atra & 1 & 1 & $?$ & 0 & $?$ & 1 & $?$ & 0 & 1 & 0 \\
\hline Fulica americana & 1 & 1 & 1 & 0 & 0 & 1 & $?$ & 0 & 1 & 0 \\
\hline Fulica armilata & 1 & 1 & 1 & 0 & 0 & 1 & 1 & 0 & 1 & 0 \\
\hline Fulica rufifrons & 1 & 1 & 1 & 0 & 0 & 1 & 1 & 0 & 1 & 0 \\
\hline
\end{tabular}




\begin{tabular}{|c|c|c|c|c|c|c|c|c|c|c|}
\hline Táxon/Caráter & 21 & 22 & 23 & 24 & 25 & 26 & 27 & 28 & 29 & 30 \\
\hline Heliornis fulica & 0 & 0 & 1 & 0 & 0 & 1 & 0 & 0 & 0 & 1 \\
\hline Coturnicops noveboracensis & 0 & 0 & 1 & 1 & 0 & 1 & 0 & 2 & 2 & 0 \\
\hline Coturnicops notata & 0 & 0 & 1 & 1 & 0 & 1 & 0 & 2 & 1 & 0 \\
\hline Anurolimnas viridis & 0 & 0 & 1 & 1 & 0 & 1 & 0 & 2 & 2 & 0 \\
\hline Laterallus melanophaius & 0 & 0 & 1 & 1 & 0 & 1 & 0 & 2 & 2 & 0 \\
\hline Rallus longirostris & 0 & 0 & 1 & 1 & 0 & 1 & 0 & 2 & 1 & 0 \\
\hline Rallus limicola & 0 & 0 & 1 & 1 & 0 & 1 & $0 / 1$ & 2 & 1 & 0 \\
\hline Rallus aquaticus & 0 & 0 & 1 & 1 & 0 & 1 & $0 / 1$ & 2 & 1 & 0 \\
\hline Crex crex & 0 & 0 & 1 & 1 & 0 & 1 & 0 & 2 & 2 & 0 \\
\hline Aramides cajanea & 0 & 0 & 1 & 1 & 1 & 1 & 1 & 2 & 1 & 0 \\
\hline Aramides saracura & 0 & 0 & 1 & 1 & 1 & 1 & 1 & 2 & 1 & 0 \\
\hline Aramides ypecaha & 0 & 0 & 1 & 1 & 1 & 1 & 1 & 2 & 1 & 0 \\
\hline Amaurornis phoenicurus & 0 & 0 & 1 & 1 & 0 & 1 & 1 & 2 & 1 & 0 \\
\hline Amaurornis flavirostris & 0 & 0 & 1 & 1 & 0 & 1 & 1 & 2 & 1 & 0 \\
\hline Porzana carolina & 0 & 0 & 1 & 1 & 0 & 1 & 0 & 2 & 1 & 0 \\
\hline Porzana albicollis & 0 & 0 & 1 & 1 & 0 & 1 & 0 & 2 & 1 & 0 \\
\hline Porzana flaviventer & 0 & 0 & 1 & 1 & 0 & 1 & 0 & 2 & 2 & 0 \\
\hline Neocrex erythrops & 0 & 0 & 1 & 1 & 0 & 1 & 0 & 2 & 2 & 0 \\
\hline Pardirallus maculatus & 0 & 0 & 1 & 1 & 0 & 1 & 1 & 2 & 1 & 0 \\
\hline Pardirallus nigricans & 0 & 0 & 1 & 1 & 0 & 1 & 1 & 2 & 1 & 0 \\
\hline Pardirallus sanguinolentus & 0 & 0 & 1 & 1 & 0 & 1 & 1 & 2 & 1 & 0 \\
\hline Porphyrio porphyrio & 0 & 0 & 1 & 1 & 0 & 0 & 0 & 2 & 1 & 0 \\
\hline Porphyrio martinica & 0 & 0 & 1 & 1 & 0 & 0 & 1 & 2 & 1 & 0 \\
\hline Porphyrio flavirostris & 0 & 0 & 1 & 1 & 0 & 0 & 1 & 2 & 1 & 0 \\
\hline Gallinula chloropus & 0 & 0 & 1 & 1 & 0 & 0 & 0 & 1 & 2 & 0 \\
\hline Gallinula tenebrosa & 0 & 0 & 1 & 1 & 0 & 0 & 0 & 1 & 2 & 0 \\
\hline Gallinula melanops & 0 & 0 & 1 & 1 & 0 & 0 & 1 & 0 & $1 / 2$ & 0 \\
\hline Fulica atra & 1 & 1 & 0 & 1 & 0 & 0 & 1 & 0 & 2 & 0 \\
\hline Fulica americana & 1 & 1 & 0 & 1 & 0 & 0 & 1 & 0 & 2 & 0 \\
\hline Fulica armilata & 1 & 1 & 0 & 1 & 0 & 0 & 1 & 0 & 2 & 0 \\
\hline Fulica rufifrons & 1 & 0 & 0 & 1 & 0 & 0 & 1 & 0 & 2 & 0 \\
\hline
\end{tabular}




\begin{tabular}{|c|c|c|c|c|c|c|c|c|c|c|}
\hline Táxon/Caráter & 31 & 32 & 33 & 34 & 35 & 36 & 37 & 38 & 39 & 40 \\
\hline Heliornis fulica & 1 & 0 & 1 & 0 & 1 & 1 & 1 & 0 & 1 & 0 \\
\hline Coturnicops noveboracensis & 0 & 1 & 0 & 1 & 0 & 0 & 0 & 1 & 0 & 1 \\
\hline Coturnicops notata & 0 & 1 & 0 & 1 & 0 & 2 & 0 & 1 & 0 & 1 \\
\hline Anurolimnas viridis & 0 & 1 & 0 & 1 & 1 & 2 & 0 & 1 & 0 & 1 \\
\hline Laterallus melanophaius & 0 & 1 & 0 & 1 & 1 & 2 & 0 & 1 & 0 & 1 \\
\hline Rallus longirostris & 0 & 1 & 0 & 1 & 0 & 0 & 0 & 1 & 0 & 1 \\
\hline Rallus limicola & 0 & 1 & 0 & 1 & 0 & 0 & 0 & 1 & 0 & 1 \\
\hline Rallus aquaticus & 0 & 1 & 0 & 1 & 0 & 0 & 0 & 1 & 0 & 1 \\
\hline Crex crex & 1 & 0 & 0 & 1 & 0 & 0 & 0 & 1 & 0 & 1 \\
\hline Aramides cajanea & 1 & 1 & 0 & 1 & 1 & 2 & 0 & 1 & 0 & 1 \\
\hline Aramides saracura & 1 & 1 & 0 & 1 & 1 & 2 & 0 & 1 & 0 & 1 \\
\hline Aramides ypecaha & $?$ & 1 & 0 & 1 & 1 & 0 & 0 & 1 & 0 & 1 \\
\hline Amaurornis phoenicurus & 0 & 1 & 0 & 1 & 1 & $0 / 2$ & 0 & 1 & 0 & 1 \\
\hline Amaurornis flavirostris & 0 & 1 & 0 & 1 & 1 & 2 & 0 & 1 & 0 & 1 \\
\hline Porzana carolina & 0 & 1 & 0 & 1 & 1 & 0 & 0 & 1 & 0 & 1 \\
\hline Porzana albicollis & 0 & 0 & 0 & 1 & 1 & 2 & 0 & 1 & 0 & 1 \\
\hline Porzana flaviventer & 0 & 0 & 0 & 1 & 0 & 2 & 0 & 1 & 0 & 1 \\
\hline Neocrex erythrops & 1 & 1 & 0 & 1 & 1 & 0 & 0 & 1 & 0 & 1 \\
\hline Pardirallus maculatus & 0 & 1 & 0 & 1 & 1 & 0 & 0 & 1 & 0 & 1 \\
\hline Pardirallus nigricans & 0 & 1 & 0 & 1 & 1 & 2 & 0 & 1 & 0 & 1 \\
\hline Pardirallus sanguinolentus & 0 & 1 & 0 & 1 & 1 & 0 & 0 & 1 & 0 & 1 \\
\hline Porphyrio porphyrio & 0 & 0 & 0 & 1 & 1 & 0 & 0 & 1 & 0 & 1 \\
\hline Porphyrio martinica & 0 & 0 & 0 & 1 & 1 & 0 & 0 & 1 & 0 & 1 \\
\hline Porphyrio flavirostris & 0 & 1 & 0 & 1 & 1 & 0 & 0 & 1 & 0 & 1 \\
\hline Gallinula chloropus & 1 & 0 & 0 & 1 & 1 & 0 & 0 & 1 & 0 & 1 \\
\hline Gallinula tenebrosa & 1 & 0 & 0 & 1 & 1 & 0 & 0 & 1 & 0 & 1 \\
\hline Gallinula melanops & 1 & 0 & 0 & 1 & 1 & 0 & 0 & 0 & 0 & 1 \\
\hline Fulica atra & 1 & 0 & 0 & 1 & 1 & 1 & 0 & 0 & 0 & 1 \\
\hline Fulica americana & 1 & 0 & 0 & 1 & 1 & 1 & 0 & 0 & 0 & 1 \\
\hline Fulica armilata & 1 & 0 & 0 & 1 & 1 & 1 & 0 & 0 & 0 & 1 \\
\hline Fulica rufifrons & 1 & 0 & 0 & 1 & 1 & 0 & 0 & 0 & 0 & 1 \\
\hline
\end{tabular}




\begin{tabular}{|c|c|c|c|c|c|c|c|c|c|c|}
\hline Táxon/Caráter & 41 & 42 & 43 & 44 & 45 & 46 & 47 & 48 & 49 & 50 \\
\hline Heliornis fulica & 1 & 0 & 0 & 0 & 1 & 0 & 1 & 0 & 1 & 1 \\
\hline Coturnicops noveboracensis & 0 & 1 & 1 & 0 & 0 & 1 & 0 & 1 & 0 & 0 \\
\hline Coturnicops notata & 0 & 1 & 1 & 0 & 0 & 1 & 0 & 1 & 0 & 0 \\
\hline Anurolimnas viridis & 0 & 1 & 1 & 0 & 0 & 1 & 0 & 1 & 0 & 0 \\
\hline Laterallus melanophaius & 0 & 1 & 1 & 0 & 0 & 1 & 0 & 1 & 0 & 0 \\
\hline Rallus longirostris & 0 & 1 & 1 & 0 & 0 & 1 & 0 & 1 & 0 & 0 \\
\hline Rallus limicola & 0 & 1 & 1 & 0 & 0 & 1 & 0 & 1 & 0 & 0 \\
\hline Rallus aquaticus & 0 & 1 & 1 & 0 & 0 & 1 & 0 & 1 & 0 & 0 \\
\hline Crex crex & 0 & 1 & 1 & 0 & 0 & 1 & 0 & 1 & 0 & 0 \\
\hline Aramides cajanea & 0 & 1 & 1 & 0 & 0 & 1 & 0 & 1 & 0 & 0 \\
\hline Aramides saracura & 0 & 1 & 1 & 0 & 0 & 1 & 0 & 1 & 0 & 0 \\
\hline Aramides ypecaha & 0 & 1 & 1 & 0 & 0 & 1 & 0 & 1 & 0 & 0 \\
\hline Amaurornis phoenicurus & 0 & 1 & 1 & 0 & 1 & 1 & 0 & 1 & 0 & 0 \\
\hline Amaurornis flavirostris & 0 & 1 & 1 & 0 & 2 & 1 & 0 & 1 & 0 & 0 \\
\hline Porzana carolina & 0 & 1 & 1 & 0 & 0 & 1 & 0 & 1 & 0 & 0 \\
\hline Porzana albicollis & 0 & 1 & 1 & 0 & 0 & 1 & 0 & 1 & 0 & 0 \\
\hline Porzana flaviventer & 0 & 1 & 1 & 0 & 0 & 1 & 0 & 1 & 0 & 0 \\
\hline Neocrex erythrops & 0 & 1 & 1 & 0 & 0 & 1 & 0 & $?$ & 0 & 0 \\
\hline Pardirallus maculatus & 0 & 1 & 1 & 0 & 0 & 1 & 0 & 1 & 0 & 0 \\
\hline Pardirallus nigricans & 0 & 1 & 1 & 0 & 0 & 1 & 0 & 1 & 0 & 0 \\
\hline Pardirallus sanguinolentus & 0 & 1 & 1 & 0 & 0 & 1 & 0 & 1 & 0 & 0 \\
\hline Porphyrio porphyrio & 0 & 1 & 1 & 0 & 2 & 1 & 0 & 0 & 1 & 1 \\
\hline Porphyrio martinica & 0 & 1 & 1 & 0 & 2 & 1 & 0 & 0 & 1 & 1 \\
\hline Porphyrio flavirostris & 0 & 1 & 1 & 1 & 2 & 1 & 0 & 0 & 1 & 1 \\
\hline Gallinula chloropus & 0 & 2 & 1 & 0 & 1 & 1 & 0 & 1 & 0 & 0 \\
\hline Gallinula tenebrosa & 0 & 2 & 1 & 0 & 1 & 1 & 0 & 1 & 0 & 0 \\
\hline Gallinula melanops & 0 & 0 & 1 & 0 & 1 & 1 & 0 & 1 & 0 & 0 \\
\hline Fulica atra & 1 & 2 & 1 & 0 & 1 & 1 & 1 & 1 & 0 & 0 \\
\hline Fulica americana & 1 & 2 & 1 & 0 & 1 & 1 & 1 & 1 & 0 & 0 \\
\hline Fulica armilata & 1 & 2 & 1 & 0 & 1 & 1 & 1 & 1 & 0 & 0 \\
\hline Fulica rufifrons & 0 & 2 & 1 & 0 & 1 & 1 & 1 & 1 & 0 & 0 \\
\hline
\end{tabular}


Anexo III - Índices de consistência (CI), retenção (IR) e consistência re-escalonado dos caracteres analisados.

\begin{tabular}{c|c|c|c}
\hline Caráter & IC & IR & RC \\
1 & 0.500 & 0.000 & 0.000 \\
2 & 1.000 & $0 / 0$ & $0 / 0$ \\
3 & 1.000 & 1.000 & 1.000 \\
4 & 1.000 & 1.000 & 1.000 \\
5 & 0.500 & 0.000 & 0.000 \\
6 & 1.000 & 1.000 & 1.000 \\
7 & 1.000 & $0 / 0$ & $0 / 0$ \\
8 & 1.000 & 1.000 & 1.000 \\
9 & 0.333 & 0.500 & 0.167 \\
10 & 1.000 & 1.000 & 1.000 \\
11 & 0.250 & 0.667 & 0.167 \\
12 & 0.500 & 0.667 & 0.333 \\
13 & 1.000 & 1.000 & 1.000 \\
14 & 0.500 & 0.875 & 0.438 \\
15 & 1.000 & $0 / 0$ & $0 / 0$ \\
16 & 0.500 & 0.667 & 0.333 \\
17 & 1.000 & 1.000 & 1.000 \\
18 & 0.333 & 0.600 & 0.200 \\
19 & 0.250 & 0.667 & 0.167 \\
20 & 0.333 & 0.714 & 0.238 \\
21 & 1.000 & 1.000 & 1.000 \\
22 & 1.000 & 1.000 & 1.000 \\
23 & 1.000 & 1.000 & 1.000 \\
24 & 1.000 & $0 / 0$ & $0 / 0$ \\
25 & 1.000 & 1.000 & 1.000 \\
26 & 0.500 & 0.889 & 0.444 \\
27 & 0.250 & 0.769 & 0.192 \\
28 & 0.667 & 0.833 & 0.556 \\
29 & 0.400 & 0.727 & 0.291 \\
30 & 1.000 & $0 / 0$ & $0 / 0$ \\
31 & 0.333 & 0.818 & 0.273 \\
32 & 0.250 & 0.750 & 0.188 \\
33 & 1.000 & $0 / 0$ & $0 / 0$ \\
34 & 1.000 & $0 / 0$ & $0 / 0$ \\
35 & 0.333 & 0.667 & 0.222 \\
36 & 0.333 & 0.363 & 0.212 \\
37 & 1.000 & $0 / 0$ & $0 / 0$ \\
& & &
\end{tabular}




\begin{tabular}{c|c|c|c}
\hline Caráter & IC & IR & RC \\
38 & 0.500 & 0.800 & 0.400 \\
39 & 1.000 & $0 / 0$ & $0 / 0$ \\
40 & 1.000 & $0 / 0$ & $0 / 0$ \\
41 & 0.500 & 0.667 & 0.333 \\
42 & 0.667 & 0.883 & 0.556 \\
43 & 1.000 & $0 / 0$ & $0 / 0$ \\
44 & 1.000 & $0 / 0$ & $0 / 0$ \\
45 & 0.400 & 0.727 & 0.291 \\
46 & 1.000 & $0 / 0$ & $0 / 0$ \\
47 & 0.500 & 0.750 & 0.375 \\
48 & 1.000 & 1.000 & 1.000 \\
49 & 1.000 & 1.000 & 1.000 \\
50 & 1.000 & 1.000 & 1.000 \\
\hline
\end{tabular}

